medRxiv preprint doi: https://doi.org/10.1101/2021.06.29.21255526; this version posted July 2,2021 . The copyright holder for this preprint

(which was not certified by peer review) is the author/funder, who has granted medRxiv a license to display the preprint in perpetuity.

It is made available under a CC-BY-ND 4.0 International license.

\title{
Transmissibility of COVID-19 among Vaccinated Individuals: A Rapid Literature Review - Update \#1
}

Oluwaseun Egunsola ${ }^{1,2}$; Liza Mastikhina ${ }^{1,2}$; Laura Dowsett ${ }^{1,2}$; Brenlea Farkas ${ }^{1,2}$; Mark Hofmeister $^{1,2}$; Lynora Saxinger ${ }^{3}$ and Fiona Clement ${ }^{1,2}$

\section{Affiliations:}

1. The Department Community Health Sciences, Teaching Research and Wellness Building, 3280 Hospital Drive NW Calgary Alberta T2N 4N1

2. O'Brien Institute for Public Health, Teaching Research and Wellness Building, 3280 Hospital Drive NW Calgary Alberta T2N 4N1

3. Department of Medicine University of Alberta, Edmonton, Alberta, Canada

Funding Statement: The SPOR Evidence Alliance (SPOR EA) is supported by the Canadian Institutes of Health Research (CIHR) under the Strategy for Patient-Oriented Research (SPOR) initiative.

COVID-19 Evidence Network to support Decision-making (COVID-END) is supported by the Canadian Institutes of Health Research (CIHR) through the Canadian 2019 Novel Coronavirus (COVID-19) Rapid Research Funding opportunity.

Copyright claims/Disclaimers: This report was prepared by The University of Calgary Health Technology Assessment Unit on behalf of the SPOR Evidence Alliance and COVIDEND. It was developed through the analysis, interpretation and synthesis of scientific research and/or health technology assessments published in peer-reviewed journals, institutional websites and other distribution channels. It also incorporates selected information provided by experts and patient partners with lived experience on the subject matter. This document may not fully reflect all the scientific evidence available at the time this report was prepared. Other relevant scientific findings may have been reported since completion of this synthesis report. SPOR Evidence Alliance, COVID-END and the project team make no warranty, express or implied, nor assume any legal liability or responsibility for the accuracy, completeness, or usefulness of any information, data, product, or process disclosed in this report. Conclusions drawn from, or actions undertaken on the basis of, information included in this report are the sole responsibility of the user.

For questions about this report, please contact:

Dr. Fiona Clement Director, Health Technology Assessment Unit, University of Calgary Email: fclement@ucalgary.ca

Phone: 403-210-9373 
medRxiv preprint doi: https://doi.org/10.1101/2021.06.29.21255526; this version posted July 2 , 2021. The copyright holder for this preprint

(which was not certified by peer review) is the author/funder, who has granted medRxiv a license to display the preprint in perpetuity.

It is made available under a CC-BY-ND 4.0 International license.

\begin{abstract}
Objectives: This is an update of a previous report that examined literature published up to March 11th, 2021. Sixteen additional studies have been included in this update. The objective of this report is to identify comparative observational studies and randomized controlled trials (RCTs) evaluating the efficacy and effectiveness of COVID-19 vaccination in reducing forward transmission from vaccinated people, and studies examining the biological plausibility of vaccination-induced transmission reduction.
\end{abstract}

Method: A search of databases, MEDLINE, Embase, L-OVE and the Cochrane Central Register of Controlled Trials was conducted to identify RCTs or comparative observational studies evaluating the efficacy and effectiveness of COVID-19 vaccination in the prevention of transmission, asymptomatic infections and transmissibility of COVID-19 among vaccinated persons. An additional search of grey literature was conducted. This search is current to May 4th, 2021.

Results: In this update, 16 additional studies, including 9 human and 7 animal studies, were included. Therefore, this review examines a total of 33 included studies: 21 human studies and 12 preclinical animal studies. Evidence from two large household surveillance studies from the UK suggests that a single or full dose of AstraZeneca (AZ) and Pfizer-BioNtech (PfBnT) vaccines may prevent household transmission of COVID-19 after 14 days of vaccination by up to $54 \%$. The AZ vaccine trials in the general population suggest that an initial low dose followed by a standard dose may provide up to $59 \%$ protection against asymptomatic or unknown infection, although efficacy against these outcomes was not demonstrated following two standard doses. PfBnT vaccine observational studies in the general population suggest up to $90 \%$ effectiveness against asymptomatic infection after seven or more days of full dose vaccination. Up to $75 \%$ effectiveness against asymptomatic infection was reported after fulldose in healthcare workers. Across RCTs examining asymptomatic infection in the general population, one dose of Moderna was shown to provide an efficacy of $61.4 \%$ against asymptomatic infection 21 days after the first dose; in another trial, the $\mathrm{J} \& \mathrm{~J}$ vaccine had an efficacy of $74 \% 28$ days after the first dose. Lastly, seven of eight studies found significantly increased cycle threshold, suggestive of lower viral load, in PfBnT or AZ vaccinated individuals compared with those who were unvaccinated.

Conclusion: The AZ and PfBnT vaccines may prevent household transmission of COVID-19 after 14 days of vaccination. More studies have found the vaccines to significantly reduce the risk of asymptomatic infection and significantly increase cycle threshold, suggestive of lower viral load. Further research is needed to evaluate post-vaccination infectivity and transmission of both the wild type COVID-19 virus and the variants of concern from other jurisdictions. 
medRxiv preprint doi: https://doi.org/10.1101/2021.06.29.21255526; this version posted July 2,2021 . The copyright holder for this preprint (which was not certified by peer review) is the author/funder, who has granted medRxiv a license to display the preprint in perpetuity. It is made available under a CC-BY-ND 4.0 International license .

\section{Background}

Coronavirus disease (COVID-19) is caused by severe acute respiratory syndrome coronavirus 2 (SARS-CoV-2). As of May 2021, there have been more than 164,000,000 confirmed cases of COVID-19, which have resulted in more than $3,400,000$ confirmed deaths worldwide. ${ }^{23}$ Since the start of the pandemic, several clinical trials have been underway to examine the safety and effectiveness of different vaccines to prevent COVID-19. Many of these have found the vaccines to be generally effective against symptomatic COVID-19 infection, with an average efficacy of $85 \%$ (95\% CI: $71-93 \%)$ after a full course of vaccination. ${ }^{24}$

People who have started or finished the COVID19 vaccine series have been documented to have detectable SARSCoV2 by RT-PCR at various time points after vaccination, ${ }^{4}$ although demonstration of cultivatable virus and definitive evidence of transmission post vaccination has not been assessed. It is not yet clear whether the current COVID-19 vaccines are as effective at reducing transmission as they are at reducing disease. Moreover, evaluating the ability of vaccinated individuals to transmit the virus after infection is challenging. Therefore, virologic surrogates of possible transmissibility may be a helpful way around this challenge.

Monoclonal antibody studies may provide useful insights into the pathophysiologic plausibility of vaccine induced transmission reduction, since they have been shown to result in circulating neutralizing antibody, with a significant decrease in quantitative viral load. ${ }^{25}$ In one study, following quantitative reverse-transcriptase-polymerase-chain-reaction (RT-PCR) testing of nasopharyngeal swabs, an antibody cocktail was found to significantly reduce viral load compared with placebo. ${ }^{25}$ The time-weighted average change in viral load in the first 7 days was $-0.56 \log 10$ copies per milliliter $(95 \% \mathrm{CI},-1.02$ to -0.11$)$ among those who were serum antibody-negative at baseline. ${ }^{25}$ Another study reported an elimination of more than $99.97 \%$ of viral RNA on day 11 after monoclonal antibody treatment. ${ }^{26}$

There is evolving data around the frequency of asymptomatic COVID-19 and if the viral load, and therefore infectiousness, is lower among people who develop COVID-19 post-vaccination compared with those who have not been vaccinated. Viral presence is an imperfect proxy of transmissibility although the quantity of virus present does appear to influence risk, as studies document transmission risk is higher with a higher viral load or lower Ct value. ${ }^{27,28}$ Marks et al. found index viral load to be a major driver of transmission in a Spanish cohort, ${ }^{28}$ with only $32 \%$ of index cases responsible for transmission, and an attack rate of $12 \%$ in contacts of index cases with a viral load $<10^{6}$ and $25 \%$ in contacts of index cases with a viral load of $10^{10}$. Similarly, Bjorkman et al. found that higher viral load increased SARS-CoV-2 transmission between asymptomatic residence hall roommates. ${ }^{29}$ The index cases who transmitted infection had an average viral load $6.5 \mathrm{log}$ higher than those who did not. Transmission from asymptomatic students to roommates occurred in $20 \%$ of rooms with an infected student, with a lower mean $\mathrm{Ct}$ (E gene) of 26.2 in transmission index cases versus 28.9, (median 26.11 in transmission index cases versus 29.32).

However, the risks related to viral presence by RT-PCR may be modulated by individual's immune status, as viral persistence after natural infection has been observed in individuals with neutralizing antibody responses after natural infection, without transmission to close contacts. ${ }^{30}$ 
medRxiv preprint doi: https://doi.org/10.1101/2021.06.29.21255526; this version posted July 2 , 2021. The copyright holder for this preprint (which was not certified by peer review) is the author/funder, who has granted medRxiv a license to display the preprint in perpetuity. It is made available under a CC-BY-ND 4.0 International license .

Although asymptomatic and especially pre-symptomatic transmission of SARSCoV-2 has been well documented, existing studies suggest that transmission risk is lower from asymptomatic individuals than symptomatic individuals. ${ }^{31}$

The evidence for the transmissibility and transmission of COVID-19 infections in vaccinated individuals is rapidly evolving; therefore, the objective of this rapid review was to identify comparative observational studies and randomized controlled trials (RCTs) evaluating the effectiveness or efficacy of COVID-19 vaccination in reducing infection transmission, asymptomatic viral carriage and other proxies of possible transmission, such as cycle threshold $(\mathrm{Ct})$ values and viral load. This is an update of a previous report with a literature search that ended 11 March 2021.

\section{Methods}

An experienced medical information specialist developed and tested the search strategies through an iterative process in consultation with the review team. The MEDLINE strategy was peer reviewed by another senior information specialist prior to execution using the PRESS Checklist. ${ }^{32}$

Using the multifile option and deduplication tool available on the OVID platform, we searched Ovid MEDLINE®, including Epub Ahead of Print, In-Process \& Other Non-Indexed Citations, Embase, and EBM Reviews - Cochrane Central Register of Controlled Trials. We also searched for primary studies on the Living Overviews of Evidence (L-OVE) platform. We performed all searches on May 4, 2021.

The strategies utilized a combination of controlled vocabulary (e.g., "COVID-19 Vaccines", "COVID-19/tm [Transmission]", "Disease Transmission, Infectious") and keywords (e.g., "mRNA vaccine", "unvaccinated", "infectiousness"). Vocabulary and syntax were adjusted across the databases. The search strategies are in Appendix 1. No language or date limits were applied. Results were downloaded and deduplicated using EndNote version 9.3.3 (Clarivate Analytics) and uploaded to word.

A grey literature search was also conducted, including: Clinicaltrials.gov, McMaster Health Forum (CoVID-END), MedRxiv, Google, regulatory submissions, and websites of the Center for Disease Control and Prevention (CDC) and World Health Organization (WHO). This search was limited to studies conducted in 2020 and 2021 and current to May 4th, 2021. There were no language limitations.

A screening form based on the eligibility criteria was prepared. Citations identified as potentially relevant from the literature search were screened by a reviewer, and subsequently read in full text by two reviewers and assessed for eligibility based on the criteria outlined below (Table 1). Discrepancies were resolved by discussion or by a third reviewer. Reference lists of included studies were hand searched to ensure all relevant literature is captured. 
medRxiv preprint doi: https://doi.org/10.1101/2021.06.29.21255526; this version posted July 2 , 2021. The copyright holder for this preprint (which was not certified by peer review) is the author/funder, who has granted medRxiv a license to display the preprint in perpetuity. It is made available under a CC-BY-ND 4.0 International license.

Table 1. Criteria for Inclusion

\begin{tabular}{|l|l|}
\hline Population & $\begin{array}{l}\text { Persons who had received COVID-19 vaccination irrespective of age, sex or } \\
\text { gender. Animal studies were also included. }\end{array}$ \\
\hline Intervention & COVID-19 vaccination \\
\hline Comparator & Non-vaccinated persons. \\
\hline Outcome & $\begin{array}{l}\text { Include, but are not limited to, Ct values, viral load, asymptomatic } \\
\text { laboratory confirmed cases by RT-PCR post-vaccination and the number of } \\
\text { persons who are infected by someone who has COVID-19 and has had the } \\
\text { vaccine. Studies evaluating the transmissibility or infectivity of COVID-19 } \\
\text { among vaccinated individuals were included. }\end{array}$ \\
\hline $\begin{array}{l}\text { Study } \\
\text { Design }\end{array}$ & $\begin{array}{l}\text { Comparative observational studies and RCTs evaluating the efficacy and } \\
\text { effectiveness of COVID-19 vaccination in the prevention of asymptomatic } \\
\text { viral infections as a proxy of a possible transmission will be included. } \\
\text { Studies eligible for inclusion must have a control group of unvaccinated } \\
\text { people. }\end{array}$ \\
\hline
\end{tabular}

A standardized data extraction sheet was used to extract the year of publication, country, study design, patient characteristics including sex, gender and age, variants of COVID-19, whether infection was symptomatic or asymptomatic, and all the reported outcomes. All reviewers completed a calibration exercise whereby data from two sample studies were extracted by all four reviewers and areas of disagreement were discussed. Data were extracted by one reviewer and verified by another reviewer.

Quality assessment was conducted based on study design: Cochrane risk of bias for nonrandomized studies (ROBINS-I) for non-randomized studies, ${ }^{33}$ Cochrane Risk of Bias (version 5.1.0) for human-subject RCTs, ${ }^{34}$ and the Systematic Review Centre for Laboratory animal Experimentation's (SYRCLE) risk of bias for animal studies. ${ }^{35}$ Quality assessment was conducted by one reviewer and verified by a second reviewer.

\section{Results}

\section{Study Characteristics}

This updated search yielded 4993 unique citations, 4749 of which were excluded after abstract review (Figure 1). Fifty studies identified from the database search proceeded to full-text review. An additional 82 studies identified through grey literature search were also reviewed. In total, ninety-nine studies were excluded for the following reasons: outcomes not of interest $(n=54)$, study design not of interest $(n=10)$, comparator not of interest $(n=4)$, intervention not of interest $(n=1)$ and duplicate $(n=30)$.

A total of 33 studies were included in this review (Figure 1). Twenty-one were human studies (Table 2 and Table 3), ${ }^{2-17,19,29,36-38}$ and 12 were preclinical animal studies, with viral challenge 1-17 weeks post vaccination (Table 4 ). ${ }^{20-22,39-47}$ In the previous report, a targeted literature 
medRxiv preprint doi: https://doi.org/10.1101/2021.06.29.21255526; this version posted July 2, 2021. The copyright holder for this preprint (which was not certified by peer review) is the author/funder, who has granted medRxiv a license to display the preprint in perpetuity.

It is made available under a CC-BY-ND 4.0 International license .

search was conducted and 17 studies included. Thus, an additional 16 studies have been included since the last update on 11 March 2011, including two studies evaluating household transmission. Five of the human studies were randomized controlled trials, ${ }^{4-6,18,19}$ eight were prospective cohort studies, ${ }^{8,11}$ seven were retrospective cohort studies, ${ }^{2,10,12,13,36-38}$ and one was a case control study. ${ }^{15}$ 
medRxiv preprint doi: https://doi.org/10.1101/2021.06.29.21255526; this version posted July 2,2021 . The copyright holder for this preprint (which was not certified by peer review) is the author/funder, who has granted medRxiv a license to display the preprint in perpetuity.

It is made available under a CC-BY-ND 4.0 International license .

Figure 1: Flowchart of Included Studies

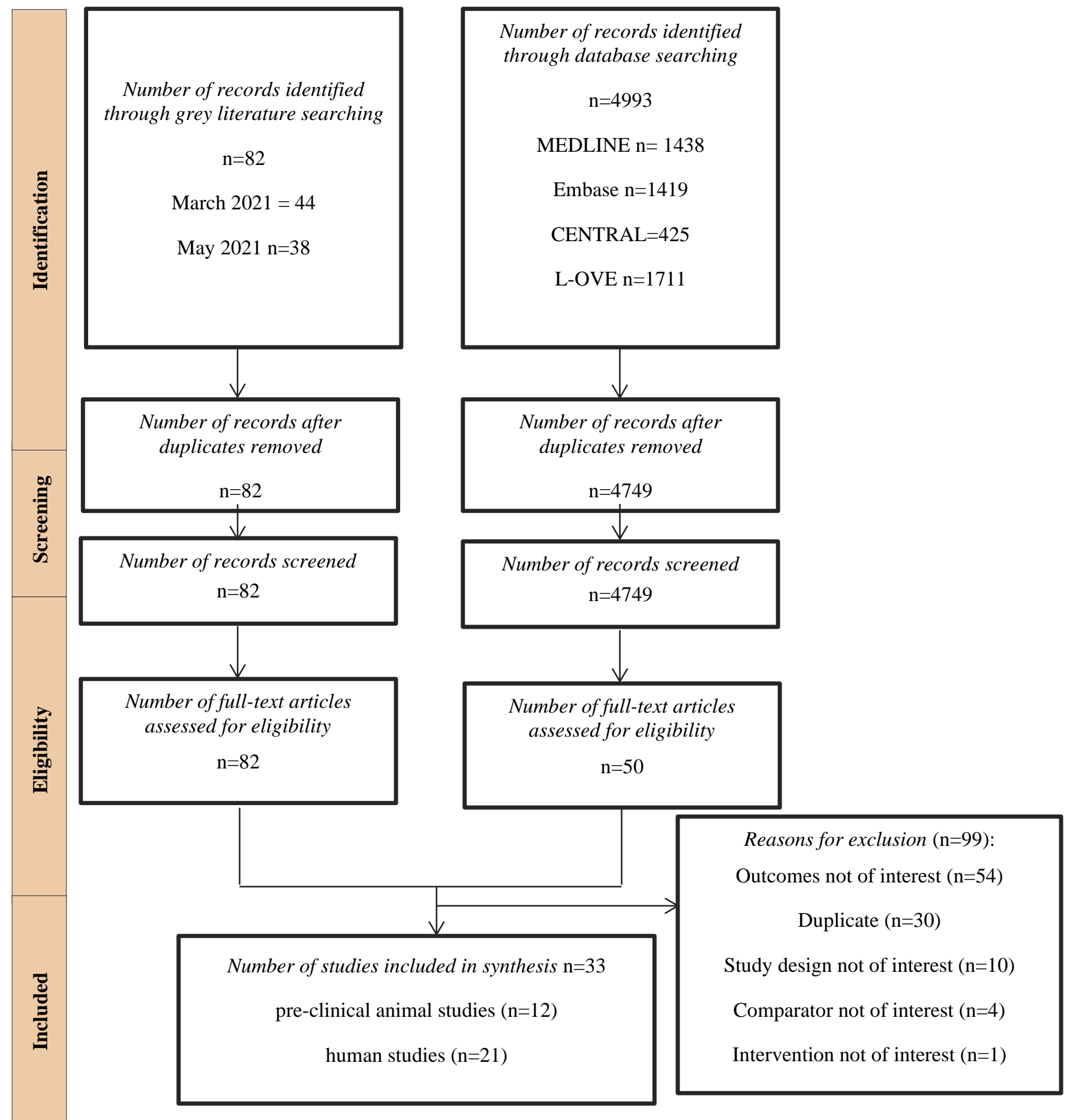


Table 2: Characteristics of Included RCTs

\begin{tabular}{|c|c|c|c|c|}
\hline Author/Country/Design & Trial Information & $\begin{array}{l}\text { Participant } \\
\text { Inclusion/Exclusion Criteria }\end{array}$ & $\begin{array}{l}\text { Vaccine } \\
\text { Information }\end{array}$ & $\begin{array}{l}\text { Efficacy/Effectiveness } \\
\text { Outcomes }\end{array}$ \\
\hline $\begin{array}{l}\text { Author: Voysey } 2021^{5} \\
\text { County: UK, Brazil, S.Africa } \\
\text { Date of Recruitment: May-Nov } 2020 \\
\text { Trial Phase: } 2 / 3 \\
\text { Design: Single Blind RCT } \\
\text { Funding: UK Research and Innovation, } \\
\text { National Institutes for Health Research } \\
\text { (NIHR), Coalition for Epidemic } \\
\text { Preparedness Innovations, Bill \& Melinda } \\
\text { Gates Foundation, Lemann Foundation, } \\
\text { Rede D’Or, Brava and Telles Foundation, } \\
\text { NIHR Oxford Biomedical Research Centre, } \\
\text { Thames Valley and South Midland's NIHR } \\
\text { Clinical Research Network, and } \\
\text { AstraZeneca. }\end{array}$ & $\begin{array}{l}\text { Age: NR } \\
\text { \%Female: Varied } \\
\text { Type of comparator: } \\
\text { Meningococcal vaccine } \\
\text { Sample Size Vaccine: } \\
\text { Varied } \\
\text { Sample Size Control: } \\
\text { Varied } \\
\text { Total Sample: Varied } \\
\text { VOC: NR }\end{array}$ & $\begin{array}{l}\text { Healthy volunteers aged over } \\
18 \text {; at risk of virus, stable pre- } \\
\text { existing conditions }\end{array}$ & $\begin{array}{l}\text { Vaccine: ChAdOx1 } \\
\text { nCoV-19 } \\
\text { Manufacturer: } \\
\text { AstraZeneca } \\
\text { Dose: Low or } \\
\text { Standard Doses } \\
\text { Number of Doses: } 2\end{array}$ & $\begin{array}{ll}\text { - } & \text { Symptomatic Infection } \\
\text { - } & \text { Severe Cases } \\
\text { - } & \text { Asymptomatic infection } \\
\text { (weekly self- administered } \\
\text { nose and throat swab for } \\
\text { NAAT testing from } 1 \text { week } \\
\text { after first vaccination using } \\
\text { kits provided by the UK } \\
\text { Department of Health and } \\
\text { Social Care) }\end{array}$ \\
\hline $\begin{array}{l}\text { Author: Voysey, } 2021^{4} \\
\text { County: UK, Brazil, S.Africa } \\
\text { Date of Recruitment: May-Dec } 2020 \\
\text { Trial Phase: } 1 / 2 / 3 \\
\text { Design: Single Blind RCT } \\
\text { Funding: UKRI, NIHR, CEPI, the Bill \& } \\
\text { Melinda Gates Foundation, the Lemann } \\
\text { Foundation, Rede D'OR, the Brava and }\end{array}$ & $\begin{array}{l}\text { Age: NR } \\
\text { \%Female: NR } \\
\text { Type of comparator: } \\
\text { Meningococcal vaccine } \\
\text { Sample Vaccine: } 8567 \\
\text { Sample Control: } 8580 \\
\text { Total Sample: } 17177\end{array}$ & NR & $\begin{array}{l}\text { Vaccine: ChAdOx1 } \\
\text { nCoV-19 } \\
\text { Manufacturer: } \\
\text { AstraZeneca } \\
\text { Dose: Low or } \\
\text { Standard Doses } \\
\text { Number of Doses: } 2\end{array}$ & $\begin{array}{ll}\text { - } & \text { Symptomatic Infection } \\
\text { - } & \text { Severe Cases } \\
\text { - } & \text { Asymptomatic infection } \\
\text { (measured by means of } \\
\text { weekly self-administered } \\
\text { nose and throat swabs using } \\
\text { kits provided by the } \\
\text { Department of Health and } \\
\text { Social Care) }\end{array}$ \\
\hline
\end{tabular}




\begin{tabular}{|c|c|c|c|c|}
\hline Author/Country/Design & Trial Information & $\begin{array}{l}\text { Participant } \\
\text { Inclusion/Exclusion Criteria }\end{array}$ & $\begin{array}{l}\text { Vaccine } \\
\text { Information }\end{array}$ & $\begin{array}{l}\text { Efficacy/Effectiveness } \\
\text { Outcomes }\end{array}$ \\
\hline $\begin{array}{l}\text { Telles Foundation, NIHR Oxford } \\
\text { Biomedical Research Centre, Thames } \\
\text { Valley and South Midland's NIHR Clinical } \\
\text { Research Network, and Astra Zeneca }\end{array}$ & VOC: NR & & & \\
\hline $\begin{array}{l}\text { Author: Emary } 2021^{6} \\
\text { County: UK } \\
\text { Date of Recruitment: Oct-Jan } 2021 \\
\text { Trial Phase: } 2 / 3 \\
\text { Design: RCT } \\
\text { Funding: UK Research and Innovation, } \\
\text { National Institutes for Health Research } \\
\text { (NIHR), Coalition for Epidemic } \\
\text { Preparedness Innovations, NIHR Oxford } \\
\text { Biomedical Research Centre, Thames Valley } \\
\text { and South Midlands NIHR Clinical } \\
\text { Research Network, and AstraZeneca. }\end{array}$ & $\begin{array}{l}\text { Age: NR } \\
\text { \%Female: NR } \\
\text { Type of comparator: } \\
\text { Meningococcal vaccine } \\
\text { Sample Vaccine: } 4236 \\
\text { Sample Control: } 4270 \\
\text { Total Sample: } 8506 \\
\text { VOC: B.1.1.7, Other }\end{array}$ & $\begin{array}{l}\text { Aged } 18 \text { and over; high- } \\
\text { exposure populations eligible } \\
\text { for vaccination under the } \\
\text { government National Health } \\
\text { Service coronavirus vaccine } \\
\text { programme. }\end{array}$ & $\begin{array}{l}\text { Vaccine: ChAdOx1 } \\
\text { nCoV-19 } \\
\text { Manufacturer: } \\
\text { AstraZeneca } \\
\text { Dose: Low or } \\
\text { Standard Doses } \\
\text { Number of Doses: } 2\end{array}$ & 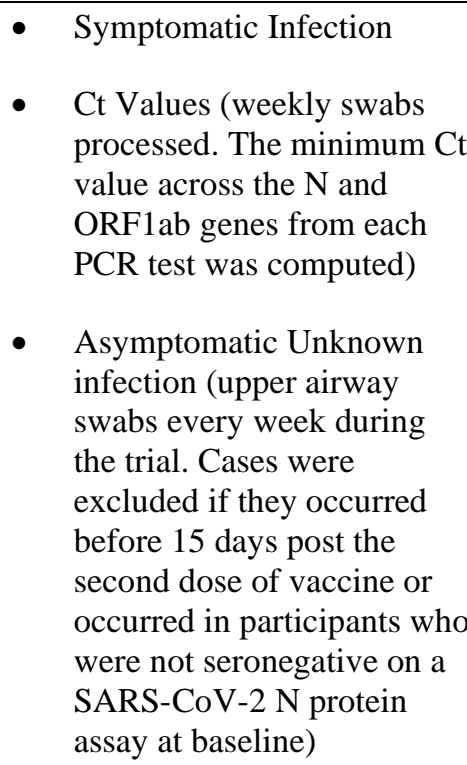 \\
\hline $\begin{array}{l}\text { Author: Janssen Biotech, } 2021^{19} \\
\text { (Regulatory Submission) } \\
\text { County: Argentina, Brazil, Chile, } \\
\text { Colombia, Mexico, Peru, South Africa, and } \\
\text { the United States } \\
\text { Date of Recruitment: Sept 2020-Jan } 2021 \\
\text { Trial Phase: } 3\end{array}$ & $\begin{array}{l}\text { Age: } 51.1 \text { (15.0) } \\
\text { \%Female: } 44.5 \\
\text { Comparator: Placebo } \\
\text { Sample Vaccine: } 19514 \\
\text { Sample Control: } 19544\end{array}$ & $\begin{array}{l}\text { Adults } 18+\text { with or without } \\
\text { comorbidities. }\end{array}$ & $\begin{array}{l}\text { Vaccine: } \\
\text { Ad26.COV2.S } \\
\text { Manufacturer: } \\
\text { Janssen Biotech } \\
\text { Dose: NR } \\
\text { Number of Doses: } 1\end{array}$ & $\begin{array}{l}\text { - } \\
\text { - } \\
\text { Moderate to Severe } \\
\text { infections } \\
\text { Asymptomatic infection (No } \\
\text { symptoms on the day } \\
\text { preceding, the day of, or any } \\
\text { time after the positive PCR } \\
\text { test AND has a SARS-CoV- } \\
2 \text { positive RT-PCR test } \\
\text { result OR develops a }\end{array}$ \\
\hline
\end{tabular}




\begin{tabular}{|c|c|c|c|c|}
\hline Author/Country/Design & Trial Information & $\begin{array}{l}\text { Participant } \\
\text { Inclusion/Exclusion Criteria }\end{array}$ & $\begin{array}{l}\text { Vaccine } \\
\text { Information }\end{array}$ & $\begin{array}{l}\text { Efficacy/Effectiveness } \\
\text { Outcomes }\end{array}$ \\
\hline $\begin{array}{l}\text { Design: Double Blind RCT } \\
\text { Funding: Janssen Biotech }\end{array}$ & $\begin{array}{l}\text { Total Sample: } 39058 \\
\text { VOC:NR }\end{array}$ & & & $\begin{array}{l}\text { positive serology based on a } \\
\text { SARS-CoV-2 N-specific } \\
\text { immunoglobulin assay } \\
\text { (Elecsys@, Roche) during } \\
\text { the study. SARS CoV-2 } \\
\text { seropositivity by non-S } \\
\text { protein was assessed at Day } \\
1 \text { (pre-vaccination), Day } 29 \\
\text { (28 days post-vaccination), } \\
\text { and Day 71) }\end{array}$ \\
\hline $\begin{array}{l}\text { Author: Baden, } 2021^{18} \\
\text { County: USA } \\
\text { Date of Recruitment: Jul-Nov, } 2020 \\
\text { Trial Phase: } 3 \\
\text { Design: Observer Blinded RCT } \\
\text { Funding: Biomedical Advanced Research } \\
\text { and Development Authority and the } \\
\text { National Institute of Allergy and Infectious } \\
\text { Diseases }\end{array}$ & $\begin{array}{l}\text { Age: } 51.4 \\
\text { \%Female: } 47.3 \\
\text { Comparator: saline } \\
\text { Sample Vaccine: } 14550 \\
\text { Sample Control: } 14598 \\
\text { Total Sample: } 29148\end{array}$ & $\begin{array}{l}\text { Include: Eligible participants } \\
\text { were persons } 18 \text { years of age or } \\
\text { older with no known history of } \\
\text { SARS-CoV-2 infection and with } \\
\text { locations or circumstances that } \\
\text { put them at an appreciable risk } \\
\text { of SARSCoV-2 infection, a high } \\
\text { risk of severe COVID-19, or } \\
\text { both. } \\
\text { Exclude: Pregnant women and } \\
\text { children }\end{array}$ & $\begin{array}{l}\text { Vaccine: mRNA- } \\
1273 \\
\text { Manufacturer: } \\
\text { Moderna } \\
\text { Dose: } 100 \mathrm{mcg} \\
\text { Number of Doses: } 2\end{array}$ & $\begin{array}{ll}\text { - } & \text { Symptomatic infection } \\
\text { - } & \text { Severe cases } \\
\text { - } & \text { Any Positive PCR } \\
\text { - } & \begin{array}{l}\text { Asymptomatic infection } \\
\text { (Surveillance swab at the } \\
\text { second dose visit) }\end{array}\end{array}$ \\
\hline
\end{tabular}


Table 3: Characteristics of Observational Studies

\begin{tabular}{|c|c|c|c|c|}
\hline Author/Country/Design & Trial Information & $\begin{array}{l}\text { Participant } \\
\text { Inclusion/Exclusion Criteria }\end{array}$ & Vaccine Information & Effectiveness Outcomes \\
\hline $\begin{array}{l}\text { Author: Hall, } 2021^{11} \\
\text { County: UK } \\
\text { Date of Recruitment: Dec 2020-Feb, } 2021 \\
\text { Trial Phase: Post Approval } \\
\text { Design: Prospective Cohort } \\
\text { Funding: Public Health England and the } \\
\text { Department of Health and Social Care; } \\
\text { NIHR }\end{array}$ & $\begin{array}{l}\text { Age: NR } \\
\text { \%Female: } 84 \\
\text { Type of comparator: } \\
\text { Unvaccinated } \\
\text { Sample Vaccine: NR } \\
\text { Sample Control: NR } \\
\text { Total Sample: NR } \\
\text { VOC: B.1.1.7 }\end{array}$ & $\begin{array}{l}\text { Health care workers at hospital, } \\
\text { who could provide informed } \\
\text { consent and anticipated } \\
\text { remaining engaged in follow-up } \\
\text { for } 12 \text { months. }\end{array}$ & $\begin{array}{l}\text { Vaccine: BNT162b2 } \\
\text { Manufacturer: Pfizer } \\
\text { BioNTech } \\
\text { Dose: NR } \\
\text { Number of Doses: } 1 \text { or } 2\end{array}$ & $\begin{array}{l}\text { - } \\
\text { - } \\
\text { Asymptomatic Infection } \\
\text { (fortnightly } \\
\text { asymptomatic PCR } \\
\text { testing (anterior nasal } \\
\text { swabs or combined nose } \\
\text { and oropharyngeal } \\
\text { swabs) and monthly } \\
\text { antibody testing) } \\
\text { Any positive PCR }\end{array}$ \\
\hline $\begin{array}{l}\text { Author: Amit, } 2021^{12} \\
\text { County: Israel } \\
\text { Date of Recruitment: Dec 2020-Jan } 2021 \\
\text { Trial Phase: Post Approval } \\
\text { Design: Retrospective Cohort } \\
\text { Funding: NR }\end{array}$ & $\begin{array}{l}\text { Age: NR } \\
\text { \%Female: NR } \\
\text { Comparator: } \\
\text { Unvaccinated } \\
\text { Sample Vaccine: NR } \\
\text { Sample Control: NR } \\
\text { Total Sample: NR } \\
\text { VOC: NR }\end{array}$ & NR & $\begin{array}{l}\text { Vaccine: BNT162b2 } \\
\text { Manufacturer: Pfizer } \\
\text { BioNTech } \\
\text { Dose: } 1 \text { or } 2 \\
\text { Number of Doses: } 2\end{array}$ & $\begin{array}{l}\text { - } \quad \text { Symptomatic Infection } \\
\text { - } \quad \text { Any positive PCR }\end{array}$ \\
\hline $\begin{array}{l}\text { Author: Dagan, } 2021^{8} \\
\text { County: Israel } \\
\text { Date of Recruitment: Dec 2020-Feb, } 2021\end{array}$ & $\begin{array}{l}\text { Age: Unvaccinated: } 45 \\
\text { (IQR:35-62), vaccinated: } \\
45(35-62 \\
\text { \%Female: } 50\end{array}$ & $\begin{array}{l}\text { Include: } 16 \text { years or older, not } \\
\text { having a previously documented } \\
\text { positive SARS-CoV-2 PCR test, } \\
\text { and being a member of the }\end{array}$ & $\begin{array}{l}\text { Vaccine: BNT162b2 } \\
\text { Manufacturer: Pfizer } \\
\text { BioNTech }\end{array}$ & $\begin{array}{ll}\text { - } & \text { Symptomatic Infection } \\
\text { - } & \text { Severe Cases }\end{array}$ \\
\hline
\end{tabular}




\begin{tabular}{|c|c|c|c|c|}
\hline Author/Country/Design & Trial Information & $\begin{array}{l}\text { Participant } \\
\text { Inclusion/Exclusion Criteria }\end{array}$ & Vaccine Information & Effectiveness Outcomes \\
\hline $\begin{array}{l}\text { Trial Phase: Post Approval } \\
\text { Design: Prospective Cohort } \\
\text { Funding: NR }\end{array}$ & $\begin{array}{l}\text { Comparator: } \\
\text { Unvaccinated } \\
\text { Sample Vaccine: } 596618 \\
\text { Sample Control: } 596618 \\
\text { Total Sample: } 1193236 \\
\text { VOC: B.1.1.7 }\end{array}$ & $\begin{array}{l}\text { health care organization during } \\
\text { the previous } 12 \text { months. } \\
\text { Exclude: probability of } \\
\text { exposure or the outcomes is } \\
\text { high and controlling for the high } \\
\text { variability is not feasible. }\end{array}$ & $\begin{array}{l}\text { Dose: NR } \\
\text { Number of Doses:2 }\end{array}$ & 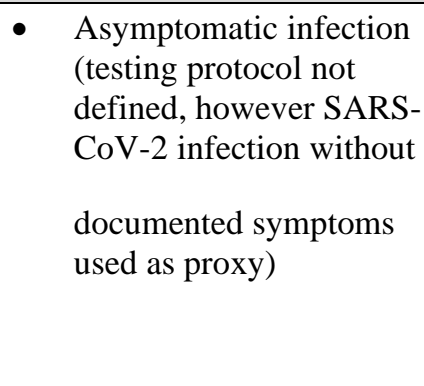 \\
\hline $\begin{array}{l}\text { Author: Levine-Tiefenbrun, } 2021^{36} \\
\text { County: Israel } \\
\text { Date of Recruitment: Dec 2020-Jan, } 2021 \\
\text { Trial Phase: Post Approval } \\
\text { Design: Retrospective Cohort } \\
\text { Funding: NR }\end{array}$ & $\begin{array}{l}\text { Age: NR } \\
\text { \%Female: NR } \\
\text { Comparator: } \\
\text { Unvaccinated } \\
\text { Sample Vaccine: Varied } \\
\text { Sample Control: Varied } \\
\text { Total Sample: Varied } \\
\text { VOC: NR }\end{array}$ & $\begin{array}{l}\text { Include: All positive post- } \\
\text { vaccination samples; } \\
\text { Exclude: Patients who had a } \\
\text { positive sample prior to } \\
\text { vaccination; patients age } 90 \text { and } \\
\text { above }\end{array}$ & $\begin{array}{l}\text { Vaccine: BNT162b2 } \\
\text { Manufacturer: Pfizer } \\
\text { BioNTech } \\
\text { Dose: NR } \\
\text { Number of Doses: } 1\end{array}$ & - $\quad$ Ct values \\
\hline $\begin{array}{l}\text { Author: Jones, } 2021^{13} \\
\text { Country: UK } \\
\text { Date of Recruitment: Jan 18-31, } 2021 \\
\text { Trial Phase: Post Approval } \\
\text { Design: Retrospective Cohort } \\
\text { Funding: Wellcome Senior Clinical } \\
\text { Research Fellowship to MPW }\end{array}$ & $\begin{array}{l}\text { Age: NR } \\
\text { \%Female: NR } \\
\text { Comparator: } \\
\text { Unvaccinated } \\
\text { Sample Vaccine: } 3535 \\
\text { Sample Control: } 3252\end{array}$ & $\begin{array}{l}\text { Include: vaccinated and } \\
\text { unvaccinated Health Care } \\
\text { Workers } \\
\text { Exclude: NR }\end{array}$ & $\begin{array}{l}\text { Vaccine: BNT162b2 } \\
\text { Manufacturer: Pfizer } \\
\text { BioNTech } \\
\text { Number of Doses: } 1\end{array}$ & $\begin{array}{ll}\text { - } & \text { Any positive PCR } \\
\text { - } & \text { Ct values } \\
\text { - } & \text { Asymptomatic (weekly } \\
& \text { Screening) }\end{array}$ \\
\hline
\end{tabular}




\begin{tabular}{|c|c|c|c|c|}
\hline Author/Country/Design & Trial Information & $\begin{array}{l}\text { Participant } \\
\text { Inclusion/Exclusion Criteria }\end{array}$ & Vaccine Information & Effectiveness Outcomes \\
\hline $\begin{array}{l}\text { (108070/Z/15/Z), a Wellcome Principal } \\
\text { Research Fellowship to PJL } \\
(210688 / Z / 18 / Z) \text {, and an MRC Clinician } \\
\text { Scientist Fellowship (MR/P008801/1) and } \\
\text { NHSBT workpackage (WPA15-02) to NJM. } \\
\text { Funding was also received from } \\
\text { Addenbrooke's Charitable Trust and the } \\
\text { Cambridge Biomedical Research Centre. }\end{array}$ & $\begin{array}{l}\text { Total Sample: Varied } \\
\text { VOC: B.1.1.7 }\end{array}$ & & & \\
\hline $\begin{array}{l}\text { Author: Tande, } 2021^{10} \\
\text { Country: USA } \\
\text { Date of recruitment: December, } 2020 \text { to } \\
\text { February, } 2021 \\
\text { Trial Phase: Post approval } \\
\text { Design: Retrospective Cohort } \\
\text { Funding: Internal funding at the Mayo } \\
\text { Clinic }\end{array}$ & $\begin{array}{l}\text { Age: } 54.2(19.7) \\
\text { \%Female: } 52.5 \\
\text { Comparator: } \\
\text { Unvaccinated } \\
\text { Sample vaccine: } 3006 \\
\text { Sample control: } 45,327 \\
\text { Total sample: } \\
\text { VOC: NR }\end{array}$ & $\begin{array}{l}\text { Include: } 18 \text { or mor years old, } \\
\text { underwent preprocedural/ } \\
\text { presurgical testing within } 48-72 \\
\text { hours of procedure } \\
\text { Exclude: Patients tested due to } \\
\text { symptoms or a known exposure } \\
\text { were tested using an alternative } \\
\text { ordering process }\end{array}$ & $\begin{array}{l}\text { Vaccine: BNT162b2 or } \\
\text { mRNA-1273 } \\
\text { Manufacturers: Pfizer } \\
\text { BioNTech or Moderna } \\
\text { Number of Doses: } 1 \text { or } 2\end{array}$ & $\begin{array}{l}\text { PCR+ among } \\
\text { Asymptomatic } \\
\text { (consecutive } \\
\text { preprocedural molecular } \\
\text { screening tests) }\end{array}$ \\
\hline $\begin{array}{l}\text { Author: Pfizer BioNTech }{ }^{38} \text { (Press Release) } \\
\text { Country: Israel } \\
\text { Date of recruitment: January } 17 \text { through } \\
\text { March 6, } 2021 \\
\text { Trial Phase: Post approval } \\
\text { Design: Retrospective cohort }\end{array}$ & $\begin{array}{l}\text { Age: NR } \\
\text { \%Female: NR } \\
\text { Sample vaccine: NR } \\
\text { Sample control: NR } \\
\text { Total sample: NR }\end{array}$ & NR & $\begin{array}{l}\text { Vaccine: BNT162b2 } \\
\text { Manufacturers: Pfizer } \\
\text { BioNtech }\end{array}$ & $\begin{array}{ll}- & \text { Symptomatic } \\
\text { - } & \text { Asymptomatic } \\
\text { (Surveillance method } \\
\text { unclear) }\end{array}$ \\
\hline Author: McEllistrem, $2021^{37}$ & Age: NR & Include: & Vaccine: BNT162b2 & - $\quad \mathrm{Ct}$ values \\
\hline
\end{tabular}




\begin{tabular}{|c|c|c|c|c|}
\hline Author/Country/Design & Trial Information & $\begin{array}{l}\text { Participant } \\
\text { Inclusion/Exclusion Criteria }\end{array}$ & Vaccine Information & Effectiveness Outcomes \\
\hline $\begin{array}{l}\text { Country: USA } \\
\text { Date of recruitment: December } 8,2020- \\
\text { February } 2,2021 \\
\text { Trial Phase: Post approval } \\
\text { Design: Retrospective Cohort } \\
\text { Funding: None }\end{array}$ & $\begin{array}{l}\text { \%Female: NR } \\
\text { Comparator: } \\
\text { Unvaccinated } \\
\text { Sample vaccine: } 5 \\
\text { Sample control: } 5 \\
\text { Total sample: } 10 \\
\text { VOC: NR }\end{array}$ & $\begin{array}{l}\text { A negative baseline } \\
\text { nasopharyngeal reverse } \\
\text { transcription polymerase chain } \\
\text { reaction test (RT-PCR, Palo } \\
\text { Alto VA, CA) for SARS-CoV-2 } \\
\text { on } 12 / 2 / 20 \text {. }\end{array}$ & $\begin{array}{l}\text { Manufacturers: Pfizer } \\
\text { BioNTech } \\
\text { Number of Doses: } 1\end{array}$ & $\begin{array}{ll}- & \text { Viral load } \\
& \text { Asymptomatic } \\
\text { (surveillance nares } \\
\text { testing for SARS-CoV-2 } \\
\text { with the BD Veritor } \\
\text { antigen every 2-5 days) }\end{array}$ \\
\hline $\begin{array}{l}\text { Author: Shah, } 2021^{2} \text { (Pre-print) } \\
\text { Country: UK } \\
\text { Date of recruitment: December } 8,2020- \\
\text { March 3, } 2021 \\
\text { Trial Phase: Post approval } \\
\text { Design: Retrospective Cohort } \\
\text { Funding: British Heart Foundation through } \\
\text { an intermediate clinical research fellowship } \\
\text { (FS/19/17/34172); Wellcome Trust } \\
\text { intermediate clinical fellowship and Beit } \\
\text { fellowship (201492/Z/16/Z) }\end{array}$ & $\begin{array}{l}\text { Age: } 44.4(11.4) \\
\text { \%Female: } 78.7 \\
\text { Comparator: } \\
\text { Unvaccinated } \\
\text { Sample vaccine: } 109,074 \\
\text { Sample control: } 144,525 \\
\text { Total sample: } \\
\text { VOC: NR }\end{array}$ & $\begin{array}{l}\text { Include: Healthcare workers } \\
\text { were included if they were } \\
\text { employed by the National } \\
\text { Health Service (NHS) in } \\
\text { Scotland on or before the } 1 \text { st of } \\
\text { March } 2020 \text { (the first positive } \\
\text { reported case of COVID-19 in } \\
\text { Scotland) and still employed by } \\
\text { the NHS on the 1st of } \\
\text { November } 2020 \text {; healthcare } \\
\text { worker cohort was restricted to } \\
\text { the working-age population (18- } \\
65 \text { years of age). The household } \\
\text { member cohort included all ages } \\
\text { but was restricted to households } \\
\text { with no more than one } \\
\text { healthcare worker ( } 4 \% \text { of } \\
\text { healthcare workers lived in } \\
\text { multiple healthcare worker } \\
\text { households) }\end{array}$ & $\begin{array}{l}\text { Vaccine: BNT162b2 or } \\
\text { ChAdOx1 nCoV-19 } \\
\text { Manufacturers: Pfizer } \\
\text { BioNTech or Oxford } \\
\text { AstraZeneca } \\
\text { Number of Doses: } 1\end{array}$ & - $\quad$ Transmission to contact \\
\hline
\end{tabular}




\begin{tabular}{|c|c|c|c|c|}
\hline Author/Country/Design & Trial Information & $\begin{array}{l}\text { Participant } \\
\text { Inclusion/Exclusion Criteria }\end{array}$ & Vaccine Information & Effectiveness Outcomes \\
\hline $\begin{array}{l}\text { Author: Bouton, } 2021^{15} \text { (Pre-print) } \\
\text { Country: USA } \\
\text { Date of recruitment: December 9, 2020- } \\
\text { February } 23,2021 \\
\text { Trial Phase: Post approval } \\
\text { Design: Case Control } \\
\text { Funding: }\end{array}$ & $\begin{array}{l}\text { Age: } 40(13) \\
\text { \%Female: NR } \\
\text { Comparator: } \\
\text { Unvaccinated } \\
\text { Sample vaccine: } 96 \\
\text { Sample control: } 329 \\
\text { Total sample: } 425 \\
\text { VOC: NR }\end{array}$ & $\begin{array}{l}\text { Include: HCWs had been } \\
\text { vaccinated prior to the vaccine } \\
\text { initiative and were included in } \\
\text { analyses. HCW who received a } \\
\text { vaccination following their } \\
\text { positive SARS-CoV-2 RT-PCR } \\
\text { were included in the } \\
\text { unvaccinated group. }\end{array}$ & $\begin{array}{l}\text { Vaccine: BNT162b2 or } \\
\text { mRNA-1273 } \\
\text { Manufacturers: Pfizer } \\
\text { BioNTech or Moderna } \\
\text { Number of Doses: } 1\end{array}$ & 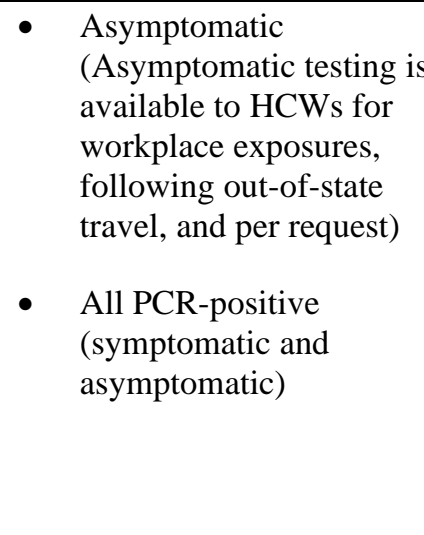 \\
\hline $\begin{array}{l}\text { Author: Regev-Yochay, } 2021^{14} \text { (Pre-print) } \\
\text { Country: Israel } \\
\text { Date of recruitment: December 19, } 2020- \\
\text { March 14, } 2021 \\
\text { Trial Phase: Post approval } \\
\text { Design: Cohort } \\
\text { Funding: Sheba Medical Center, Israel }\end{array}$ & $\begin{array}{l}\text { Age: NR } \\
\text { \%Female: NR } \\
\text { Comparator: } \\
\text { Unvaccinated } \\
\text { Sample vaccine: } \\
\text { Sample control: } \\
\text { Total sample: } 3578 \\
\text { VOC: NR }\end{array}$ & $\begin{array}{l}\text { Include: HCW at Sheba } \\
\text { Medical Center (Israel) }\end{array}$ & $\begin{array}{l}\text { Vaccine: BNT162b2 or } \\
\text { mRNA-1273 } \\
\text { Manufacturers: Pfizer } \\
\text { BioNTech or Moderna } \\
\text { Number of Doses: } 1 \text { or } 2\end{array}$ & $\begin{array}{l}\text { - } \begin{array}{l}\text { Asymptomatic } \\
\text { (Symptomatic or } \\
\text { exposed to confirmed } \\
\text { case) }\end{array} \\
\text { - Symptomatic } \\
\text { - Severe cases }\end{array}$ \\
\hline $\begin{array}{l}\text { Author: Lumley, } 2021^{17} \text { (Pre-print) } \\
\text { Country: England } \\
\text { Date of recruitment: Through to February } \\
28,2021\end{array}$ & $\begin{array}{l}\text { Age: } 39 \text { (IQR:30-50) } \\
\text { \%Female: } 74.0 \\
\text { Comparator: } \\
\text { Unvaccinated seronegative }\end{array}$ & $\begin{array}{l}\text { Include: Only those who } \\
\text { participated in asymptomatic } \\
\text { screening, symptomatic testing } \\
\text { or vaccination from } 01- \\
\text { September- } 2020 \text { onwards were } \\
\text { included. All staff working for }\end{array}$ & $\begin{array}{l}\text { Vaccine: BNT162b2 or } \\
\text { ChAdOx1 nCoV-19 } \\
\text { Manufacturers: Pfizer } \\
\text { BioNTech or Oxford } \\
\text { AstraZeneca }\end{array}$ & $\begin{array}{ll}\text { - } & \text { Ct values } \\
\text { - } & \text { Symptomatic } \\
\text { - } & \text { Asymptomatic } \\
& \text { Asymptomatic } \\
\text { (voluntary nasal and } \\
\text { oropharyngeal swab } \\
\end{array}$ \\
\hline
\end{tabular}




\begin{tabular}{|c|c|c|c|c|}
\hline Author/Country/Design & Trial Information & $\begin{array}{l}\text { Participant } \\
\text { Inclusion/Exclusion Criteria }\end{array}$ & Vaccine Information & Effectiveness Outcomes \\
\hline $\begin{array}{l}\text { Trial Phase: Post approval } \\
\text { Design: Longitudinal Cohort } \\
\text { Funding: Supported by the UK } \\
\text { Government's Department of Health and } \\
\text { Social Care. Also supported by the National } \\
\text { Institute for Health Research Health } \\
\text { Protection Research Unit (NIHR HPRU) in } \\
\text { Healthcare Associated Infections and } \\
\text { Antimicrobial Resistance at Oxford } \\
\text { University in partnership with Public Health } \\
\text { England (PHE) (NIHR200915), the NIHR } \\
\text { Biomedical Research Centre, Oxford, and } \\
\text { benefactions from the Huo Family } \\
\text { Foundation and Andrew Spokes. }\end{array}$ & $\begin{array}{l}\text { Sample vaccine: NR } \\
\text { Sample control: NR } \\
\text { Total sample: } 13,109 \\
\text { VOC: B.1.1.7 }\end{array}$ & $\begin{array}{l}\text { the hospitals were eligible to } \\
\text { participate. }\end{array}$ & Number of Doses: 1 or 2 & $\begin{array}{l}\text { PCR testing every two } \\
\text { weeks and serological } \\
\text { testing every two } \\
\text { months) }\end{array}$ \\
\hline $\begin{array}{l}\text { Author: Pritchard, } 2021^{7} \text { (Pre-print) } \\
\text { Country: UK } \\
\text { Date of recruitment: December 1, } 2020 \text { - } \\
\text { April 3, } 2021 \\
\text { Trial Phase: Post approval } \\
\text { Design: Prospective Cohort } \\
\text { Funding: Department of Health and Social } \\
\text { Care with in-kind support from the Welsh } \\
\text { Government, the Department of Health on } \\
\text { behalf of the Northern Ireland Government } \\
\text { and the Scottish Government. }\end{array}$ & $\begin{array}{l}\text { Age: NR } \\
\text { \%Female: NR } \\
\text { Comparator: } \\
\text { Unvaccinated } \\
\text { Sample vaccine: } \\
\text { Sample control: } \\
\text { Total sample: } 373,402 \\
\text { VOC: NR }\end{array}$ & $\begin{array}{l}\text { Include: This analysis included } \\
\text { participants aged } 16 \text { years or } \\
\text { over (i.e. those who } \\
\text { theoretically could have } \\
\text { received vaccination), and all } \\
\text { visits with positive or negative } \\
\text { swab results from } 1 \text { December } \\
2020 \text { to } 3 \text { April } 2021 \text {. }\end{array}$ & $\begin{array}{l}\text { Vaccine: BNT162b2 or } \\
\text { ChAdOx1 nCoV-19 } \\
\text { Manufacturers: Pfizer } \\
\text { BioNTech or Oxford } \\
\text { AstraZeneca } \\
\text { Number of Doses: } 1 \text { or } 2\end{array}$ & $\begin{array}{l}\text { - Asymptomatic (Weekly } \\
\text { nose and throat self- } \\
\text { swab for first month, } \\
\text { then monthly for } 12 \\
\text { months from enrolment) } \\
\text { - Ct values } \\
\text { - Symptomatic }\end{array}$ \\
\hline
\end{tabular}




\begin{tabular}{|c|c|c|c|c|}
\hline Author/Country/Design & Trial Information & $\begin{array}{l}\text { Participant } \\
\text { Inclusion/Exclusion Criteria }\end{array}$ & Vaccine Information & Effectiveness Outcomes \\
\hline $\begin{array}{l}\text { Author: Shrotri, } 2021 .{ }^{16} \text { (Pre-print) } \\
\text { Country: UK } \\
\text { Date of recruitment: December } 8,2020 \text { - } \\
\text { March 15, } 2021 \\
\text { Trial Phase: Post approval } \\
\text { Design: Prospective Cohort } \\
\text { Funding: UK Government Department of } \\
\text { Health and Social Care. }\end{array}$ & $\begin{array}{l}\text { Age: } 86 \text { (IQR: } 80-91 \text { ) } \\
\text { \%Female: } 69.6 \\
\text { Comparator: } \\
\text { Unvaccinated } \\
\text { Sample vaccine: } \\
\text { Sample control: } \\
\text { Total sample: } 10,412 \\
\text { VOC: NR }\end{array}$ & $\begin{array}{l}\text { Include: At least two PCR test } \\
\text { results in total, and } \geq 1 \text { PCR } \\
\text { result during the analysis period. } \\
\text { Residents entered the risk } \\
\text { period on } 8 \text { December } 2020 \text { if } \\
\text { they had } \geq 1 \text { valid PCR result on } \\
\text { or prior to that date; or, if they } \\
\text { had no PCR results before } 8 \\
\text { December } 2020 \text {, on the date of } \\
\text { their first negative PCR test. } \\
\text { Residents with a positive PCR } \\
\text { result } \leq 90 \text { days before } 8 \\
\text { December entered the risk } \\
\text { period } 90 \text { days after their } \\
\text { positive test. }\end{array}$ & $\begin{array}{l}\text { Vaccine: BNT162b2 or } \\
\text { ChAdOx1 nCoV-19 } \\
\text { Manufacturers: Pfizer } \\
\text { BioNTech or Oxford } \\
\text { AstraZeneca } \\
\text { Number of Doses: } 1 \text { or } 2\end{array}$ & $\begin{array}{l}\text { - } \quad \text { Ct values } \\
\text { - } \quad \text { Symptomatic }\end{array}$ \\
\hline $\begin{array}{l}\text { Author: Haas, } 2021^{9} \\
\text { Country: Israel } \\
\text { Date of recruitment: Jan 24, 2021-April 3, } \\
2021 \\
\text { Trial Phase: Post approval } \\
\text { Design: Prospective Cohort } \\
\text { Funding: Israel MoH and Pfizer. }\end{array}$ & $\begin{array}{l}\text { Age: NR } \\
\text { \%Female: } 50.8 \\
\text { Comparator: } \\
\text { Unvaccinated } \\
\text { Sample vaccine: NR } \\
\text { Sample control: NR } \\
\text { Total sample: NR } \\
\text { VOC: B. } 1.1 .7\end{array}$ & $\begin{array}{l}\text { Include: unvaccinated and } \\
\text { vaccinated individuals aged } \geq 16 \\
\text { years. }\end{array}$ & $\begin{array}{l}\text { Vaccine: BNT162b2 } \\
\text { Manufacturers: Pfizer } \\
\text { BioNTech } \\
\text { Number of Doses: } 1 \text { or } 2\end{array}$ & $\begin{array}{ll}\text { - } & \begin{array}{l}\text { Asymptomatic (routine } \\
\text { testing) }\end{array} \\
\text { - } & \text { Severe cases } \\
\text { - } & \text { Symptomatic }\end{array}$ \\
\hline $\begin{array}{l}\text { Author: Harris, } 2021^{3} \text { (Pre-print) } \\
\text { Country: UK }\end{array}$ & $\begin{array}{l}\text { Age: NR } \\
\text { \%Female: Unvaccinated } \\
\text { index case: } 47.6 \%, \text { Index }\end{array}$ & $\begin{array}{l}\text { Include: Households with an } \\
\text { index case occurring between } 4 \\
\text { January } 2021 \text { to } 28 \text { February } \\
2021 \text {, with } 14 \text { days observable }\end{array}$ & $\begin{array}{l}\text { Vaccine: BNT162b2 or } \\
\text { ChAdOx1 nCoV-19 }\end{array}$ & - Transmission to contact \\
\hline
\end{tabular}




\begin{tabular}{|c|c|c|c|c|}
\hline Author/Country/Design & Trial Information & $\begin{array}{l}\text { Participant } \\
\text { Inclusion/Exclusion Criteria }\end{array}$ & Vaccine Information & Effectiveness Outcomes \\
\hline $\begin{array}{l}\text { Date of recruitment: January } 4-\text { February } \\
28,2021 \\
\text { Trial Phase: Post approval } \\
\text { Design: Prospective Cohort } \\
\text { Funding: This work was undertaken as part } \\
\text { of the core functions of Public Health } \\
\text { England in relation to the surveillance of } \\
\text { communicable diseases and outbreak } \\
\text { response }\end{array}$ & $\begin{array}{l}\text { case vaccinated } 21+\text { day } \\
\text { before: } 38.3 \% \text {, Index case } \\
\text { vaccinated }<21 \text { days } \\
\text { before: } 40.6 \% \\
\text { Comparator: } \\
\text { Unvaccinated } \\
\text { Sample vaccine: } \\
\text { Sample control: } \\
\text { Total sample: } 1,018,842 \\
\text { VOC: NR }\end{array}$ & $\begin{array}{l}\text { follow up for all contacts; } \\
\text { households with a single index } \\
\text { case age } 16+\text {, and no co-primary } \\
\text { cases. }\end{array}$ & $\begin{array}{l}\text { Manufacturers: Pfizer } \\
\text { BioNTech or Oxford } \\
\text { AstraZeneca } \\
\text { Number of Doses: } 1\end{array}$ & \\
\hline
\end{tabular}

IQR: interquartile range, NR: Not Reported, PCR: Polymerase Chain Reaction, RCT: randomized controlled trial, VOC: Variant of Concern, NR: Not Reported. Studies are peer-reviewed publications except otherwise stated.

Table 4: Characteristics of Included Peer-Reviewed Animal Studies

\begin{tabular}{|c|c|c|c|c|c|c|c|c|c|c|c|c|}
\hline $\begin{array}{l}\text { Author } \\
\text { (Year) } \\
\text { Country }\end{array}$ & $\begin{array}{l}\text { Type of } \\
\text { experimental } \\
\text { animal }\end{array}$ & $\begin{array}{l}\text { Vaccine } \\
\text { Sample } \\
\text { Size } \\
\end{array}$ & $\begin{array}{l}\text { Control } \\
\text { Sample } \\
\text { Size } \\
\end{array}$ & $\begin{array}{l}\text { Type } \\
\text { of } \\
\text { virus }\end{array}$ & Virus strain & $\begin{array}{l}\text { Route of } \\
\text { Challenge }\end{array}$ & $\begin{array}{l}\text { Dose/quantity } \\
\text { of virus } \\
\text { (PFU) }\end{array}$ & $\begin{array}{l}\text { Time of } \\
\text { Viral } \\
\text { Challenge } \\
\end{array}$ & $\begin{array}{l}\text { Vaccine Name/ } \\
\text { Number of Doses }\end{array}$ & $\begin{array}{l}\text { Vaccine } \\
\text { Dose }\end{array}$ & $\begin{array}{l}\text { Vaccine } \\
\text { Sponsor }\end{array}$ & $\begin{array}{l}\text { Status of } \\
\text { Vaccine }\end{array}$ \\
\hline $\begin{array}{l}\text { Corbett } \\
(2020)^{21} \\
\text { USA }\end{array}$ & $\begin{array}{l}\text { Rhesus } \\
\text { Macaques }\end{array}$ & 16 & 8 & $\begin{array}{l}\text { Wild } \\
\text { type }\end{array}$ & $\begin{array}{l}\text { SARS-CoV-2 } \\
\text { (USAWA1/2020 } \\
\text { strain) }\end{array}$ & $\begin{array}{l}\text { Intratracheal } \\
\text { and/or } \\
\text { intranasal }\end{array}$ & $7.6 \times 10^{5}$ & 8 weeks & $\begin{array}{l}\text { mRNA-1273 } \\
2 \text { doses }\end{array}$ & $\begin{array}{l}10 \mu \mathrm{g} \text { or } 100 \\
\mu \mathrm{g}\end{array}$ & Moderna & Approved \\
\hline $\begin{array}{l}\text { Van } \\
\text { Doremalen } \\
(2020)^{20} \\
\text { USA } \\
\end{array}$ & $\begin{array}{l}\text { Rhesus } \\
\text { Macaques }\end{array}$ & 6 & 6 & $\begin{array}{l}\text { Wild } \\
\text { type }\end{array}$ & nCoV-WA1-2020 & Others & $2.6 \times 10^{2}$ & 28 days & $\begin{array}{l}\text { ChAdOx1 nCoV- } \\
19 \\
2 \text { doses }\end{array}$ & $\begin{array}{l}2.5 \times 10^{10} \\
\text { virus } \\
\text { particles }\end{array}$ & AstraZeneca & Approved \\
\hline $\begin{array}{l}\text { Gorman } \\
(2021)^{39} \\
\text { USA }\end{array}$ & $\begin{array}{l}\text { Rhesus } \\
\text { Macaques }\end{array}$ & 20 & 4 & $\begin{array}{l}\text { Wild } \\
\text { type }\end{array}$ & $\begin{array}{l}\text { SARS-CoV-2 isolate } \\
\text { USA-WA1/2020 }\end{array}$ & $\begin{array}{l}\text { Intratracheal } \\
\text { and or } \\
\text { intranasal }\end{array}$ & $\begin{array}{l}\text { IN route } 5.25 \times \\
10^{5} \mathrm{PFU} \text { in } \\
250 \mu \mathrm{L}, \mathrm{IT} \\
\text { route } 5.25 \times\end{array}$ & Day 38 & $\begin{array}{l}\text { NVX-CoV2373+ } \\
50 \mu g \text { Matrix-M } \\
1 \text { or } 2 \text { doses }\end{array}$ & $\begin{array}{l}5 \mu \mathrm{g} \text { or } 10 \\
\mu \mathrm{g}\end{array}$ & Novavax & Phase 3 \\
\hline
\end{tabular}




\begin{tabular}{|c|c|c|c|c|c|c|c|c|c|c|c|c|}
\hline $\begin{array}{l}\begin{array}{l}\text { Author } \\
\text { (Year) } \\
\text { Country }\end{array} \\
\end{array}$ & $\begin{array}{l}\text { Type of } \\
\text { experimental } \\
\text { animal }\end{array}$ & $\begin{array}{l}\text { Vaccine } \\
\text { Sample } \\
\text { Size }\end{array}$ & $\begin{array}{l}\text { Control } \\
\text { Sample } \\
\text { Size } \\
\end{array}$ & $\begin{array}{l}\text { Type } \\
\text { of } \\
\text { virus }\end{array}$ & Virus strain & $\begin{array}{l}\text { Route of } \\
\text { Challenge }\end{array}$ & $\begin{array}{l}\text { Dose/quantity } \\
\text { of virus } \\
\text { (PFU) }\end{array}$ & $\begin{array}{l}\text { Time of } \\
\text { Viral } \\
\text { Challenge }\end{array}$ & $\begin{array}{l}\text { Vaccine Name/ } \\
\text { Number of Doses }\end{array}$ & $\begin{array}{l}\text { Vaccine } \\
\text { Dose }\end{array}$ & $\begin{array}{l}\text { Vaccine } \\
\text { Sponsor }\end{array}$ & $\begin{array}{l}\text { Status of } \\
\text { Vaccine }\end{array}$ \\
\hline & & & & & & & $\begin{array}{l}10^{5} \mathrm{PFU} \text { in } \\
250 \mu \mathrm{L}\end{array}$ & & & & & \\
\hline $\begin{array}{l}\text { Guebre- } \\
\text { Xabier } \\
(2020)^{22} \\
\text { USA }\end{array}$ & $\begin{array}{l}\text { Cynomolgus } \\
\text { macaques }\end{array}$ & 12 & 4 & $\begin{array}{l}\text { Wild } \\
\text { type }\end{array}$ & $\begin{array}{l}\text { 2019-nCoV/USA- } \\
\text { WA1/2020 }\end{array}$ & $\begin{array}{l}\text { Intratracheal } \\
\text { and/or } \\
\text { intranasal }\end{array}$ & $1.04 \times 10^{4}$ & Day 35 & $\begin{array}{l}\text { NVX-CoV2373 } \\
2 \text { doses }\end{array}$ & $\begin{array}{l}2.5 \mu \mathrm{g} \text { or } 5 \\
\mu \mathrm{g} \text { or } 25 \mu \mathrm{g}\end{array}$ & Novavax & Phase 3 \\
\hline $\begin{array}{l}\text { Ji }(2021)^{40} \\
\text { China }\end{array}$ & $\begin{array}{l}\text { hACE2 } \\
\text { knockin mice }\end{array}$ & 20 & 8 & $\begin{array}{l}\text { Wild } \\
\text { type }\end{array}$ & $\begin{array}{l}\text { SARS-CoV-2/WH- } \\
\text { 09/human/2020/CHN }\end{array}$ & Intranasal & $\begin{array}{l}50 \mu \mathrm{L} \text { viral } \\
\text { suspension at } \\
10^{5} \mathrm{TCID}^{50} / 50 \\
\mu \mathrm{L}\end{array}$ & Day 42 & $\begin{array}{l}\text { BNT162b2 } \\
2 \text { doses }\end{array}$ & $1 \mu \mathrm{g}$ or $5 \mu \mathrm{g}$ & BioNTech & Approved \\
\hline $\begin{array}{l}\text { Mercado } \\
(2020)^{41} \\
\text { USA }\end{array}$ & $\begin{array}{l}\text { Rhesus } \\
\text { Macaques }\end{array}$ & 52 & 20 & $\begin{array}{l}\text { Wild } \\
\text { type }\end{array}$ & $\begin{array}{l}\text { SARS-CoV-2 USA- } \\
\text { WA1/2020 (NR- } \\
\text { 52281; BEI } \\
\text { Resources) }\end{array}$ & $\begin{array}{l}\text { intratracheal } \\
\text { and or } \\
\text { intranasal }\end{array}$ & $\begin{array}{l}1.0 \times 10^{5} \\
\text { TCID } 50 \\
\left(1.2 \times 10^{8} \mathrm{RNA}\right. \\
\text { copies, } \\
\left.1.1 \times 10^{4} \mathrm{PFU}\right) \\
\end{array}$ & Week 6 & $\begin{array}{l}\text { Ad26 vector } \\
\text { expressing } 7 \\
\text { different } \\
\text { sequences* } \\
1 \text { dose } \\
\end{array}$ & $\begin{array}{l}1 \times 10^{11} \text { viral } \\
\text { particles }\end{array}$ & Janssen & $\begin{array}{l}\text { Progressed to } \\
\text { human trials }\end{array}$ \\
\hline $\begin{array}{l}\text { Patel } \\
(2020)^{42} \\
\text { USA }\end{array}$ & $\begin{array}{l}\text { Rhesus } \\
\text { Macaques }\end{array}$ & 5 & 5 & $\begin{array}{l}\text { Wild } \\
\text { type }\end{array}$ & USA-WA1/2020 & $\begin{array}{l}\text { intratracheal } \\
\text { and or } \\
\text { intranasal }\end{array}$ & $1.1 \times 10^{4} \mathrm{PFU}$ & Week 17 & INO-4800 & $\begin{array}{l}1 \mathrm{mg} \\
2 \text { doses }\end{array}$ & NR & $\begin{array}{l}\text { Progressed to } \\
\text { human trials }\end{array}$ \\
\hline $\begin{array}{l}\text { Tian } \\
(2021)^{43} \\
\text { USA }\end{array}$ & $\begin{array}{l}\text { Mice } \\
(\mathrm{BALB} / \mathrm{c})\end{array}$ & 20 & 5 & $\begin{array}{l}\text { Wild } \\
\text { type }\end{array}$ & WA1 strain & intranasal & $1.5 \times 10^{5} \mathrm{PFU}$ & Day 42 & $\begin{array}{l}\text { NVX-CoV2373 } \\
\text { with or without } \\
\text { adjuvant }\end{array}$ & $\begin{array}{l}10 \mu \mathrm{g}, 1 \mu \mathrm{g}, \\
0.1 \mu \mathrm{g}, 0.01 \\
\mu \mathrm{g}\end{array}$ & Novavax & $\begin{array}{l}\text { Progressed to } \\
\text { human trials }\end{array}$ \\
\hline $\begin{array}{l}\text { Vogel } \\
(2021) \\
\text { USA }\end{array}$ & $\begin{array}{l}\text { Rhesus } \\
\text { Macaques }\end{array}$ & 12 & 9 & $\begin{array}{l}\text { Wild } \\
\text { type }\end{array}$ & USA-WA1/2020 & $\begin{array}{l}\text { intratracheal } \\
\text { and or } \\
\text { intranasal }\end{array}$ & $1.05 \times 10^{6} \mathrm{PFU}$ & Day $44-55$ & $\begin{array}{l}\text { BNT162b2 } \\
2 \text { doses }\end{array}$ & $100 \mu \mathrm{g}$ & $\begin{array}{l}\text { Pfizer- } \\
\text { BioNTech }\end{array}$ & Approved \\
\hline $\begin{array}{l}\text { Wang } \\
(2020)^{45} \\
\text { China }\end{array}$ & $\begin{array}{l}\text { Rhesus } \\
\text { Macaques }\end{array}$ & 8 & 2 & $\begin{array}{l}\text { Wild } \\
\text { type }\end{array}$ & $\begin{array}{l}\text { 19nCoV-CDC-Tan- } \\
\text { HB02 (HB02) }\end{array}$ & intratracheal & $10^{6} \mathrm{TCID}^{50}$ & Day 24 & $\begin{array}{l}\text { BBIBP-CorV } \\
2 \text { doses }\end{array}$ & $2 \mu \mathrm{g}$ or $4 \mu \mathrm{g}$ & NR & $\begin{array}{l}\text { Progressed to } \\
\text { human trials }\end{array}$ \\
\hline $\begin{array}{l}\text { Yadav } \\
(2021)^{46} \\
\text { India }\end{array}$ & $\begin{array}{l}\text { Rhesus } \\
\text { Macaques }\end{array}$ & 15 & 5 & $\begin{array}{l}\text { Wild } \\
\text { type }\end{array}$ & $\begin{array}{l}\text { SARS-CoV-2 (P-3, } \\
\text { NIV-2020770) }\end{array}$ & $\begin{array}{l}\text { intratracheal } \\
\text { and or } \\
\text { intranasal }\end{array}$ & $\begin{array}{l}1 \mathrm{ml}, \mathrm{TCID}^{50} \\
10^{6.5 / \mathrm{ml}}\end{array}$ & Day 28 & $\begin{array}{l}\text { BBV152+adjuvant } \\
\text { A or } \\
\text { BBV152+adjuvant } \\
\text { B } \\
2 \text { doses } \\
\end{array}$ & $3 \mu \mathrm{g}$ or $6 \mu \mathrm{g}$ & $\begin{array}{l}\text { Bharat } \\
\text { Biotech }\end{array}$ & $\begin{array}{l}\text { Progressed to } \\
\text { human trials }\end{array}$ \\
\hline $\begin{array}{l}\text { Yahalom- } \\
\text { Ronen } \\
(\mathbf{2 0 2 0})^{47} \\
\text { Israel }\end{array}$ & $\begin{array}{l}\text { Golden } \\
\text { Syrian } \\
\text { Hamsters }\end{array}$ & 15 & 7 & $\begin{array}{l}\text { Wild } \\
\text { type }\end{array}$ & $\begin{array}{l}\text { SARS-CoV-2 } \\
\text { (GISAID accession } \\
\text { EPI_ISL_406862) }\end{array}$ & Intranasal & $5 \times 10^{6} \mathrm{PFU}$ & $\begin{array}{l}\sim 4 \text { weeks } \\
\text { post } \\
\text { vaccination }\end{array}$ & $\begin{array}{l}\text { rVSV- } \Delta \text { G-spike } \\
1 \text { dose }\end{array}$ & $\begin{array}{l}10^{4} \mathrm{PFU} \text { or } \\
10^{5} \mathrm{PFU} \text { or } \\
10^{6} \mathrm{PFU} \text { or } \\
10^{7} \mathrm{PFU} \text { or } \\
10^{8} \mathrm{PFU}\end{array}$ & NR & $\begin{array}{l}\text { Progressed to } \\
\text { human trials }\end{array}$ \\
\hline
\end{tabular}

Abbreviations: DNA: deoxyribonucleic acid; IN: intranasal; IT: intratracheal; NR: not reported; ml: millilitre; mg: milligram; PFU: plaque forming units; TCID: median tissue culture infectious dose; $\mu$ : microgram 
*tPA.S: tPA leader sequence with full-length S; tPA.S.PP: tPA leader sequence with full-length S with mutation of the furin cleavage site and two proline stabilizing mutations; S: wild-type leader sequence with native full-length S; S.dCT: wild-type leader sequence with S with deletion of the cytoplasmic tail; tPA.WT.S: tandem tPA and wild-type leader sequences with full-length $\mathrm{S}$ as a strategy to enhance expression; S.dTM.PP: wild-type leader sequence with $\mathrm{S}$ with deletion of the transmembrane region and cytoplasmic tail, reflecting the soluble ectodomain, with mutation of the furin cleavage site, proline stabilizing mutations and a foldon trimerization domain

**S.dCT: full-length deletion of the cytoplasmic tail; S.dTM: deletion of the transmembrane domain and cytoplasmic tail reflecting the soluble ectodomain; S1: S1 domain with a foldon trimerization tag; RBD: receptor-binding domain with a foldon trimerization tag; S.dTM.PP: prefusion-stabilized soluble ectodomain with deletion of the furin cleavage site, two proline mutations, and a foldon trimerization tag 
medRxiv preprint doi: https://doi.org/10.1101/2021.06.29.21255526; this version posted July 2,2021 . The copyright holder for this preprint (which was not certified by peer review) is the author/funder, who has granted medRxiv a license to display the preprint in perpetuity. It is made available under a CC-BY-ND 4.0 International license .

\section{Risk of Bias Assessment}

The five included RCTs ${ }^{4-6,18,19}$ were assessed with the Cochrane Risk of Bias Assessment Tool. ${ }^{34}$ Two studies had some concerns regarding randomization, ${ }^{6,19}$ two were of low risk ${ }^{5,18}$ and one study had no sufficient information for assessment. ${ }^{4}$ All but one low risk study ${ }^{18}$ was assessed to have some concerns regarding deviation from intended intervention. Four studies were of some concerns for missing outcome data, ${ }^{4,5,18,19}$ one was assessed to be of high risk of bias. $^{6}$ All the studies were of low risk of bias for the measurement of outcomes. All but one study with some concern ${ }^{6}$ were of low risk for the selection of reported results. ${ }^{4-6,18,19}$ Overall, four of the RCTs were of some concerns for bias ${ }^{4,5,18,19}$ and one had a high risk of bias ${ }^{6}$ (Table $5)$.

The sixteen non-RCTs were assessed using the ROBINS-I tool. ${ }^{33}$ Overall, all but one low risk study ${ }^{15}$ were of moderate risk of bias; while one study did not have enough information for risk assessment $^{12}$ (Table 6). Table 7 describes the results of the SYRCLE risk of bias assessment for the animal studies. ${ }^{35}$ The majority of the studies were assessed as having unclear risks of bias for all domains. 
Table 5: Risk of Bias Assessment for RCTs

\begin{tabular}{|c|c|c|c|c|c|c|}
\hline Author & Randomization & $\begin{array}{c}\text { Deviation from } \\
\text { intended } \\
\text { intervention }\end{array}$ & $\begin{array}{c}\text { Missing outcome } \\
\text { data }\end{array}$ & $\begin{array}{c}\text { Measurement of } \\
\text { outcome }\end{array}$ & $\begin{array}{c}\text { Selection of } \\
\text { reported results }\end{array}$ & Overall Bias \\
\hline Baden et al. ${ }^{18}$ & Low & Low & Some concerns & Low & Low & Some concerns \\
\hline Janssen Biotech $^{19}$ & Some concerns & Some concerns & Some concerns & Low & Low & Some concerns \\
\hline Voysey et al. $^{5}$ & Low & Some concerns & Some concerns & Low & Low & Some concerns \\
\hline Voysey et al. ${ }^{4}$ & NI & Some concerns & Some concerns & Low & Low & Some concerns \\
\hline
\end{tabular}

All studies were published in 2021

Table 6: ROBINS-I Risk of Bias for non-RCTs

\begin{tabular}{|c|c|c|c|c|c|c|c|c|}
\hline Author & $\begin{array}{l}\text { Bias due to } \\
\text { confounding: } \\
\text { Risk of bias } \\
\text { judgment }\end{array}$ & $\begin{array}{c}\text { Bias in } \\
\text { selection of } \\
\text { participants } \\
\text { into the study }\end{array}$ & $\begin{array}{c}\text { Bias in } \\
\text { classification } \\
\text { of } \\
\text { interventions } \\
\end{array}$ & $\begin{array}{c}\text { Bias due to } \\
\text { deviations } \\
\text { from } \\
\text { intended } \\
\text { interventions } \\
\end{array}$ & $\begin{array}{c}\text { Bias due to } \\
\text { missing data }\end{array}$ & $\begin{array}{c}\text { Bias in } \\
\text { measurement } \\
\text { of outcomes }\end{array}$ & $\begin{array}{c}\text { Bias in } \\
\text { selection of } \\
\text { the reported } \\
\text { result } \\
\end{array}$ & $\begin{array}{c}\text { Overall Risk } \\
\text { of Bias }\end{array}$ \\
\hline Amit et al. ${ }^{12}$ & NI & Low & Moderate & NI & NI & Moderate & NI & NI \\
\hline Bouton et al. ${ }^{15}$ & Low & Low & Low & Low & Low & Low & Low & Low \\
\hline Dagan et al. ${ }^{8}$ & Moderate & Moderate & Low & Low & Low & Low & Low & Moderate \\
\hline Haas et al. ${ }^{9}$ & Moderate & Low & Low & Low & Moderate & Low & NI & Moderate \\
\hline Hall et al. ${ }^{11}$ & Moderate & Moderate & Low & Moderate & $\mathrm{NI}$ & Low & $\mathrm{NI}$ & Moderate \\
\hline Harris et al. ${ }^{3}$ & Moderate & Low & Low & Low & Moderate & Low & $\mathrm{NI}$ & Moderate \\
\hline Levine-Tiefenbrun et al. ${ }^{36}$ & Moderate & Low & Low & Low & NI & Low & $\mathrm{NI}$ & Moderate \\
\hline Lumley et al. ${ }^{17}$ & Low & Low & Low & Low & Moderate & Low & Moderate & Moderate \\
\hline McEllistrem et al. ${ }^{37}$ & Moderate & Low & Low & Low & Low & Low & $\mathrm{NI}$ & Moderate \\
\hline Pritchard et al. ${ }^{7}$ & Low & Low & Low & Low & Moderate & Low & Moderate & Moderate \\
\hline Regev-Yochay et al. ${ }^{14}$ & Low & Low & Low & Low & Low & Low & Moderate & Moderate \\
\hline
\end{tabular}




\begin{tabular}{|c|c|c|c|c|c|c|c|c|}
\hline Shah et al. ${ }^{2}$ & Moderate & Moderate & Low & Low & Low & Low & $\mathrm{NI}$ & Moderate \\
\hline Shrotri et al. ${ }^{16}$ & Moderate & Low & Low & Low & Moderate & Low & NI & Moderate \\
\hline Tande et al. ${ }^{10}$ & Moderate & Low & Low & Low & Low & Low & $\mathrm{NI}$ & Moderate \\
\hline Joness et al. $^{13}$ & Moderate & Low & Low & Low & $\mathrm{NI}$ & Low & $\mathrm{NI}$ & Moderate \\
\hline
\end{tabular}

All studies conducted in 2021, NI, No information

Table 7: SYRCLE Risk of Bias Assessment for Animal Studies

\begin{tabular}{|c|c|c|c|c|c|c|c|c|c|c|}
\hline Author & $\begin{array}{c}\text { Allocation } \\
\text { Sequence }\end{array}$ & $\begin{array}{c}\text { Similar } \\
\text { Baseline }\end{array}$ & $\begin{array}{c}\begin{array}{c}\text { Allocation } \\
\text { Concealm } \\
\text { ent }\end{array} \\
\end{array}$ & $\begin{array}{c}\text { Random } \\
\text { Housing } \\
\text { of } \\
\text { Animals } \\
\end{array}$ & $\begin{array}{c}\text { Blinding of } \\
\text { Investigator } \\
\text { s and } \\
\text { Caregivers } \\
\end{array}$ & $\begin{array}{c}\text { Random } \\
\text { Selection } \\
\text { for } \\
\text { Assessmen } \\
\text { t } \\
\end{array}$ & $\begin{array}{c}\text { Blinding } \\
\text { of } \\
\text { Assessors } \\
\end{array}$ & $\begin{array}{c}\text { Incomplet } \\
\text { e Outcome } \\
\text { Data }\end{array}$ & $\begin{array}{c}\text { Selective } \\
\text { Outcome } \\
\text { Reporting } \\
\end{array}$ & $\begin{array}{c}\text { Any other } \\
\text { possible } \\
\text { Bias } \\
\end{array}$ \\
\hline Corbett et al. $(2020)^{21}$ & Unclear & Unclear & No & Unclear & Unclear & Unclear & Unclear & Unclear & Unclear & Unclear \\
\hline $\begin{array}{l}\text { Van Doremalen et al. } \\
(2020)^{20}\end{array}$ & Yes & Unclear & Unclear & Unclear & Yes & Unclear & Yes & Unclear & Unclear & Unclear \\
\hline Gorman et al.(2021) ${ }^{39}$ & Yes & Yes & Yes & Unclear & Yes & Unclear & Yes & Unclear & Unclear & Unclear \\
\hline $\begin{array}{l}\text { Guebre-Xabier et al. } \\
(2020)^{22}\end{array}$ & Unclear & Unclear & Unclear & Unclear & Unclear & Unclear & Unclear & Unclear & Unclear & Unclear \\
\hline Ji et al. $(2021)^{40}$ & Unclear & Unclear & Unclear & Unclear & Unclear & Unclear & Unclear & Unclear & Unclear & Unclear \\
\hline Mercado et al. $(2020)^{41}$ & Unclear & Yes & Unclear & Unclear & Unclear & Unclear & Yes & Unclear & Unclear & Unclear \\
\hline Patel et al. $(2020)^{42}$ & Unclear & Unclear & Unclear & Unclear & Unclear & Unclear & Unclear & Unclear & Unclear & Unclear \\
\hline Tian et al. $(2021)^{43}$ & Unclear & Unclear & Unclear & Unclear & Unclear & Unclear & Yes & Unclear & Unclear & Unclear \\
\hline Vogel et al. $(2021)^{44}$ & No & Unclear & No & Unclear & No & Unclear & No & Unclear & No & Unclear \\
\hline Wang et al. $(2020)^{45}$ & Unclear & Unclear & Unclear & Unclear & Unclear & Unclear & Unclear & Unclear & Unclear & Unclear \\
\hline Yadav et al. $(2021)^{46}$ & Unclear & Unclear & Unclear & Unclear & Unclear & Unclear & Unclear & Unclear & Unclear & Unclear \\
\hline $\begin{array}{l}\text { Yahalom-Ronen et al. } \\
(2020)^{47}\end{array}$ & Unclear & Unclear & Unclear & Unclear & Unclear & Unclear & Unclear & Unclear & Unclear & Unclear \\
\hline
\end{tabular}


medRxiv preprint doi: https://doi.org/10.1101/2021.06.29.21255526; this version posted July 2,2021 . The copyright holder for this preprint (which was not certified by peer review) is the author/funder, who has granted medRxiv a license to display the preprint in perpetuity. It is made available under a CC-BY-ND 4.0 International license .

Vaccine Efficacy and Effectiveness Against Symptomatic Infection

Several RCTs and observational studies have shown the efficacies and effectiveness of COVID-19 vaccination with ChAdOx1 nCoV-19 (Oxford-AstraZeneca, AZ vaccine), CoronaVac (Sinopharm), BNT162b2 (Pfizer-BionNtech, PfBnT vaccine), Ad26.COV2.S (Janssen, J\&J vaccine), mRNA-1273 (Moderna) and NVX-CoV2373 (Novavax) vaccines, against symptomatic COVID-19 infection. Efficacies ranged between 66.1\% (95\% CI: 5574.8) and 94.8\% (95\% CI 89.8-97.6). These have been compiled and presented in detail in Appendix 2 and Appendix 3. This review however focuses on the transmission of COVID-19 asymptomatic infection and the effect of vaccines on post-infection proxy measures of infectivity such as $\mathrm{Ct}$ values and viral load.

\section{Vaccine Effectiveness against Infection Transmission}

Two studies, reported on the effectiveness of both PfBNT and AZ vaccines against disease transmission.

Shah et al. in a retrospective study of 194,362 household members of 144,525 healthcare workers, who had received at least one dose of the PfBnT or AZ, found that from the $14^{\text {th }}$ postvaccination day onwards, vaccinating a co-habiting healthcare worker was associated with a significantly reduced risk of documented COVID-19 among household members (rate per 100 person-years: 9.40 versus 5.93; HR: 0.70, (95\% CI: 0.63-0.78)). ${ }^{2}$ The risk of hospitalization was also significantly lower among household contacts of vaccinated HCWs (rate per 100 person-years: 0.51 versus 0.31; HR: 0.77, (95\% CI: 0.53-1.10)). ${ }^{2}$ Following a second dose, the risks of infection and hospitalization involving a household member were significantly lower, rate per 100 person-years of 9.40 versus 2.98, HR: 0.46 (95\% CI: $0.30-0.70)$ and 0.51 versus 0.22 per 100 person-years, HR: 0.68 (95\% CI: $0.17-2.83)$, respectively). ${ }^{2}$ The baseline serology and PCR of household contacts were not reported (Table 8).

In a second study, Harris et al. evaluated the risks of transmission of COVID-19 after one dose of PfBnT and $\mathrm{AZ}$ vaccination to unvaccinated household contacts using a retrospective design and a matched case-control method. ${ }^{3}$ In the retrospective cohort analysis, there were 96,898 secondary cases among 960,765 household contacts of unvaccinated individuals $(10.1 \%)$. There were 196 secondary cases in 3,424 contacts $(5.72 \%)$ where the index case received AZ vaccine more than 21 days before PCR positivity, and 371 secondary cases in 5,939 contacts $(6.25 \%)$ where the index case received the PfBnT vaccine. Adjusted odds ratio of transmission were 0.53 (95\% CI: 0.43-0.63) and 0.51 (95\% CI: 0.44-0.59), respectively, which were significantly lower. ${ }^{3}$ In the matched case-control method, the odds of secondary infection among contacts of $\mathrm{AZ}$ and PfBnT vaccinated individuals were also significantly lower, 0.62 (95\% CI: 0.48-0.79) and 0.51 (95\% CI: 0.42-0.62) respectively. ${ }^{3}$ The baseline serology and PCR of household contacts were not reported (Table 8).

\section{Vaccine Efficacy or Effectiveness Against Asymptomatic Infection}

Ten studies reported vaccine efficacy or effectiveness against asymptomatic COVID-19 infection (Table 9 and Table 10). Three of these involved AZ vaccine, ${ }^{4-6}$ another four examined 
medRxiv preprint doi: https://doi.org/10.1101/2021.06.29.21255526; this version posted July 2 , 2021. The copyright holder for this preprint (which was not certified by peer review) is the author/funder, who has granted medRxiv a license to display the preprint in perpetuity. It is made available under a CC-BY-ND 4.0 International license .

PfBnT vaccine ${ }^{8,11,12,38}$ and one study each evaluated mRNA- $1273^{18}$ and $\mathbf{J}$ and $\mathrm{J}^{19}$ vaccines and one evaluated both mRNA-1273 and BNT162b2. ${ }^{10}$ The methods of assessing efficacy or effectiveness against asymptomatic infection used in some of these studies include RT-PCR nasopharyngeal swabs at time intervals.

\section{AstraZeneca Vaccine Efficacy in the General Population}

\section{First Dose AstraZeneca}

Asymptomatic infection data were presented for only the UK component of the AZ vaccine studies. Two AZ vaccine studies reported vaccine efficacy against asymptomatic or unknown infection of $7.8 \%(-46.7-42.1)^{5}$ and $16 \%(-88-62)^{4}$ respectively, after more than 21 days and 22 to 90 days of the first dose. However, vaccine efficacy among participants with positive results, irrespective of symptoms, were $46.3 \%(31.8-57.8)^{5}$ and $67 \%(49-78)^{4}$, respectively over the same period (Table 9). These trials implemented weekly self-administered nose and throat swabs for testing on baseline seronegative participants. The PCR status of these participants was not established at baseline.

\section{Full Dose AstraZeneca}

After 14 days of the second dose, two AZ vaccine studies did not demonstrate efficacy against asymptomatic or unknown infection with the wild type virus $22.2 \%(-9.9-45)$ and $27.3 \%$ (95\% CI: -17-54.9)) respectively. ${ }^{4,5}$ A third study did not show efficacy against asymptomatic infection with the B.1.1.7 variant (26.5\% (95\% CI: -112-74.5)), following low or standard dose vaccination. ${ }^{6}$ All three studies involved baseline seronegative participants. The baseline PCR results of the participants were not reported, therefore, persistent carriage after previous infection was not ruled out. In the subgroup of participants with an initial low dose of the vaccine, followed by a standard dose, two studies reported $49.3 \%(95 \% \text { CI: } 7.4-72.2)^{4}$ and $58.9 \%(95 \% \mathrm{CI}: 1-82.9)^{5}$ respective efficacies against asymptomatic and unknown infection 14 days after the second dose (Table 10).

However, when participants who were PCR positive irrespective of symptoms were considered, two doses of AZ vaccine showed efficacies of $55.7 \%(41.1-66.7)^{5}$ and $54.1 \%$ $(44.7 \%, 61.9 \%)^{4}$ after 14 days of second dose vaccination.

\section{AstraZeneca Vaccine Effectiveness in the General Population}

\section{First Dose AstraZeneca}

In a large UK household survey with longitudinal follow-up among seronegative or seropositive individuals, Pritchard et al. reported significant reductions in the odds of asymptomatic infections following AZ vaccine 0-7 days, 8-20 days and 21 or more days after the first dose (ORs: 0.45 (95\% CI: 0.35-0.57), 0.47 (95\% CI: 0.37-0.6) and 0.39 (95\% CI: 0.3 -0.51), respectively). ${ }^{7}$ Nose and throat self-swabs were conducted every week for a month, and subsequently monthly for 12 months from enrolment. ${ }^{7}$ 
medRxiv preprint doi: https://doi.org/10.1101/2021.06.29.21255526; this version posted July 2,2021 . The copyright holder for this preprint (which was not certified by peer review) is the author/funder, who has granted medRxiv a license to display the preprint in perpetuity. It is made available under a CC-BY-ND 4.0 International license .

Pfizer BioNTech Vaccine Effectiveness in the General Population First Dose Pfizer BioNTech Vaccine

An Israeli observational study by Dagan et al., which did not establish baseline seronegativity, showed that one dose of BNT162b2 significantly reduced asymptomatic infection by $29 \%$ (95\% CI: 17-39) and 52\% (95\% CI: 41-60) after 14 to 20 days and 21 to 27 days of follow-up respectively, as assessed by confirmed positive PCR SARS-CoV-2 test without documented symptoms. No routine swabbing was documented for the participants (Table 9).

In a large UK household survey with longitudinal follow-up involving participants with unknown baseline serology status, Pritchard et al. reported significant reductions in the odds of asymptomatic infections following PfBnT vaccine 0-7 days, 8-20 days and 21 or more days after the first dose, ORs: 0.48 (95\% CI: 0.39-0.6) and 0.54 (95\% CI: 0.45-0.65) respectively, compared with unvaccinated previously PCR negative individuals. ${ }^{7}$ Nose and throat self-swabs were conducted every week for a month, and subsequently monthly for 12 months from enrolment. $^{7}$

\section{Full Dose Pfizer BioNTech Vaccine}

Dagan et al. also demonstrated 90\% effectiveness (95\% CI: 83-94) against asymptomatic infection seven days after the second dose. ${ }^{8} \mathrm{~A}$ press release by the vaccine manufacturer reported two weeks post-second dose effectiveness of $94 \%$ against asymptomatic infection in Israel. ${ }^{38}$ The study utilized de-identified aggregate Israel Ministry of Health public health surveillance data. The analysis was conducted when more than $80 \%$ of tested specimens in Israel were variant B.1.1.7. ${ }^{38}$ In another Israeli study, which utilized the national public health surveillance data, Haas et al. reported significantly higher vaccine effectiveness seven or more days after full dose PfBnT vaccination, 90.4\% (95\% CI: 89.1-91.5). ${ }^{9}$ The incidence rate per 100000 person-days among unvaccinated individuals was 54.6 compared with 3.2 in those vaccinated. Vaccine effectiveness after 14 or more days was 93.8\% (95\% CI: 93.3-94.2). ${ }^{9}$ Pritchard et al. also found full dose vaccination with PfBnT vaccine to significantly reduce the odds of asymptomatic infection compared with unvaccinated previously PCR negative UK residents, 0.48 (95\% CI: $0.36-0.66)^{7}$

mRNA (Pfizer BioNTech and Moderna) Vaccines Effectiveness in the General Population First or second dose of $m R N A$ vaccine

Tande et al. evaluated the effectiveness of at least one dose of either mRNA-1273 or PfBnT vaccine among people who underwent molecular tests prior to a procedure or surgery. ${ }^{10}$ The relative risk for a positive test during asymptomatic pre-procedure screening in vaccinated compared with unvaccinated was significantly lower (0.44 (95\% CI: $0.33-0.60)$ ). Ten or more days after the 1st dose, the risk of a positive test was also significantly lower among the vaccinated (0.28 (95\% CI: $0.16-0.49 ; \mathrm{p}<.0001)$ ). The risk of test positivity was similarly lower among the vaccinated, after the second dose 0.27 (95\% CI: 0.12-0.60). ${ }^{10}$ 
medRxiv preprint doi: https://doi.org/10.1101/2021.06.29.21255526; this version posted July 2, 2021. The copyright holder for this preprint (which was not certified by peer review) is the author/funder, who has granted medRxiv a license to display the preprint in perpetuity. It is made available under a CC-BY-ND 4.0 International license.

\section{Moderna Vaccine Efficacy in the General Population}

\section{First Dose Moderna Vaccine}

A study of the mRNA-1273 reported that $0.1 \%$ of the participants receiving the first dose developed asymptomatic infection, assessed at second dose with nasal swabs, compared with $0.27 \%$ of the unvaccinated group, 21 days after the first dose; which is suggestive of $61.4 \%$ efficacy against asymptomatic carriage. Participants in this trial were negative for COVID-19 by RT-PCR or antibody testing at baseline. ${ }^{18}$ There was no data on asymptomatic infection after full dose (Table 9).

\section{Janssen Vaccine Efficacy in the General Population}

\section{Full Dose Janssen vaccine}

This is a single dose vaccine. The $J \& J$ vaccine did not show statistically significant efficacy against asymptomatic infection in the first 29 days of follow-up. However, after 29 days postvaccination, asymptomatic infection, assessed via surveillance swabs at unspecified intervals among baseline seronegative participants, was significantly lower among vaccinated participants $\left(74 \%, 95 \%\right.$ CI: 46.8-88.4\%). ${ }^{19}$ Asymptomatic infection in this trial was assessed by lack of symptoms on the day preceding, the day of, or any time after a positive PCR test. Furthermore, efficacy as demonstrated by seroconversion in previously asymptomatic participants was $74.2 \%$ compared with placebo $\left(95 \%\right.$ CI: 47.1; 88.6). ${ }^{19}$

\section{Effectiveness of Vaccines in Health Care Workers (HCWs)}

Hall et al. in a surveillance study of HCWs with documented baseline PCR and antibody in the UK, reported a higher incidence density of asymptomatic or unknown test positivity in unvaccinated HCWs than PfBnT or AZ vaccine recipients. In this biweekly surveillance of vaccine status, symptoms, and nasal or nasal plus oral swabs, the vaccine recipients were followed up for 396,318 person-days compared with 710,587 person days in unvaccinated group, with 35 and 218 asymptomatic or unknown infections reported, translating to 0.88 and 3 infections per 10,000 person-days respectively. ${ }^{11}$ The vaccine effectiveness overall was $72 \%$ from 21 days after dose one and 86\% after two. Protection was noted from day 10 post first dose in these data. The study took place over two months and involved 23,320 HCWs in 104 hospitals, of whom $35 \%$ were previously documented SARS-CoV-2 positive. Also, of practical relevance in those testing positive, the unvaccinated group had a higher proportion with "classic" symptoms at 63\%: 14\% had other symptoms, 5\% were asymptomatic and 17\% unknown. In the vaccinated group only $40 \%$ had classic symptoms, $13 \%$ had other symptoms, $13 \%$ were asymptomatic, and $31 \%$ had unknown - therefore asymptomatic or non-classic symptoms comprised $26 \%$ of the post vaccine test positive. In a second observational HCW study in Israel by Amit et al., ${ }^{12}$ asymptomatic test positive data was limited, and reasons for tests done without documented symptoms was not reported. The baseline RT-PCR status was not assessed; therefore, prolonged RT-PCR positivity after prior infection was not ruled out. Estimated asymptomatic infection prevalence in the vaccinated group was 1.7 per 10,000person years between 15 and 28 days after vaccination, compared with 2.4 per 10,000 personyears in the unvaccinated group (VE: 29\%). ${ }^{12}$ The overall infection rate in the whole cohort for 
medRxiv preprint doi: https://doi.org/10.1101/2021.06.29.21255526; this version posted July 2 , 2021. The copyright holder for this preprint (which was not certified by peer review) is the author/funder, who has granted medRxiv a license to display the preprint in perpetuity. It is made available under a CC-BY-ND 4.0 International license.

the 2-month study was $1.9 \%$. Matheson et al. in an asymptomatic weekly screening study among HCWs who were vaccinated with one dose of PfBnT vaccine compared with unvaccinated HCWs, showed that $0.8 \%$ of tests from unvaccinated HCWs were positive compared with $0.37 \%$ and $0.2 \%$ from vaccinated ones at $<12$ days and $>12$ days postvaccination respectively ( $\mathrm{p}=0.023$ and $\mathrm{p}=0.004$, respectively). ${ }^{13}$

In another large Israeli cohort study of HCWs who were either seropositive or negative at baseline, Regev-Yochay et al. ${ }^{14}$ reported a prevalence of PCR positive asymptomatic (at first testing) infection following exposure to COVID-19 of 5.2\% among unvaccinated HCW compared with 1.8\% among fully PfBNT vaccinated HCW (VE:65\%, 95\%CI: 45-79\%). The prevalence of infection among true asymptomatic (who never became symptomatic) was $3.3 \%$ among unvaccinated and $0.9 \%$ among vaccinated individuals. The vaccine effectiveness was $72 \%$ (95\% CI: $48-86 \%) .{ }^{14}$ Furthermore, the vaccine was $70 \%$ effective (95\% CI: $43-84 \%$ ) in preventing all presumably infectious cases (with $\mathrm{Ct}$ values <30) and $83 \%$ effective $(95 \% \mathrm{CI}$ : 51-94\%) against presumably infectious asymptomatic cases. ${ }^{14}$ Bouton et al. however did not find any significant difference in asymptomatic cases (assessed following workplace exposure, out of state travel or upon request) at any time from the first dose of vaccination with either Moderna or PfBnT vaccines compared with unvaccinated HCWs at a tertiary health centre. ${ }^{15}$ 
Table 8: Observational Studies of Vaccine Effectiveness Against Transmission to Household Contacts (Baseline Serology Unknown)

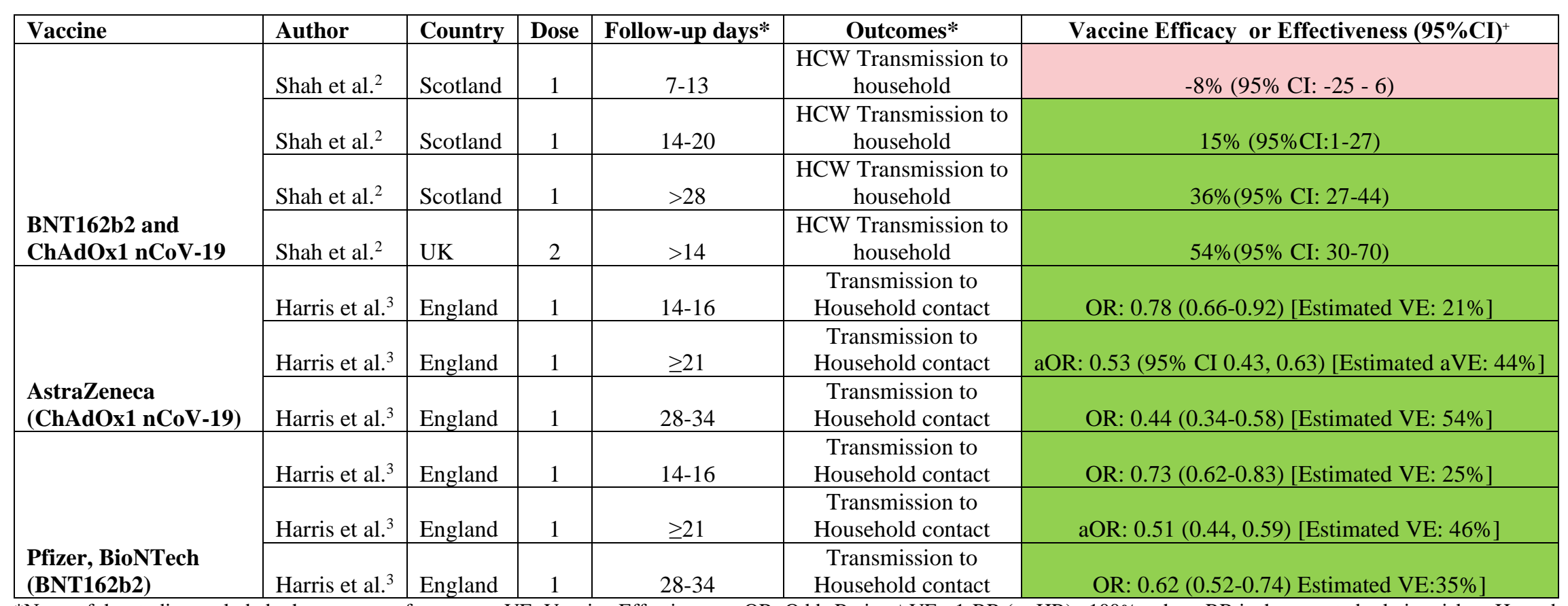

*None of the studies excluded other sources of exposure. VE: Vaccine Effectiveness, OR: Odds Ratio, ${ }^{+}$VE $=1-\mathrm{RR}$ (or HR) x100\%, where RR is the reported relative risk or Hazard ratio; or derived from reported baseline prevalence in unvaccinated group and $\mathrm{OR}^{48}$. 
Table 9: First-dose Vaccine Efficacy or Effectiveness Against Asymptomatic Infection

\begin{tabular}{|c|c|c|c|c|c|c|c|c|}
\hline Vaccine & Author & Country & $\begin{array}{l}\text { Strain targeted } \\
\text { by PCR }\end{array}$ & $\begin{array}{l}\text { Baseline } \\
\text { Serology }\end{array}$ & $\begin{array}{l}\text { Dosing } \\
\text { Schedule }\end{array}$ & $\begin{array}{l}\text { Follow- } \\
\text { up } \\
\text { days* }\end{array}$ & Outcomes & $\begin{array}{c}\text { Vaccine Efficacy or } \\
\text { effectiveness }(95 \% \mathrm{CI})^{+}\end{array}$ \\
\hline \multirow{9}{*}{$\begin{array}{l}\text { AstraZeneca } \\
(\mathrm{ChAdOx} 1 \\
\mathrm{nCoV}-19)\end{array}$} & Voysey et al..$^{5}$ (RCT) & UK & Wild type & Negative & $\begin{array}{l}\text { LD or } \\
\text { SD }\end{array}$ & $>21$ & $\begin{array}{l}\text { Asymptomatic } \\
\text { or unknown }\end{array}$ & $7.8 \%(-46.7-42.1)$ \\
\hline & Voysey et al. $^{5}$ & UK & Wild type & Negative & $\begin{array}{l}\text { LD or } \\
\text { SD }\end{array}$ & $>21$ & Any PCR+ & $46.3 \%(31.8-57.8)$ \\
\hline & Voysey et al. ${ }^{4}$ (RCT) & UK/Brazil/S.Afrca & Wild type & Negative & $\begin{array}{l}\text { LD or } \\
\text { SD }\end{array}$ & $22-90$ & Any PCR+ & $67 \%(49-78)$ \\
\hline & Voysey et al. ${ }^{4}$ & UK/Brazil/S.Afrca & Wild type & Negative & SD & $22-30$ & $\begin{array}{l}\text { Asymptomatic } \\
\text { or Unknown }\end{array}$ & $0.2(-209-68)$ \\
\hline & Voysey et al. ${ }^{4}$ & UK/Brazil/S.Afrca & Wild type & Negative & SD & $31-60$ & $\begin{array}{l}\text { Asymptomatic } \\
\text { or Unknown }\end{array}$ & $17 \%(-172-75)$ \\
\hline & Voysey et al. ${ }^{4}$ & UK/Brazil/S.Afrca & Wild type & Negative & SD & $22-90$ & $\begin{array}{c}\text { Asymptomatic } \\
\text { or unknown }\end{array}$ & $16 \%(-88-62)$ \\
\hline & Pritchard et al. ${ }^{7}$ & UK & $\begin{array}{c}\text { Wild type and } \\
\text { B.1.1.7 }\end{array}$ & Both & NA & $0-7$ & Asymptomatic & OR: $0.45(0.35$ to 0.57$)$ \\
\hline & Pritchard et al & UK & $\begin{array}{c}\text { Wild type and } \\
\text { B.1.1.7 } \\
\end{array}$ & Both & NA & $8-20$ & Asymptomatic & OR: $0.47(0.37$ to 0.6$)$ \\
\hline & Pritchard et al & UK & $\begin{array}{l}\text { Wild type and } \\
\text { B. } 117\end{array}$ & Both & NA & $\geq 29$ & Asymptomatic & OR: $0.39(0.3$ to 0.51$)$ \\
\hline \multirow{2}{*}{$\begin{array}{l}\text { Janssen } \\
\text { Biotech } \\
\text { (Ad26.COV2. } \\
\text { S) } \\
\end{array}$} & $\begin{array}{l}\text { Janssen Biotech }^{19} \\
\text { (Regulatory } \\
\text { submission) }\end{array}$ & Multiple & Wild type & Negative & NA & $1-29$ & Asymptomatic & $20 \%(-7-40.4)$ \\
\hline & Janssen Biotech $^{19}$ & Multiple & Wild type & Negative & NA & $\geq 29$ & Asymptomatic & $74 \%(46.8-88.4)$ \\
\hline \multirow{5}{*}{$\begin{array}{l}\text { Pfizer, } \\
\text { BioNTech } \\
\text { (BNT162b2) }\end{array}$} & Amit et al. ${ }^{12}$ & Israel & Wild type & Unknown & NA & $1-14$ & $\begin{array}{l}\text { Asymptomatic } \\
\text { or unknown }\end{array}$ & $\mathrm{NR}^{\# \#}$ \\
\hline & Amit et al. ${ }^{12}$ & Israel & Wild type & Unknown & NA & $15-28$ & $\begin{array}{l}\text { Asymptomatic } \\
\text { or unknown }\end{array}$ & $\mathrm{NR}^{\# \# \#}$ \\
\hline & Dagan et al. ${ }^{8}$ & Israel & $\begin{array}{l}\text { Wild type and } \\
\text { B.1.1.7 }\end{array}$ & Unknown & NA & $14-20$ & Asymptomatic & $29 \%(17-39)$ \\
\hline & Dagan et al. ${ }^{8}$ & Israel & $\begin{array}{l}\text { Wild type and } \\
\text { B.1.1.7 }\end{array}$ & Unknown & NA & $21-27$ & Asymptomatic & $52 \%(41-60)$ \\
\hline & Hall et al. ${ }^{11}$ & UK & Wild type & Unknown & NA & $\begin{array}{l}21 \text { days } \\
\text { after } 1^{\text {st }} \\
\text { dose }\end{array}$ & $\begin{array}{c}\text { Asymptomatic } \\
\text { or unknown }\end{array}$ & $97.2 \%{ }^{\#}$ \\
\hline
\end{tabular}




\begin{tabular}{|c|c|c|c|c|c|c|c|c|}
\hline Vaccine & Author & Country & $\begin{array}{l}\text { Strain targeted } \\
\text { by PCR }\end{array}$ & $\begin{array}{l}\text { Baseline } \\
\text { Serology }\end{array}$ & $\begin{array}{l}\text { Dosing } \\
\text { Schedule }\end{array}$ & $\begin{array}{c}\text { Follow- } \\
\text { up } \\
\text { days* }\end{array}$ & Outcomes & $\begin{array}{c}\text { Vaccine Efficacy or } \\
\text { effectiveness }(95 \% \mathrm{CI})^{+}\end{array}$ \\
\hline & & & & & & $\begin{array}{l}\text { and } 7 \\
\text { days } \\
\text { after } 2^{\text {nd }}\end{array}$ & & \\
\hline & Haas et al. ${ }^{9}$ & Israel & $\begin{array}{l}\text { Wild type and } \\
\text { B.1.1.7 }\end{array}$ & Unknown & NA & $\begin{array}{l}14-21 \\
\text { days }\end{array}$ & Asymptomatic & $52 \%(48 \cdot 9-55 \cdot 0)$ \\
\hline & Pritchard et al. ${ }^{7}$ & UK & $\begin{array}{l}\text { Wild type and } \\
\text { B.117 }\end{array}$ & Both & NA & $0-7$ & Asymptomatic & OR: $0.48(0.39$ to 0.6$)$ \\
\hline & Pritchard et al. ${ }^{7}$ & UK & $\begin{array}{c}\text { Wild type and } \\
\text { B.117 } \\
\end{array}$ & Both & NA & $8-20$ & Asymptomatic & OR:0.54(0.45 to 0.65$)$ \\
\hline & Pritchard et al. ${ }^{7}$ & UK & $\begin{array}{c}\text { Wild type and } \\
\text { B.1.1.7 }\end{array}$ & Both & NA & $\geq 29$ & Asymptomatic & OR: $0.44(0.36$ to 0.55$)$ \\
\hline & $\begin{array}{l}\text { Regev-Yochay et } \\
\text { al. }^{14}\end{array}$ & Israel & Wild type & Both & NA & $4-10$ & $\begin{array}{l}\text { Asymptomatic } \\
\text { at first test }\end{array}$ & $28(-18$ to 57$)$ \\
\hline & $\begin{array}{l}\text { Regev-Yochay et } \\
\text { al. }{ }^{14}\end{array}$ & Israel & Wild type & Both & NA & $4-10$ & $\begin{array}{l}\text { Asymptomatic } \\
\text { (who never } \\
\text { became } \\
\text { symptomatic) }\end{array}$ & $27(-38$ to 61$)$ \\
\hline & McEllistrem et al. ${ }^{37}$ & USA & Wild Type & Unknown & NA & $\begin{array}{c}12-15 \\
\text { days }\end{array}$ & Asymptomatic & NR \\
\hline & Joness et al. ${ }^{13}$ & UK & $\begin{array}{c}\text { Wild type and } \\
\text { B.1.1.7 }\end{array}$ & Unknown & NA & $\begin{array}{l}<12 \text { and } \\
>12\end{array}$ & Asymptomatic & NR \\
\hline $\begin{array}{l}\text { Moderna } \\
\text { (mRNA-1273) }\end{array}$ & Baden et al. ${ }^{18}$ (RCT) & USA & Wild type & Negative & NA & $\begin{array}{l}\text { From } \\
\text { day } 1\end{array}$ & Asymptomatic & $61.4 \%{ }^{\#}$ \\
\hline \multirow{2}{*}{$\begin{array}{l}\text { mRNA } \\
\text { vaccines } \\
\text { (BNT162b2 } \\
\text { or mRNA- } \\
\text { 1273) }\end{array}$} & Tande et al. ${ }^{10}$ & USA & & Unknown & NA & $\begin{array}{l}\text { From } \\
\text { day } 1, \\
\text { at least } \\
\text { one } \\
\text { dose } \\
\end{array}$ & $\begin{array}{c}\text { PCR+ in } \\
\text { asymptomatic }\end{array}$ & $56 \%(40-67)$ \\
\hline & Bouton et al. ${ }^{15}$ & USA & Wild type & Unknown & NA & $\begin{array}{c}\text { From } \\
\text { day } 1,1 \\
\text { dose } \\
\end{array}$ & Asymptomatic & $\begin{array}{l}\text { RR calculated: }-1 \%(-57- \\
35)\end{array}$ \\
\hline
\end{tabular}

* Time PCR was conducted after first or second dose; LD: Low dose, SD: Standard dose, \#Calculated from raw values. \#\# 2.7 cases per 10000 person-days in vaccine vs 2.4 cases per 10000 person-days in control. \#\#\#1.7 cases per 10000 person-days in vaccine vs 2.4 cases per 10000 person-days, Calculated from raw values). ${ }^{+}$Efficacy reported for RCTs and

Effectiveness for observational studies. All Pfizer BioNtech's studies except Dagan et al. involved healthcare workers. 0.44 (95\% CI: 0.33-0.60). Studies are observational except otherwise stated. , ${ }^{+}$VE $=1-R R$ (or HR) $\times 100 \%$ 
Table 10: Full-dose Vaccine Efficacy or Effectiveness Against Asymptomatic Infection

\begin{tabular}{|c|c|c|c|c|c|c|c|c|}
\hline Vaccine & Author & Country & Strain targeted by PCR & $\begin{array}{l}\text { Baseline } \\
\text { Serology }\end{array}$ & $\begin{array}{c}\text { Dosing } \\
\text { Schedule }\end{array}$ & Follow-up days* & Outcomes & Vaccine Efficacy $(95 \% \mathrm{CI})^{+}$ \\
\hline & Voysey et al. ${ }^{5}$ (RCT) & UK & Wild type & Negative & $\begin{array}{c}\text { LD or SD } \\
\text { and SD }\end{array}$ & $>14$ & $\begin{array}{l}\text { Asymptomatic } \\
\text { or unknown }\end{array}$ & $27.3 \%(-17-54.9)$ \\
\hline \multirow{10}{*}{$\begin{array}{l}\text { AstraZeneca } \\
(\mathrm{ChAdOx} 1 \\
\text { nCoV-19) }\end{array}$} & Voysey et al. ${ }^{5}$ & UK & Wild type & Negative & LD and SD & $>14$ & $\begin{array}{l}\text { Asymptomatic } \\
\text { or unknown }\end{array}$ & $58.9 \%(1-82.9)$ \\
\hline & Voysey et al. ${ }^{5}$ & UK & Wild type & Negative & SD and SD & $>14$ & $\begin{array}{l}\text { Asymptomatic } \\
\text { or unknown }\end{array}$ & $3.8 \%(-72.4-46.3)$ \\
\hline & Voysey et al. ${ }^{5}$ & UK & Wild type & Negative & $\begin{array}{c}\text { LD or SD } \\
\text { and SD }\end{array}$ & $>14$ & Any PCR+ & $55.7 \%(41.1-66.7)$ \\
\hline & Voysey et al. ${ }^{4}$ (RCT) & UK & Wild type & Negative & $\begin{array}{c}\text { LD or SD } \\
\text { and SD }\end{array}$ & $>14$ & Any PCR+ & $54.1 \%(44.7 \%, 61.9 \%)$ \\
\hline & Voysey et al. ${ }^{4}$ & UK & Wild type & Negative & $\begin{array}{c}\text { LD or SD } \\
\text { and SD }\end{array}$ & $>14$ & $\begin{array}{l}\text { Asymptomatic } \\
\text { or unknown }\end{array}$ & $22.2 \%(-9.9-45)$ \\
\hline & Voysey et al. ${ }^{4}$ & UK & Wild type & Negative & SD and SD & $>14$ & $\begin{array}{l}\text { Asymptomatic } \\
\text { or unknown }\end{array}$ & $2.0 \%(-50.7-36.2)$ \\
\hline & Voysey et al. ${ }^{4}$ & UK & Wild type & Negative & LD and SD & $>14$ & $\begin{array}{l}\text { Asymptomatic } \\
\text { or unknown }\end{array}$ & $49.3 \%(7.4-72.2)$ \\
\hline & Emary et al. ${ }^{6}(\mathrm{RCT})$ & UK & Wild type, B.1.1.7, Other & Negative & $\begin{array}{c}\text { LD or SD } \\
\text { and SD }\end{array}$ & $>14$ & Asymptomatic & $15.7 \%(-10.7-35.8)$ \\
\hline & Emary et al. ${ }^{6}$ & UK & B.1.1.7 & Negative & $\begin{array}{l}\text { LD or SD } \\
\text { and SD }\end{array}$ & $>14$ & Asymptomatic & $26.5 \%(-112-74.5)$ \\
\hline & Emary et al. ${ }^{6}$ & UK & Variants not B.1.1.7 & Negative & $\begin{array}{c}\text { LD or SD } \\
\text { and SD }\end{array}$ & $>14$ & Asymptomatic & $75.4 \%(39.9-89.9)$ \\
\hline \multirow{2}{*}{$\begin{array}{l}\text { Janssen } \\
\text { Biotech } \\
(\mathrm{Ad} 26 . \mathrm{COV} 2 . \mathrm{S})\end{array}$} & $\begin{array}{l}\text { Janssen Biotech }{ }^{19} \\
\text { (Report) }\end{array}$ & Multiple & Wild type & Negative & NA & $1-29$ & Asymptomatic & $20 \%(-7-40.4)$ \\
\hline & Janssen Biotech $^{19}$ & Multiple & Wild type & Negative & NA & $\geq 29$ & Asymptomatic & $74 \%(46.8-88.4)$ \\
\hline \multirow{5}{*}{$\begin{array}{l}\text { Pfizer } \\
\text { BioNTech } \\
(\text { BNT162b2) }\end{array}$} & Dagan et al. $^{8}$ & Israel & Wild type and B.1.1.7 & Unknown & NA & $>7$ & Asymptomatic & $90 \%(83-94)$ \\
\hline & Hall et al. ${ }^{11}$ & UK & Wild type & Unknown & NA & $\begin{array}{c}21 \text { days after } 1^{\text {st }} \\
\text { dose } \\
\text { and } 7 \text { days after } \\
2^{\text {nd }}\end{array}$ & $\begin{array}{l}\text { Asymptomatic } \\
\text { or unknown }\end{array}$ & NR \\
\hline & Haas et al. ${ }^{9}$ & Israel & Wild type and B.1.1.7 & Unknown & NA & $\geq 7$ & Asymptomatic & $91 \cdot 5 \%(90 \cdot 7-92 \cdot 2)$ \\
\hline & Haas et al. ${ }^{9}$ & Israel & Wild type and B.1.1.7 & Unknown & NA & $\geq 14$ & Asymptomatic & $93 \cdot 8 \%(93 \cdot 3-94 \cdot 2)$ \\
\hline & Regev-Yochay et al. ${ }^{14}$ & Israel & Wild & Both & NA & $>10$ & $\begin{array}{l}\text { Asymptomatic } \\
\text { at first testing }\end{array}$ & $65 \%$ (45 to 79$)$ \\
\hline
\end{tabular}




\begin{tabular}{|c|c|c|c|c|c|c|c|c|}
\hline Vaccine & Author & Country & Strain targeted by PCR & $\begin{array}{c}\text { Baseline } \\
\text { Serology }\end{array}$ & $\begin{array}{c}\text { Dosing } \\
\text { Schedule }\end{array}$ & Follow-up days* & Outcomes & Vaccine Efficacy $(95 \% \mathrm{CI})^{+}$ \\
\hline & Regev-Yochay et al. ${ }^{14}$ & Israel & Wild & Both & NA & $>10$ & $\begin{array}{l}\text { Asymptomatic } \\
\text { (who never } \\
\text { became } \\
\text { symptomatic) }\end{array}$ & $72 \%(48-86 \%)$ \\
\hline & Pritchard et al. ${ }^{7}$ & UK & Wild type and B.117 & Both & NA & NR & Asymptomatic & OR:0.48(0.36 to 0.66$)$ \\
\hline & $\begin{array}{l}\text { Pfizer } \\
\text { [Press Release] }^{38}\end{array}$ & Israel & Wild type and B.1.1.7 & Unknown & NA & $>14$ & Asymptomatic & - \\
\hline $\begin{array}{l}\text { BNT162b2 and } \\
\text { ChAdOx1 } \\
\text { nCoV-19 }\end{array}$ & Shah et al. ${ }^{2}$ & UK & Wild type & Unknown & NA & $>14$ & $\begin{array}{c}\text { HCW } \\
\text { Transmission } \\
\text { to household }\end{array}$ & $\mathrm{HR}=0.46(95 \%$ CI: $0.30-0.70)$ \\
\hline
\end{tabular}

* Time PCR was conducted after first or second dose; LD: Low dose, SD: Standard dose, \#Calculated from raw values. ${ }^{+}$Efficacy reported for RCTs and Effectiveness for observational studies.

Hall et al. was the only full-dose study healthcare workers' data. Studies are observational, except otherwise stated. 
medRxiv preprint doi: https://doi.org/10.1101/2021.06.29.21255526; this version posted July 2,2021 . The copyright holder for this preprint

(which was not certified by peer review) is the author/funder, who has granted medRxiv a license to display the preprint in perpetuity.

It is made available under a CC-BY-ND 4.0 International license .

\section{Risk of Vaccinated HCW Developing COVID-19}

Table 11 to Table 13 utilized estimates from the current HCW specific literature on likelihood of asymptomatic, symptomatic or any infection over a range of attack rates (to encompass a range of exposure risk) to describe the risk of vaccinated HCW developing COVID-19 after a potential exposure to support decision makers in policy design. The risk reduction values used are from an evolving body of literature and a range of study designs, with reduction of risk noted by weeks from first dose as extracted from the studies. Vaccine related risk reduction ranges are based on available HCW study data, from the following time points: 3 weeks post dose 1 mRNA; 3 weeks to 12 weeks post dose 1 nonreplicating adenovirus. Vaccination protection following first dose was selected both based on available data and because this is relevant as the dosing schedules are currently based on an extended interval for many vaccinees. These data should be considered within the context of current uncertainties including long-term follow up data beyond three months after vaccination.

As an example, the risk of a HCW developing an asymptomatic COVID-19 infection (estimated to be $20 \%$ of all infections) following a low-risk exposure $(0.5 \%)$ after receiving first dose of vaccine would be between 1/757 (3 weeks post vaccination) and 1/1,136 (12 weeks post vaccination) for adenovirus vector vaccines and 1/833 to 1/5,000 3 weeks post vaccination for mRNA vaccines. 
Table 11: Risk of First Dose Vaccinated HCW Developing Asymptomatic COVID-19 (Approximately 20\% of All Cases) After a Potential Exposure (Data Estimates from Wild Type SARS-CoV-2)

\begin{tabular}{|c|c|c|c|c|}
\hline $\begin{array}{l}\text { Attack Rate based } \\
\text { on Exposure Risk }\end{array}$ & $\begin{array}{c}\text { Risk of Developing COVID-19 based on } \\
\text { Proportion of Type of COVID-19 } \\
\text { Infection x Exposure Risk } \\
\text { B } \\
(A x 20 \%)\end{array}$ & $\begin{array}{l}\text { Vaccination Type } \\
\text { Nonreplicating adenovirus } \\
\text { vaccine or mRNA vaccine }\end{array}$ & $\begin{array}{c}\text { Vaccine Risk Reduction } \\
\text { (assuming risk reduction } \\
\text { [protection] remains the same } \\
\text { regardless of exposure risk) } \\
\text { C }\end{array}$ & $\begin{array}{l}\text { Risk of developing } \\
\text { COVID-19 following } \\
\text { vaccination regimen } \\
\text { D } \\
(B x C)\end{array}$ \\
\hline \multirow{2}{*}{$\begin{array}{l}\text { Low risk } \\
0.5 \%\end{array}$} & \multirow{2}{*}{$0.1 \%$} & mRNA vaccine & $\begin{array}{c}0.39-0.03 \\
(61 \%-97 \% 3 \text { weeks after first dose })\end{array}$ & $1 / 2,564-1 / 33,333$ \\
\hline & & $\begin{array}{l}\text { Nonreplicating adenovirus } \\
\text { vaccine }\end{array}$ & $\begin{array}{c}0.25 \\
(75 \% \text { 12 weeks after first dose })\end{array}$ & $1 / 4,000$ \\
\hline \multirow{2}{*}{$\begin{array}{l}\text { Medium risk } \\
1 \%\end{array}$} & \multirow{2}{*}{$0.2 \%$} & mRNA vaccine & $\begin{array}{c}0.39-0.03 \\
(61 \%-97 \% 3 \text { weeks after first dose }) \\
\end{array}$ & $1 / 1,282-1 / 16,666$ \\
\hline & & $\begin{array}{l}\text { Nonreplicating adenovirus } \\
\text { vaccine }\end{array}$ & $\begin{array}{c}0.25 \\
(75 \% 12 \text { weeks after first dose }) \\
\end{array}$ & $1 / 2,000$ \\
\hline \multirow{2}{*}{$\begin{array}{l}\text { High risk } \\
5 \%\end{array}$} & \multirow{2}{*}{$1 \%$} & mRNA vaccine & $\begin{array}{c}0.39-0.03 \\
(61 \%-97 \% 3 \text { weeks after first dose })\end{array}$ & $1 / 256-1 / 3,333$ \\
\hline & & $\begin{array}{l}\text { Nonreplicating adenovirus } \\
\text { vaccine }\end{array}$ & $\begin{array}{c}0.25 \\
(75 \% \text { 12 weeks after first dose })\end{array}$ & $1 / 400$ \\
\hline \multirow{2}{*}{$\begin{array}{l}\text { Superspreader event } \\
10 \%\end{array}$} & \multirow{2}{*}{$2 \%$} & mRNA vaccine & $\begin{array}{c}0.39-0.03 \\
(61 \%-97 \% 3 \text { weeks after first dose) }\end{array}$ & 1/128 - 1/1,666 \\
\hline & & $\begin{array}{l}\text { Nonreplicating adenovirus } \\
\text { vaccine }\end{array}$ & $\begin{array}{c}0.25 \\
(75 \% 12 \text { weeks after first dose })\end{array}$ & $1 / 200$ \\
\hline
\end{tabular}

2 Estimates for attack rate derived from study data and stratified to estimate range from low risk to superspreader event risk. from Abbas et al. which identified HCW risk to range from $\sim 2-8 \%$.

Abbas, M., Robalo Nunes, T., Martischang, R. et al. Nosocomial transmission and outbreaks of coronavirus disease 2019: the need to protect both patients and healthcare workers. Antimicrob Resist Infect Control 10, 7 (2021). https://doi.org/10.1186/s13756-020-00875-7

3 Study data applied to all infections and asymptomatic infections: nonreplicating adenovirus vaccines - AZ: 16\% after 3 weeks, (25-60\% after 12 weeks, NS); Janssen: 75\% after 12 weeks (PCR and/or serology without previous symptoms). mRNA vaccines - Moderna: 61\% from 3 weeks after dose 1; Pfizer BioNTech (Hall et al): $97 \% 21$ days after dose 1; Pfizer BioNTech (Daagen et al): $29 \%$ effectiveness 15 days after dose 1 in $\mathrm{HCW}$

Table 12: Risk of Vaccinated HCW Developing Symptomatic COVID-19 (80\% of All Cases) After a Potential Exposure (Data Estimates from Wild Type SARS-CoV-2) Compared with No Vaccination ${ }^{1}$ 


\begin{tabular}{|c|c|c|c|c|}
\hline $\begin{array}{l}\text { Attack Rate based } \\
\text { on Exposure Risk }\end{array}$ & $\begin{array}{l}\text { Risk of Developing COVID-19 based } \\
\text { on Proportion of Type of COVID-19 } \\
\text { Infection x Exposure Risk } \\
\text { B } \\
(A x 80 \%)\end{array}$ & \begin{tabular}{l}
\multicolumn{1}{c}{ Vaccination Type } \\
Nonreplicating adenovirus \\
vaccine or mRNA vaccine
\end{tabular} & $\begin{array}{l}\text { Vaccine Risk Reduction, time } \\
\text { after first dose by vaccine type } \\
\text { (assuming risk reduction } \\
\text { [protection] remains the same } \\
\text { regardless of exposure risk })^{3} \\
\text { C }\end{array}$ & $\begin{array}{c}\text { Risk of vaccinated person } \\
\text { developing COVID-19 by } \\
\text { regimen } \\
\\
\text { D } \\
(B \times C) \\
\end{array}$ \\
\hline \multirow{2}{*}{$\begin{array}{c}\text { Low risk } \\
0.5 \%\end{array}$} & \multirow{2}{*}{$0.4 \%$} & $\begin{array}{l}\text { Nonreplicating adenovirus } \\
\text { vaccine effectiveness range } \\
\text { across studies } \\
(67 \% 3 \mathrm{w} \text { post dose } 1 \text { to }-75 \% \\
12 \text { w post dose } 1)\end{array}$ & 0.22 to 0.66 & $\begin{array}{c}1 / 757 \\
\text { to } \\
1 / 1,136\end{array}$ \\
\hline & & $\begin{array}{l}\text { mRNA vaccine effectiveness } \\
\text { range } \\
(70 \% 3 \mathrm{w} \text { post dose } 1 \text { to } 95 \% 2 \\
\text { wks post dose } 1)\end{array}$ & 0.3 to 0.05 & $\begin{array}{c}1 / 833 \\
\text { to } \\
1 / 5,000 \\
\end{array}$ \\
\hline \multirow{4}{*}{$\begin{array}{l}\text { Medium risk } \\
1 \%\end{array}$} & \multirow{4}{*}{$0.8 \%$} & \multirow{2}{*}{$\begin{array}{l}\text { Nonreplicating adenovirus } \\
\text { vaccine effectiveness range }\end{array}$} & $\begin{array}{c}0.33 \\
(67 \% \text { effectiveness } 3 \text { weeks post } \\
\text { first dose) }\end{array}$ & $1 / 378$ \\
\hline & & & $\begin{array}{c}0.22 \\
\text { (75\% maximum reduction from } 12 \\
\text { weeks onwards) }\end{array}$ & $1 / 568$ \\
\hline & & \multirow{2}{*}{$\begin{array}{l}\text { mRNA vaccine effectiveness } \\
\text { range }\end{array}$} & $\begin{array}{c}0.3 \\
(70 \% \text { reduction } 3 \text { weeks after first } \\
\text { dose })\end{array}$ & $1 / 416$ \\
\hline & & & $\begin{array}{c}0.05 \\
(95 \% \text { reduction } 2 \text { weeks after first } \\
\text { dose) }\end{array}$ & $1 / 2,500$ \\
\hline \multirow{3}{*}{$\begin{array}{l}\text { High risk } \\
5 \%\end{array}$} & \multirow{3}{*}{$4 \%$} & \multirow{2}{*}{$\begin{array}{l}\text { Nonreplicating adenovirus } \\
\text { vaccine effectiveness range }\end{array}$} & $\begin{array}{c}0.33 \\
(67 \% \text { effectiveness } 3 \text { weeks post } \\
\text { first dose) }\end{array}$ & $1 / 75$ \\
\hline & & & $\begin{array}{c}0.22 \\
\text { (75\% maximum reduction from } 12 \\
\text { weeks onwards) }\end{array}$ & $1 / 113$ \\
\hline & & $\begin{array}{l}\text { mRNA vaccine effectiveness } \\
\text { range }\end{array}$ & $\begin{array}{c}0.3 \\
(70 \% \text { reduction } 3 \text { weeks after first } \\
\text { dose) }\end{array}$ & $1 / 83$ \\
\hline
\end{tabular}




\begin{tabular}{|c|c|c|c|c|}
\hline & & & $\begin{array}{c}0.05 \\
\left(\begin{array}{c}95 \% \text { reduction } 2 \text { weeks after first } \\
\text { dose })\end{array}\right. \\
\end{array}$ & $1 / 500$ \\
\hline \multirow{4}{*}{$\begin{array}{c}\text { Superspreader event } \\
10 \%\end{array}$} & \multirow{4}{*}{$8 \%$} & \multirow{2}{*}{$\begin{array}{l}\text { Nonreplicating adenovirus } \\
\text { vaccine effectiveness range }\end{array}$} & $\begin{array}{c}0.33 \\
(67 \% \text { effectiveness } 3 \text { weeks post } \\
\text { first dose })\end{array}$ & $1 / 37$ \\
\hline & & & $\begin{array}{c}0.22 \\
\text { (75\% maximum reduction from } 12 \\
\text { weeks onwards) }\end{array}$ & $1 / 56$ \\
\hline & & \multirow{2}{*}{$\begin{array}{l}\text { mRNA vaccine effectiveness } \\
\text { range }\end{array}$} & $\begin{array}{c}0.3 \\
(70 \% \text { reduction } 3 \text { weeks after first } \\
\text { dose) }\end{array}$ & $1 / 41$ \\
\hline & & & $\begin{array}{c}0.05 \\
(95 \% \text { reduction } 2 \text { weeks after first } \\
\text { dose) }\end{array}$ & $1 / 250$ \\
\hline
\end{tabular}

${ }^{1}$ Estimate of type of COVID-19 cases (symptomatic $~ 80 \%$ ) is a conservative estimate derived from a meta-analysis on the proportion of asymptomatic case and potential range for community transmission. Byambasuren O, Cardona M, Bell K, Clark J, McLaws M-L, Glasziou P. Estimating the extent of asymptomatic COVID-19 and its potential for community transmission: systematic review and meta-analysis. Official Journal of the Association of Medical Microbiology and Infectious Disease Canada. 2020;5(4):223-234. https://jammi.utpjournals.press/doi/pdf/10.3138/jammi-2020-0030

${ }^{2}$ Estimates for attack rate derived from study data and stratified to estimate range from low risk to superspreader event risk. from Abbas et al. which identified $\mathrm{HCW}$ risk to range from $\sim 2-8 \%$. Abbas, M., Robalo Nunes, T., Martischang, R. et al. Nosocomial transmission and outbreaks of coronavirus disease 2019: the need to protect both patients and healthcare workers. Antimicrob Resist Infect Control 10, 7 (2021). https://doi.org/10.1186/s13756-020-00875-7

${ }^{3}$ Study data applied to all infections and asymptomatic infections: nonreplicating adenovirus vaccines - AZ: 16\% after 3 weeks, (25-60\% after 12 weeks, NS); Janssen: $75 \%$ after 12 weeks (PCR and/or serology without previous symptoms). mRNA vaccines - Moderna: 61\% from 3 weeks after dose 1; Pfizer BioNTech (Hall et al): $97 \%$ 21 days after dose 1; Pfizer BioNTech (Dagen et al): $29 \%$ effectiveness 15 days after dose 1 in HCW

Table 13: Estimated Risk of Vaccinated HCWs Developing Symptomatic or Asymptomatic COVID-19 After Varied Risk Exposures (Current Data Estimates from Wild Type SARS-CoV-2 and Are Evolving - Will Require Frequent Updates) Compared with No Vaccination ${ }^{1}$ 


\begin{tabular}{|c|c|c|c|c|}
\hline $\begin{array}{l}\text { Attack Rate based } \\
\text { on Exposure Risk }\end{array}$ & $\begin{array}{l}\text { Risk of Developing COVID-19 based } \\
\text { on Proportion of Type of COVID-19 } \\
\text { Infection x Exposure Risk } \\
\text { B } \\
(A x 100 \%)\end{array}$ & $\begin{array}{l}\text { Vaccination Type } \\
\text { Nonreplicating adenovirus } \\
\text { vaccine or mRNA vaccine }\end{array}$ & $\begin{array}{c}\text { Vaccine Risk Reduction } \\
\text { (assuming risk reduction } \\
\text { [protection] remains the same } \\
\text { regardless of exposure risk) })^{3,4} \\
C\end{array}$ & $\begin{array}{l}\text { Risk of developing } \\
\text { COVID-19 following } \\
\text { vaccination regimen } \\
\\
D \\
(B x C) \\
\end{array}$ \\
\hline \multirow{4}{*}{$\begin{array}{c}\text { Low risk } \\
0.5 \%\end{array}$} & \multirow{4}{*}{$0.5 \%$} & \multirow{2}{*}{$\begin{array}{l}\text { Nonreplicating adenovirus } \\
\text { vaccine effectiveness range }\end{array}$} & $\begin{array}{c}0.84 \\
(16 \% \text { effectiveness } 3 \text { weeks post first } \\
\text { dose }) \\
\end{array}$ & $1 / 250$ \\
\hline & & & $\begin{array}{c}0.25 \\
(75 \% \text { maximum reduction from } 12 \\
\text { weeks onwards) } \\
\end{array}$ & $1 / 800$ \\
\hline & & \multirow{2}{*}{$\begin{array}{l}\text { mRNA vaccine } \\
\text { effectiveness range }\end{array}$} & $\begin{array}{c}0.39 \\
(61 \% \text { reduction } 3 \text { weeks after first } \\
\text { dose })\end{array}$ & $1 / 512$ \\
\hline & & & $\begin{array}{c}0.03 \\
(97 \% \text { reduction } 3 \text { weeks after first } \\
\text { dose) }\end{array}$ & $1 / 6,666$ \\
\hline \multirow{4}{*}{$\begin{array}{l}\text { Medium risk } \\
1 \%\end{array}$} & \multirow{4}{*}{$1 \%$} & \multirow{2}{*}{$\begin{array}{l}\text { Nonreplicating adenovirus } \\
\text { vaccine effectiveness range }\end{array}$} & $\begin{array}{c}0.84 \\
(16 \% \text { effectiveness } 3 \text { weeks post first } \\
\text { dose }) \\
\end{array}$ & $1 / 119$ \\
\hline & & & $\begin{array}{c}0.25 \\
(75 \% \text { maximum reduction from } 12 \\
\text { weeks onwards) }\end{array}$ & $1 / 400$ \\
\hline & & \multirow{2}{*}{$\begin{array}{l}\text { mRNA vaccine } \\
\text { effectiveness range }\end{array}$} & $\begin{array}{c}0.39 \\
(61 \% \text { reduction } 3 \text { weeks after first } \\
\text { dose })\end{array}$ & $1 / 256$ \\
\hline & & & $\begin{array}{c}0.03 \\
(97 \% \text { reduction } 3 \text { weeks after first } \\
\text { dose) }\end{array}$ & $1 / 3,333$ \\
\hline \multirow{3}{*}{$\begin{array}{l}\text { High risk } \\
5 \%\end{array}$} & \multirow{3}{*}{$5 \%$} & \multirow{2}{*}{$\begin{array}{l}\text { Nonreplicating adenovirus } \\
\text { vaccine effectiveness range }\end{array}$} & $\begin{array}{c}0.84 \\
(16 \% \text { effectiveness } 3 \text { weeks post first } \\
\text { dose })\end{array}$ & $1 / 23$ \\
\hline & & & $\begin{array}{c}0.25 \\
(75 \% \text { maximum reduction from } 12 \\
\text { weeks onwards) }\end{array}$ & $1 / 80$ \\
\hline & & & 0.39 & $1 / 51$ \\
\hline
\end{tabular}




\begin{tabular}{|c|c|c|c|c|}
\hline & & & $\begin{array}{c}\text { (61\% reduction } 3 \text { weeks after first } \\
\text { dose) }\end{array}$ & \\
\hline & & $\begin{array}{l}\text { mRNA vaccine } \\
\text { effectiveness range }\end{array}$ & $\begin{array}{c}0.03 \\
(97 \% \text { reduction } 3 \text { weeks after first } \\
\text { dose) }\end{array}$ & $1 / 666$ \\
\hline \multirow{4}{*}{$\begin{array}{c}\text { Superspreader event } \\
10 \%\end{array}$} & \multirow{4}{*}{$10 \%$} & \multirow{2}{*}{$\begin{array}{l}\text { Nonreplicating adenovirus } \\
\text { vaccine effectiveness range }\end{array}$} & $\begin{array}{c}0.84 \\
(16 \% \text { effectiveness } 3 \text { weeks post first } \\
\text { dose })\end{array}$ & $1 / 11$ \\
\hline & & & $\begin{array}{c}0.25 \\
\text { (75\% maximum reduction from } 12 \\
\text { weeks onwards) }\end{array}$ & $1 / 40$ \\
\hline & & \multirow{2}{*}{$\begin{array}{l}\text { mRNA vaccine } \\
\text { effectiveness range }\end{array}$} & $\begin{array}{c}0.39 \\
(61 \% \text { reduction } 3 \text { weeks after first } \\
\text { dose })\end{array}$ & $1 / 25$ \\
\hline & & & $\begin{array}{c}0.03 \\
(97 \% \text { reduction } 3 \text { weeks after first } \\
\text { dose) } \\
\end{array}$ & $1 / 333$ \\
\hline
\end{tabular}

1 Estimate of type of COVID-19 cases (symptomatic $~ 80 \%$ ) is a conservative estimate derived from a meta-analysis on the proportion of asymptomatic case and potential range for community transmission. Byambasuren O, Cardona M, Bell K, Clark J, McLaws M-L, Glasziou P. Estimating the extent of asymptomatic COVID-19 and its potential for community transmission: systematic review and meta-analysis. Official Journal of the Association of Medical Microbiology and Infectious Disease Canada. 2020;5(4):223-234.

https://jammi.utpjournals.press/doi/pdf/10.3138/jammi-2020-0030

2 Estimates for attack rate derived from study data and stratified to estimate range from low risk to superspreader event risk. from Abbas et al. which identified HCW risk to range from $~ 2-8 \%$. Abbas, M., Robalo Nunes, T., Martischang, R. et al. Nosocomial transmission and outbreaks of coronavirus disease 2019: the need to protect both patients and healthcare workers. Antimicrob Resist Infect Control 10, 7 (2021). https://doi.org/10.1186/s13756-020-00875-7

3 Study data applied to all infections and asymptomatic infections: nonreplicating adenovirus vaccines - AZ: 16\% after 3 weeks, (25-60\% after 12 weeks, NS); Janssen: 75\% after 12 weeks (PCR and/or serology without previous symptoms). mRNA vaccines - Moderna: 61\% from 3 weeks after dose 1; Pfizer BioNTech (Hall et al): $97 \%$ 21 days after dose 1; Pfizer BioNTech (Dagen et al): $29 \%$ effectiveness 15 days after dose 1 in HCW 
medRxiv preprint doi: https://doi.org/10.1101/2021.06.29.21255526; this version posted July 2,2021 . The copyright holder for this preprint (which was not certified by peer review) is the author/funder, who has granted medRxiv a license to display the preprint in perpetuity. It is made available under a CC-BY-ND 4.0 International license .

\section{Cycle Threshold (Ct) Values}

Eight studies reported on $\mathrm{Ct}$, an inverse proxy for viral load. Five of these are new to the updated version of this report.

Results from Phase 2/3 vaccine efficacy studies of $A Z$ vaccine compared with a comparator meningococcal vaccine in the United Kingdom, showed that the $\mathrm{Ct}$ values in infected vaccinated participants were statistically significantly higher than the comparator $(\mathrm{p}<0.0001)$, after 14 days of the second dose in baseline seronegative efficacy cohorts. ${ }^{6}$ Furthermore, the vaccine recipients were PCR-positive for a significantly shorter period of time $(\mathrm{p}<0.0001)$. The $\mathrm{Ct}$ values in asymptomatic cases were also significantly higher among vaccine recipients than control ( $\mathrm{p}=0.0040)$; however, this difference was not significant for primary symptomatic cases $(\mathrm{p}=0.1534)$. Vaccine recipients infected with the B.1.1.7 variant also showed significantly higher $\mathrm{Ct}$ values than control $(\mathrm{p}=0.0113){ }^{6}$

A longitudinal UK household survey by Pritchard el al. found statistically significant increase in the median $\mathrm{Ct}$ values of PfBnT or AZ single or full dose vaccinated individuals compared with unvaccinated individuals at any time point before or after 21 days post-vaccination ( $\mathrm{p}<0.001){ }^{7}$ Similarly, in another UK study by Shrotri et al., the mean Ct value of unvaccinated individuals within 27 days of vaccination was 26.6 (95\% CI: 26-27.1) compared with 26.6 (95\% CI: 25.19-26.62) with one dose of PfBnT or AZ, which was not significantly different $(\mathrm{p}=0.158) .{ }^{16}$ However, after 28 days, there was a statistically significant decrease in the mean $\mathrm{Ct}$ between vaccinated and unvaccinated persons (mean Ct 26.6 (95\% CI: 26-27.1) vs 31.3 (95\% CI: 29.6-32.9), p<0·001). ${ }^{16}$ Monthly routine PCR testing was conducted in these patients; however, the baseline serology was not reported. ${ }^{16}$ In a longitudinal cohort study of HCWs who were offered voluntary nasal and oropharyngeal swab PCR testing every two weeks as well as serological testing, Lumley et al., found vaccination with either PfBnT or AZ to nonsignificantly increase $\mathrm{Ct}$ value by a mean of $2.7 .^{17}$

A retrospective study of PfBnT mRNA vaccine recipients compared with demographically matched control group of unvaccinated individuals in Israel, found no significant differences in the $\mathrm{Ct}$ values for any of the 3 genes ( $\mathrm{RdRp}, \mathrm{N}$ and $\mathrm{E}$ ) measured less than 12 days after the first dose in infected persons. However, between 12 and 28 days after the first dose, the $\mathrm{Ct}$ values for the 3 genes were significantly higher among infected vaccinated persons than controls $\left(\mathrm{p}<10^{-8}\right) \cdot{ }^{36}$ In another UK study of one dose of BNT162b2 vaccine, the median $\mathrm{Ct}$ values of infected HCWs were reported to have shown a non-significant trend towards increase between unvaccinated (Median=20.3) and vaccinated HCWs after 12 days post-vaccination (Median=30.3), suggesting that samples from infected vaccinated individuals had lower viral loads. ${ }^{13}$ A study by McEllistrem et al. among Community Living Centre residents reported five cases of asymptomatic infections (determined by surveillance nasal swabs every 2-5 days) among baseline PCR negative PfBnT vaccinated and unvaccinated residents. The median $\mathrm{Ct}$ values among unvaccinated residents (12.8, IQR: 12.4-14.9) were significantly lower $(\mathrm{p}=0.009)$ than vaccinated residents $(19.4$, IQR: $18.9-25.5) .{ }^{37}$ Furthermore, viral load was -2.4 mean $\log 10$ lower among the vaccinated cohort $(\mathrm{p}=0.004) .{ }^{37}$ In another large cohort study of HCWs at a large medical centre in Israel by Regev-Yochay et al, the mean Ct values among 
medRxiv preprint doi: https://doi.org/10.1101/2021.06.29.21255526; this version posted July 2,2021 . The copyright holder for this preprint (which was not certified by peer review) is the author/funder, who has granted medRxiv a license to display the preprint in perpetuity. It is made available under a CC-BY-ND 4.0 International license .

PfBNT fully vaccinated HCWs (27.3 \pm 2.2$)$ was significantly higher (mean difference $5.09,95 \%$ CI: $2.8-7.4, \mathrm{p}<0.001)$ than unvaccinated HCWs $(22.2 \pm 1.0) .{ }^{14}$

\section{Animal Studies}

All the animal studies estimated viral load by using viral genomic RNA (gRNA) and subgenomic RNA (sgRNA), from nasal or bronchoalveolar lavage (BAL) samples. The vaccines have either been approved or have progressed to human trials.

\section{$\underline{\text { Adenovirus Based Vaccines }}$}

van Doremalen et al. found that the $A Z$ vaccine significantly reduced viral load in the bronchoalveolar lavage fluid of vaccinated rhesus macaques on the third, fifth and seventh day post viral challenge, compared with control animals. ${ }^{20}$ In the BAL fluid obtained from control animals, viral genomic and subgenomic RNA were detected on all days; while two of the vaccinated animals had detectable viral gRNA three days after challenge. Viral gRNA was detected in nose swabs from all animals and no difference was found on any day between vaccinated and control animals. Mercado et al. reported that all or almost all macaques vaccinated with Ad26-S.PP, an adenovirus serotype 26 (Ad26) vector-based vaccines expressing tPA leader sequence by $\mathrm{J} \& \mathrm{~J}$, had no detectable virus in BAL or nasal samples respectively, compared with sham controls, which showed high titres of viral sgRNA $\left(p<0.0001\right.$ and $p<0.0001$, respectively) ${ }^{41}$

\section{DNA Vaccines}

Patel et al. found that peak viral sgmRNA and RNA loads in the BAL were significantly lower in INO-4800 vaccinated macaques (two doses) at day 7 post-challenge (peak: $p=0.048$, day 7 : $\mathrm{p}=0.024) .{ }^{42}$ However, viral sgmRNA was still detectable in the nasal swabs of both the control and INO-4800 vaccinated animals. Viral mRNA levels trended downwards in INO-4800 vaccinated animals. ${ }^{42}$

\section{$\underline{\text { mRNA Vaccines }}$}

The mRNA-1273 vaccine showed significantly lower RNA and subgenomic RNA, in BAL and nasal swabs, in the 100- $\mu \mathrm{g}$ dose group compared with the control group. ${ }^{21}$ Only one of the eight vaccinated had detectable subgenomic RNA in BAL fluid two days after challenge, while all the control animals had detectable RNA. Similarly, none of the eight animals administered the $100-\mu \mathrm{g}$ dose had detectable subgenomic RNA detected in nasal swab compared with six of eight in the control. Ji et al. found no viral RNA in the lung tissues of mice 42 days after a second dose of BNT162b2-vaccination, compared with a mean of $10^{6}$ copies $/ \mathrm{mL}$ in control animals $(\mathrm{p}<0.001) .{ }^{40}$ A study by Vogel et al. showed BNT162b2-immunized, SARS-CoV-2 challenged macaques cleared all viral RNA by day 3 after challenge; while viral RNA was detected in bronchoalveolar lavage fluid from seven of nine control macaques. One day post challenge, 4 of 9 control animals had detectable viral RNA. In subsequent nasal swabs, viral RNA was detected from some of the control macaques at each sampling time point (5 of 9 on 
medRxiv preprint doi: https://doi.org/10.1101/2021.06.29.21255526; this version posted July 2,2021 . The copyright holder for this preprint (which was not certified by peer review) is the author/funder, who has granted medRxiv a license to display the preprint in perpetuity. It is made available under a CC-BY-ND 4.0 International license .

day 3 ; 4 of 9 on day 6 ; and 2 of 9 on days 7-23), but none of the BNT162b2-immunized macaques at any sampling time point. ${ }^{44}$

\section{$\underline{\text { Recombinant Nanoparticle Vaccine }}$}

In the Novavax's NVX-CoV2373 vaccine study, macaques administered placebo had elevated viral load two and four days post viral challenge, while all but one of the vaccinated animals had no detectable sgRNA in their BAL fluid. ${ }^{22}$ Similarly, half of the placebo group had elevated viral RNA in their nasal swabs, while none was detectable in vaccinated animals. ${ }^{22}$ Gorman et al. in a macaque study of the $5 \mu \mathrm{g}$ or $25 \mu \mathrm{g}$ doses of NVX-CoV2373 vaccine, found the highest levels of viral sgRNA in placebo animals across the upper and lower-respiratory tract samples, compared with vaccinated animals. By day 8 , sgRNA was undetectable in the BAL of animals vaccinated with either doses. ${ }^{39}$ Similarly, Tian et al. showed that placebo-treated mice had an average of $10^{4}$ SARS-CoV-2 pfu/lung, while those vaccinated with NVX-CoV2373 without Matrix-M had $10^{3} \mathrm{pfu} / \mathrm{lung}$ and those with Matrix-M had limited to no detectable virus load. ${ }^{43}$

\section{Inactivated Virus-based Vaccines}

After two doses of BBV152, an inactivated virus-based COVID-19 vaccine, Yadav et al. detected gRNA and sgRNA in the BAL, nasal and throat swab specimens of all or almost all the macaques in the placebo group by the $7^{\text {th }}$ day post infection, while vaccinated animals had no detectable virus by day $7 .{ }^{46}$ Full dose Sinopharm's BBIBP-CorV vaccine was reported by Wang et al. to clear COVID-19 virus from the lungs and throats of vaccinated macaques, which were significantly different from the results in the placebo group. ${ }^{45}$ Another study showed that PiCoVacc, a vaccine developed by Sinovac Biotech (China), significantly reduced viral load in the pharynx and lungs of all the vaccinated animals compared with control animals, on the third and seventh day post-viral challenge. ${ }^{49}$

\section{$\underline{\text { Others }}$}

Following vaccination with a single dose of recombinant vesicular stomatitis virus-based vaccine (rVSV- $\Delta \mathrm{G}$-spike vaccine), Yahalom-Ronen et al. found infectious SARS-CoV-2 in the lungs of infected unvaccinated golden Syrian hamsters, with an average viral titre of $1.3 \times 10^{5}$ pfu/lung, compared with viral titres of $10^{4}-10^{8}$ pfu in the lungs of animals vaccinated with varying doses of the vaccine, which were below the limit of detection. ${ }^{47}$

\section{Discussion}

In this update, 16 additional studies, including 9 human and 7 animal studies, were included. Therefore, this review has a total of 33 included studies, twenty-one of which were in humans and 12 were preclinical animal studies. Two new studies from Scotland and England evaluated household transmission following vaccination and found PfBnT and AZ to significantly reduce the risk of household transmission., ${ }^{2,3}$ The majority of the vaccines included in this review demonstrated efficacy and effectiveness against asymptomatic wild-type COVID-19 infections. 
medRxiv preprint doi: https://doi.org/10.1101/2021.06.29.21255526; this version posted July 2 , 2021. The copyright holder for this preprint

(which was not certified by peer review) is the author/funder, who has granted medRxiv a license to display the preprint in perpetuity.

It is made available under a CC-BY-ND 4.0 International license.

The AZ and PfBnT vaccines were found to be significantly associated with higher $\mathrm{Ct}$ values than their respective comparators, suggesting that these vaccines may potentially reduce viral load and consequently lower the risk of transmission. It is however noteworthy that the relationship between viral load, viral shedding, infectivity and the duration of infectivity are not well understood. $\mathrm{Ct}$ values are also subject to error. ${ }^{50}$

Preclinical primate studies showed that vaccinated animals receiving the Moderna mRNA (8 weeks prior), ${ }^{21} \mathrm{PfBnT}$, or Novavax protein vaccine (35 days prior), ${ }^{22}$ were less likely to have the virus recovered from nasal or lower respiratory samples than unvaccinated animals. The AZ vaccine was more protective against lower respiratory replication, while showing no difference in nasal virus replication. ${ }^{20}$

Studies suggesting the plausibility of vaccine-induced reduction of transmission, including monoclonal antibody therapeutics trials and epidemiologic evidence of transmission from individuals who were persistently RT-PCR positive after natural infection, with evidence of an immunologic response, indicated that viral load can be reduced by circulating antibodies, and that a lower viral load or higher Ct on RT-PCR was associated with a reduced risk of transmission. ${ }^{25,26}$ However, RT-PCR positivity in the presence of neutralizing antibody and or correlates of cell mediated immunity should not be considered to necessarily represent transmissible infection.

There were significant limitations to many of the included studies. The primary endpoint of the vaccine randomized controlled trials were detection of test positive symptomatic COVID-19, however some studies presented data, which suggest a reduction in the likelihood of testing positive for SARS-CoV-2 RT-PCR in the absence of documented symptoms after vaccination. Furthermore, it was not possible to directly compare findings across studies owing to variations in the assessment of symptom status, and the testing used and timing of these assessments. Also, the possibility of persistent PCR positivity after COVID-19 infection ${ }^{51}$ could not be excluded in some of the studies without baseline PCR assessment. Few studies included surveillance nasal swabs for PCR positivity. Most of the current data were around viral detection, rather than evidence of cultivatable virus. Therefore, there was limited data to evaluate the efficacy or effectiveness of COVID-19 vaccines in decreasing viral loads. In addition, there are only a limited number of epidemiologic data addressing evidence of forward transmission after vaccination.

Based on the current evidence, we suggest the following:

1) all vaccinees should self-isolate and seek testing after the development of COVID-19 compatible symptoms

2) Following exposure, the risk of contracting COVID-19 and subsequent forward transmission from asymptomatic or pauci symptomatic viral carriage should be considered in light of whether the exposed individual was vaccinated the time elapsed since immunization and the consequent expected degree of protection on, a case-by-case basis for those in vulnerable setting. When possible, a case-by-case consideration for whether exposed persons are 
medRxiv preprint doi: https://doi.org/10.1101/2021.06.29.21255526; this version posted July 2 , 2021. The copyright holder for this preprint

(which was not certified by peer review) is the author/funder, who has granted medRxiv a license to display the preprint in perpetuity.

It is made available under a CC-BY-ND 4.0 International license .

immunized, is necessary. Low-moderate risk exposures could potentially be managed with careful use of personal protective equipment (PPE), and self-monitoring.

3) If a vaccinated $\mathrm{HCW}$ is assessed as having a significant exposure before the period of expected robust immunity, high risk exposures may be managed as for unvaccinated persons.

4) All vaccinated persons should continue to use recommended PPE when in close contact with unvaccinated persons.

5) Population and public health data being collected on positive COVID-19 tests occurring after vaccination should be combined with laboratory data on $\mathrm{Ct}$ values, identification of variant strain infections, and epidemiologic contact tracing data to prospectively monitor for evidence of forward transmission of infection from vaccinated persons.

\section{Conclusion}

Two months since the publication of the previous version of this report, 16 additional relevant studies have been published. Two of these are large household surveillance studies from the UK suggesting single or full dose of $\mathrm{AZ}$ and $\mathrm{PfBnT}$ vaccines may prevent household transmission of COVID-19 after 14 days of vaccination. More studies have found the vaccines to significantly reduce the risk of asymptomatic infection and seven of eight studies found significantly increased cycle threshold, suggestive of lower viral load, in AZ or PfBnT vaccinated individuals compared with unvaccinated. Some studies, such as the AZ vaccine RCTs, included data on cross sectional prevalence of positive SARS-CoV-2 RT-PCR from routine swabbing, which suggested efficacy against asymptomatic infection, although this was not routinely assessed in a comparable way across studies. Evidence regarding the $\mathrm{Ct}$ values for $\mathrm{AZ}$ vaccine and the PfBnT vaccine suggest their potential to reduce viral load and possibly transmission. Further research is needed to evaluate post-vaccination infectivity and transmission of both the wild type COVID-19 virus and the variants of concern from other jurisdictions. 


\section{References}

1. Egunsola O, Mastikhina L, Dowsett L, Clement F. Transmissibility of COVID-19 among vaccinated individuals.

2. Shah AS, Gribben C, Bishop J, et al. Effect of vaccination on transmission of COVID-19: an observational study in healthcare workers and their households. MedRxiv. 2021.

3. Harris R, Hall J, Zaidi A, Andrews NJ, Dunbar JK, Dabrera G. Impact of vaccination on household transmission of SARS-COV-2 in England. Preprint Disponible en: https://khub net/documents/135939561/390853656/Impact + of + vaccination + on+ household + transmission + of + SARS-COV-2+ in + England pdf/35bf4bbl-6aded3eb-a39e-9c9b25a8122a.

4. Voysey M, Clemens SAC, Madhi SA, et al. Single-dose administration and the influence of the timing of the booster dose on immunogenicity and efficacy of ChAdOx1 nCoV-19 (AZD1222) vaccine: a pooled analysis of four randomised trials. The Lancet. 2021.

5. Voysey M, Clemens SAC, Madhi SA, et al. Safety and efficacy of the ChAdOx1 nCoV-19 vaccine (AZD1222) against SARS-CoV-2: an interim analysis of four randomised controlled trials in Brazil, South Africa, and the UK. The Lancet. 2021;397(10269):99-111.

6. Emary KR, Golubchik T, Aley PK, et al. Efficacy of ChAdOx1 nCoV-19 (AZD1222) vaccine against SARS-CoV-2 variant of concern 202012/01 (B.1.1.7): an exploratory analysis of a randomised controlled trial. Lancet. 2021;397:1351-1362.

7. Pritchard E, Matthews PC, Stoesser N, et al. Impact of vaccination on SARS-CoV-2 cases in the community: a population-based study using the UK's COVID-19 Infection Survey. medRxiv. 2021.

8. Dagan N, Barda N, Kepten E, et al. BNT162b2 mRNA Covid-19 Vaccine in a Nationwide Mass Vaccination Setting. New England Journal of Medicine. 2021;384:1412-1423.

9. Haas EJ, Angulo FJ, McLaughlin JM, et al. Impact and effectiveness of mRNA BNT162b2 vaccine against SARS-CoV-2 infections and COVID-19 cases, hospitalisations, and deaths following a nationwide vaccination campaign in Israel: an observational study using national surveillance data. The Lancet. 2021.

10. Tande AJ, Pollock BD, Shah ND, et al. Impact of the COVID-19 Vaccine on Asymptomatic Infection Among Patients Undergoing Pre-Procedural COVID-19 Molecular Screening. Clinical Infectious Diseases. 2021.

11. Hall VJ, Foulkes S, Saei A, et al. COVID-19 vaccine coverage in health-care workers in England and effectiveness of BNT162b2 mRNA vaccine against infection (SIREN): a prospective, multicentre, cohort study. Lancet. 2021;397:1725-1735.

12. Amit S, Regev-Yochay G, Afek A, Kreiss Y, Leshem E. Early rate reductions of SARS-CoV-2 infection and COVID-19 in BNT162b2 vaccine recipients. The Lancet. 2021.

13. Jones NK, Rivett L, Seaman S, et al. Single-dose BNT162b2 vaccine protects against asymptomatic SARS-CoV-2 infection. eLife. 2021;10:e68808.

14. Regev-Yochay G, Amit S, Bergwerk M, et al. Decreased infectivity following BNT162b2 vaccination. 2021.

15. Bouton TC, Lodi S, Turcinovic J, et al. COVID-19 vaccine impact on rates of SARSCoV-2 cases and post vaccination strain sequences among healthcare workers at an urban academic medical center: a prospective cohort study. medRxiv. 2021. 
16. Shrotri M, Krutikov M, Palmer T, et al. Vaccine Effectiveness of the First Dose of ChAdox1 nCOV-19 and BNT162b2 Against SARS-CoV-2 Infection in Residents of Long Term Care Facilities (VIVALDI Study). 2021.

17. Lumley SF, Rodger G, Constantinides B, et al. An observational cohort study on the incidence of SARS-CoV-2 infection and B. 1.1. 7 variant infection in healthcare workers by antibody and vaccination status. medRxiv. 2021.

18. Baden LR, El Sahly HM, Essink B, et al. Efficacy and safety of the mRNA-1273 SARS-CoV-2 vaccine. New England Journal of Medicine. 2021;384(5):403-416.

19. Janssen Biotech I. Vaccines and Related Biological Products Advisory Committee Meeting February 26, 2021: FDA Briefing Document. 26 February 20212021.

20. van Doremalen N, Lambe T, Spencer A, et al. ChAdOx1 nCoV-19 vaccine prevents SARS-CoV-2 pneumonia in rhesus macaques. Nature. 2020;586(7830):578-582.

21. Corbett KS, Flynn B, Foulds KE, et al. Evaluation of the mRNA-1273 vaccine against SARS-CoV-2 in nonhuman primates. New England Journal of Medicine. 2020;383(16):1544-1555.

22. Guebre-Xabier M, Patel N, Tian J-H, et al. NVX-CoV2373 vaccine protects cynomolgus macaque upper and lower airways against SARS-CoV-2 challenge. Vaccine. 2020;38(50):7892-7896.

23. Johns Hopkins University. COVID-19 Dashboard by the Center for Systems Science and Engineering (CSSE) at Johns Hopkins University (JHU). https://www.covidtracker.com/. Published 2021. Accessed 27 February 2021.

24. Shapiro J, Dean NE, Madewell ZJ, Yang Y, Halloran ME, Longini IM. Efficacy Estimates for Various COVID-19 Vaccines: What we Know from the Literature and Reports. medRxiv. 2021.

25. Weinreich DM, Sivapalasingam S, Norton T, et al. REGN-COV2, a neutralizing antibody cocktail, in outpatients with Covid-19. N Engl J Med. 2021:238-251.

26. Chen P, Nirula A, Heller B, et al. SARS-CoV-2 neutralizing antibody LY-CoV555 in outpatients with Covid-19. New England Journal of Medicine. 2021;384(3):229-237.

27. Lyngse FP, Mølbak K, Franck KT, Nielsen C, Skov RL, Kirkeby CT. Association between SARS-CoV-2 Transmission Risk, Viral Load, and Age: A Nationwide Study in Danish Households. medRxiv. 2021.

28. Marks M, Millat-Martinez P, Ouchi D, et al. Transmission of COVID-19 in 282 clusters in Catalonia, Spain: a cohort study. The Lancet Infectious Diseases. 2021.

29. Bjorkman KK, Saldi TK, Lasda E, et al. Higher viral load drives infrequent SARS$\mathrm{CoV}-2$ transmission between asymptomatic residence hall roommates. medRxiv. 2021.

30. Vibholm LK, Nielsen SS, Pahus MH, et al. SARS-CoV-2 persistence is associated with antigen-specific CD8 T-cell responses. EBioMedicine. 2021;64:103230.

31. Madewell ZJ, Yang Y, Longini IM, Halloran ME, Dean NE. Household Transmission of SARS-CoV-2: A Systematic Review and Meta-analysis. JAMA network open. 2020;3(12):e2031756-e2031756.

32. McGowan J, Sampson M, Salzwedel DM, Cogo E, Foerster V, Lefebvre C. PRESS peer review of electronic search strategies: 2015 guideline statement. Journal of clinical epidemiology. 2016;75:40-46.

33. Sterne JA, Hernán MA, Reeves BC, et al. ROBINS-I: a tool for assessing risk of bias in non-randomised studies of interventions. BMJ. 2016;355:i4919.

34. Higgins JP, Altman DG, Gøtzsche PC, et al. The Cochrane Collaboration's tool for assessing risk of bias in randomised trials. Bmj. 2011;343. 
medRxiv preprint doi: https://doi.org/10.1101/2021.06.29.21255526; this version posted July 2,2021 . The copyright holder for this preprint (which was not certified by peer review) is the author/funder, who has granted medRxiv a license to display the preprint in perpetuity. It is made available under a CC-BY-ND 4.0 International license .

35. Hooijmans CR, Rovers MM, De Vries RB, Leenaars M, Ritskes-Hoitinga M, Langendam MW. SYRCLE's risk of bias tool for animal studies. BMC medical research methodology. 2014;14(1):1-9.

36. Levine-Tiefenbrun M, Yelin I, Katz R, et al. Initial report of decreased SARS-CoV-2 viral load after inoculation with the BNT162b2 vaccine. Nature Medicine. 2021;27:790-792.

37. McEllistrem MC, Clancy CJ, Buehrle DJ, Lucas A, Decker BK. Single dose of a mRNA SARS-CoV-2 vaccine is associated with lower nasopharyngeal viral load among nursing home residents with asymptomatic COVID-19. Clinical Infectious Diseases. 2021.

38. Real-World Evidence Confirms High Effectiveness of Pfizer-BioNTech COVID-19 Vaccine and Profound Public Health Impact of Vaccination One Year After Pandemic Declared [press release]. 2021.

39. Gorman MJ, Patel N, Guebre-Xabier M, et al. Collaboration between the Fab and Fc contribute to maximal protection against SARS-CoV-2 in nonhuman primates following NVX-CoV2373 subunit vaccine with Matrix-M ${ }^{\mathrm{TM}}$ vaccination. bioRxiv. 2021.

40. Ji R-R, Qu Y, Zhu H, et al. BNT162b2 Vaccine Encoding the SARS-CoV-2 P2 S Protects Transgenic hACE2 Mice against COVID-19. Vaccines. 2021;9(4):324.

41. Mercado NB, Zahn R, Wegmann F, et al. Single-shot Ad26 vaccine protects against SARS-CoV-2 in rhesus macaques. Nature. 2020;586(7830):583-588.

42. Patel A, Walters J, Reuschel EL, et al. Intradermal-delivered DNA vaccine provides anamnestic protection in a rhesus macaque SARS-CoV-2 challenge model. bioRxiv. 2020.

43. Tian J-H, Patel N, Haupt R, et al. SARS-CoV-2 spike glycoprotein vaccine candidate NVX-CoV2373 immunogenicity in baboons and protection in mice. Nature communications. 2021;12(1):1-14.

44. Vogel AB, Kanevsky I, Che Y, et al. BNT162b vaccines protect rhesus macaques from SARS-CoV-2. Nature. 2021;592(7853):283-289.

45. Wang H, Zhang Y, Huang B, et al. Development of an inactivated vaccine candidate, BBIBP-CorV, with potent protection against SARS-CoV-2. Cell. 2020;182(3):713721. e719.

46. Yadav PD, Ella R, Kumar S, et al. Immunogenicity and protective efficacy of inactivated SARS-CoV-2 vaccine candidate, BBV152 in rhesus macaques. Nature communications. 2021;12(1):1-11.

47. Yahalom-Ronen Y, Tamir H, Melamed S, et al. A single dose of recombinant VSV- $\Delta$ G-spike vaccine provides protection against SARS-CoV-2 challenge. Nature communications. 2020;11(1):1-13.

48. Zhang J, Kai FY. What's the relative risk?: A method of correcting the odds ratio in cohort studies of common outcomes. Jama. 1998;280(19):1690-1691.

49. Gao Q, Bao L, Mao H, et al. Development of an inactivated vaccine candidate for SARS-CoV-2. Science. 2020;369(6499):77-81.

50. Pollock AM, Lancaster J. Asymptomatic transmission of covid-19. BMJ. 2020;371:m4851.

51. Kim S-m, Hwang YJ, Kwak Y. Prolonged SARS-CoV-2 detection and reversed RTPCR results in mild or asymptomatic patients. Infectious Diseases. 2021;53(1):31-37.

52. Madhi SA, Baillie VL, Cutland CL, et al. Safety and efficacy of the ChAdOx1 nCoV19 (AZD1222) Covid-19 vaccine against the B. 1.351 variant in South Africa. medRxiv. 2021. 
53. Bernal JL, Andrews N, Gower C, et al. Early effectiveness of COVID-19 vaccination with BNT162b2 mRNA vaccine and ChAdOx1 adenovirus vector vaccine on symptomatic disease, hospitalisations and mortality in older adults in England. MedRxiv. 2021.

54. Logunov DY, Dolzhikova IV, Shcheblyakov DV, et al. Safety and efficacy of an rAd26 and rAd5 vector-based heterologous prime-boost COVID-19 vaccine: an interim analysis of a randomised controlled phase 3 trial in Russia. The Lancet. 2021.

55. Novavax COVID-19 Vaccine Demonstrates 89.3\% Efficacy in UK Phase 3 Trial [press release]. 28 January 20212021.

56. Shinde V, Bhikha S, Hossain Z, et al. Preliminary efficacy of the NVX-CoV2373 Covid-19 vaccine against the B. 1.351 variant. MedRxiv. 2021.

57. Hitchings MD, Ranzani OT, Torres MSS, et al. Effectiveness of CoronaVac in the setting of high SARS-CoV-2 P. 1 variant transmission in Brazil: A test-negative casecontrol study. medRxiv. 2021.

58. Polack FP, Thomas SJ, Kitchin N, et al. Safety and efficacy of the BNT162b2 mRNA Covid-19 vaccine. New England Journal of Medicine. 2020;383(27):2603-2615.

59. Cabezas C, Coma E, Mora-Fernandez N, et al. Effects of BNT162b2 mRNA Vaccination on COVID-19 Disease, Hospitalisation and Mortality in Nursing Homes and Healthcare Workers: A Prospective Cohort Study Including 28,594 Nursing Home Residents, 26,238 Nursing Home Staff, and 61,951 Healthcare Workers in Catalonia.

60. Yelin I, Katz R, Herzel E, et al. Associations of the BNT162b2 COVID-19 vaccine effectiveness with patient age and comorbidities. medRxiv. 2021.

61. Mason TF, Whitston M, Hodgson J, et al. Effects of BNT162b2 mRNA vaccine on Covid-19 infection and hospitalisation among older people: matched case control study for England. medRxiv. 2021.

62. Britton A, Slifka KMJ, Edens C, et al. Effectiveness of the Pfizer-BioNTech COVID19 vaccine among residents of two skilled nursing facilities experiencing COVID-19 outbreaks - Connecticut, December 2020-February 2021. Morbidity and Mortality Weekly Report. 2021;70(11):396.

63. Glampson B, Brittain J, Kaura A, et al. North West London Covid-19 Vaccination Programme: Real-world evidence for Vaccine uptake and effectiveness. medRxiv. 2021.

64. Gras-Valentí P, Chico-Sánchez P, Algado-Sellés N, et al. Effectiveness of the first dose of BNT162b2 vaccine to preventing covid-19 in healthcare personnel. Revista Espanola de Salud Publica. 2021;95.

65. Kustin T, Harel N, Finkel U, et al. Evidence for increased breakthrough rates of SARS-CoV-2 variants of concern in BNT162b2 mRNA vaccinated individuals. MedRxiv. 2021.

66. Menni C, Klaser K, May A, et al. Vaccine side-effects and SARS-CoV-2 infection after vaccination in users of the COVID Symptom Study app in the UK: a prospective observational study. The Lancet Infectious Diseases. 2021.

67. Moustsen-Helms IR, Emborg H-D, Nielsen J, et al. Vaccine effectiveness after 1st and 2nd dose of the BNT162b2 mRNA Covid-19 Vaccine in long-term care facility residents and healthcare workers-a Danish cohort study. MedRxiv. 2021.

68. Heymann AD, Zacay G, Shasha D, et al. BNT162b2 Vaccine Effectiveness in Preventing Asymptomatic Infection with SARS-CoV-2 Virus: A Nationwide Historical Cohort Study. Available at SSRN 3796868.

69. Corchado-Garcia J, Hughes T, Cristea-Platon T, et al. Real-world effectiveness of Ad26. COV2. S adenoviral vector vaccine for COVID-19. 2021. 
medRxiv preprint doi: https://doi.org/10.1101/2021.06.29.21255526; this version posted July 2,2021 . The copyright holder for this preprint (which was not certified by peer review) is the author/funder, who has granted medRxiv a license to display the preprint in perpetuity. It is made available under a CC-BY-ND 4.0 International license .

70. Andrejko K, Pry J, Myers JF, et al. Early evidence of COVID-19 vaccine effectiveness within the general population of California. medRxiv. 2021.

71. Monge S, Olmedo C, Alejos B, Lapena M, Sierra MJ, Limia A. Direct and indirect effectiveness of mRNA vaccination against SARS-CoV-2 infection in long-term care facilities in Spain. medRxiv. 2021.

72. Pawlowski C, Lenehan P, Puranik A, et al. FDA-authorized COVID-19 vaccines are effective per real-world evidence synthesized across a multi-state health system. MedRxiv. 2021.

73. Thompson MG, Burgess JL, Naleway AL, et al. Interim estimates of vaccine effectiveness of BNT162b2 and mRNA-1273 COVID-19 vaccines in preventing SARS-CoV-2 infection among health care personnel, first responders, and other essential and frontline workers - eight US locations, December 2020-March 2021. Morbidity and Mortality Weekly Report. 2021;70(13):495.

74. Rudolph JL, Hartronft S, McConeghy K, et al. Proportion of SARS-CoV- 2 positive tests and Vaccination in VA Community Living Centers. Journal of the American Geriatrics Society. 2021. 
medRxiv preprint doi: https://doi.org/10.1101/2021.06.29.21255526; this version posted July 2,2021 . The copyright holder for this preprint (which was not certified by peer review) is the author/funder, who has granted medRxiv a license to display the preprint in perpetuity. It is made available under a CC-BY-ND 4.0 International license .

\section{Appendix 1: Search Strategy}

Ovid Multifile

Database: EBM Reviews - Cochrane Central Register of Controlled Trials <March 2021>, Embase <1974 to 2021 May 03>, Ovid MEDLINE(R) and Epub Ahead of Print, In-Process, In-Data-Review \& Other Non-Indexed Citations and Daily <1946 to May 03, 2021>

Search Strategy:

1 exp COVID-19 Vaccines/ (2374)

2 ((COVID-19 or COVID19) adj5 (immun* or inoculat* or vaccin*)).tw,kf. (12155)

3 ((coronavirus* or corona virus*) adj5 (immun* or inoculat* or vaccin*)).tw,kf. (3738)

4 ((2019-nCoV or nCoV or n-CoV or SARS-CoV-2 or SARS-CoV2 or SARSCoV-2 or SARSCoV2 or SARS2) adj5 (immun* or inoculat* or vaccin*)).tw,kf. (7493)

5 (((BNT162 or BNT162-01 or BNT162a1 or BNT162b1 or BNT162b2 or BNT162c2) and vaccin*) or N38TVC63NU).tw,kf. (313)

6 (((AZD1222 or ChAdOx1) and vaccin*) or Covishield\$2 or B5S3K2V0G8).tw,kf. (290)

7 ((mRNA-1273 and vaccin*) or EPK39PL4R4).tw,kf. (188)

8 ((mRNA adj3 vaccin*) and (COVID-19 or COVID19 or coronavirus* or corona virus* or 2019-nCoV or nCoV or $\mathrm{n}-\mathrm{CoV}$ or SARS-CoV-2 or SARS-CoV2 or SARSCoV-2 or SARSCoV2 or SARS2)).tw,kf. (621)

9 ((messenger RNA adj3 vaccin*) and (COVID-19 or COVID19 or coronavirus* or corona virus* or 2019-nCoV or nCoV or n-CoV or SARS-CoV-2 or SARS-CoV2 or SARSCoV-2 or SARSCoV2 or SARS2)).tw,kf. (48)

10 (LV-SMENP-DC and vaccin*).tw,kf. (4)

11 ((Ad5-nCoV and vaccin*) or hAdOx1 nCoV-19).tw,kf. (27)

12 (("Ad26.COV2.S" or Ad26COVS1 or JNJ 78436735 or JNJ-78436735 or JT2NS6183B) and vaccin*).tw,kf. (48)

13 Viral Vaccines/ and (Coronavirus/ or Betacoronavirus/ or Coronavirus Infections/) (1912)

14 or/1-13 [COVID-19 VACCINES] (21782)

15 COVID-19/pc [prevention \& control] (5797)

16 Coronavirus Infections/pc [prevention \& control] (10731) 
medRxiv preprint doi: https://doi.org/10.1101/2021.06.29.21255526; this version posted July 2,2021 . The copyright holder for this preprint

17 Pandemics/pc [prevention \& control] (13225)

18 ((control* or decreas* ${ }^{*}$ or halt* or prevent* or reduc* ${ }^{*}$ or stop*) adj5 (COVID-19 or COVID19)).tw,kf. (20175)

19 ((control* or decreas* or halt* or prevent* or reduc* or stop*) adj5 (coronavirus* or corona virus*)).tw,kf. (3109)

20 ((control* or decreas* or halt* or prevent* or reduc* or stop*) adj5 (2019-nCoV or nCoV or n-CoV or SARS-CoV-2 or SARS-CoV2 or SARSCoV-2 or SARSCoV2 or SARS2)).tw,kf. (5036)

21 ((control* or decreas* or halt* or prevent* or reduc* or stop*) adj5 spread*).tw,kf. (50306)

22 COVID-19/ep [Epidemiology] (11936)

23 COVID-19/tm [Transmission] (2511)

24 COVID-19/vi [Virology] (4305)

25 Coronavirus Infections/ep [Epidemiology] (23489)

26 Coronavirus Infections/tm [Transmission] (4693)

27 Coronavirus Infections/vi [Virology] (7620)

28 exp Disease Transmission, Infectious/ (350027)

29 (transmit* or transmissi* or infectiousness* or infectivit*).tw,kf. (1218179)

30 ((COVID-19 or COVID19) adj5 (caus* or pass or passed or passes or passing or spread*)).tw,kf. (25577)

31 ((coronavirus* or corona virus*) adj5 (caus* or pass or passed or passes or passing or spread*)).tw,kf. (14942)

32 ((virus* or infection*) adj5 (caus* or pass or passed or passes or passing or spread*)).tw,kf. (377793)

33 ((2019-nCoV or nCoV or n-CoV or SARS-CoV-2 or SARS-CoV2 or SARSCoV-2 or SARSCoV2 or SARS2) adj5 spread*).tw,kf. (4124)

34 (unvaccinat* or nonvaccinat* or non-vaccinat* or "not vaccinat*").tw,kf. (41533)

35 or/15-34 [TRANSMISSION] (1879195)

3614 and 35 [COVID-19 VACCINES - DISEASE TRANSMISSION] (11455)

37 (controlled clinical trial or randomized controlled trial or pragmatic clinical trial or equivalence trial).pt. (1223388) 
medRxiv preprint doi: https://doi.org/10.1101/2021.06.29.21255526; this version posted July 2,2021 . The copyright holder for this preprint

38 "Clinical Trials as Topic"/ (311975)

39 exp "Controlled Clinical Trials as Topic"/ (372323)

40 (randomi\#ed or randomi\#ation? or randomly or RCT or placebo*).tw,kf. (3654919)

41 ((singl* or doubl* or trebl* or tripl*) adj (mask* or blind* or dumm*)).tw,kf. (722847)

42 trial.ti. (918992)

43 or/37-42 [RCT FILTER] (4595242)

4436 and 43 [RCTs] (1202)

45 controlled clinical trial.pt. (186181)

46 Controlled Clinical Trial/ or Controlled Clinical Trials as Topic/ (581332)

47 (control* adj2 trial).tw,kf. (674053)

48 Non-Randomized Controlled Trials as Topic/ (12653)

49 (nonrandom* or non-random* or quasi-random* or quasi-experiment*).tw,kf. (154248)

$50 \quad$ (nRCT or non-RCT).tw,kf. (985)

51 Controlled Before-After Studies/ (208005)

52 (control* adj3 ("before and after" or "before after")).tw,kf. (802572)

53 Interrupted Time Series Analysis/ (200857)

54 time series.tw,kf. (75281)

55 (pre- adj3 post-).tw,kf. (286836)

56 (pretest adj3 posttest).tw,kf. (16300)

57 Historically Controlled Study/ (218468)

58 (control* adj2 study).tw,kf. (547197)

59 Control Groups/ (111939)

60 (control* adj2 group?).tw,kf. (1548833)

61 trial.ti. (918992)

62 or/45-61 [nRCT FILTER] (4285786)

$63 \quad 36$ and 62 [nRCTs] (724)

64 exp Cohort Studies/ (2983557) 
medRxiv preprint doi: https://doi.org/10.1101/2021.06.29.21255526; this version posted July 2 , 2021. The copyright holder for this preprint (which was not certified by peer review) is the author/funder, who has granted medRxiv a license to display the preprint in perpetuity.

It is made available under a CC-BY-ND 4.0 International license .

65 cohort?.tw,kf. (1848042)

66 Retrospective Studies/ (1693557)

67 (longitudinal or prospective or retrospective).tw,kf. (3742018)

68 ((followup or follow-up) adj (study or studies)).tw,kf. (129595)

69 Observational study.pt. (98909)

70 (observation\$2 adj (study or studies)).tw,kf. (328692)

71 ((population or population-based) adj (study or studies or analys\#s)).tw,kf. (46388)

72 ((multidimensional or multi-dimensional) adj (study or studies)).tw,kf. (273)

73 Comparative Study.pt. (2057815)

74 ((comparative or comparison) adj (study or studies)).tw,kf. (281790)

75 exp Case-Control Studies/ (1370600)

76 ((case-control* or case-based or case-comparison) adj (study or studies)).tw,kf. (267951)

77 Cross-Sectional Studies/ (649801)

78 (crosssection* or cross-section*).tw,kf. (1021542)

79 or/64-78 [OBSERVATIONAL STUDY FILTER] (9618587)

8036 and 79 [OBSERVATIONAL STUDIES] (1512)

8144 or 63 or 80 [ALL STUDY DESIGNS] (2679)

8281 use ppez [MEDLINE RECORDS] (1476)

83 SARS-CoV-2 vaccine/ (4620)

84 ((COVID-19 or COVID19) adj5 (immun* or inoculat* or vaccin*)).tw,kw. (14214)

85 ((coronavirus* or corona virus*) adj5 (immun* or inoculat* or vaccin*)).tw,kw. (4344)

86 ((2019-nCoV or $\mathrm{nCoV}$ or $\mathrm{n}-\mathrm{CoV}$ or SARS-CoV-2 or SARS-CoV2 or SARSCoV-2 or SARSCoV2 or SARS2) adj5 (immun* or inoculat* or vaccin*)).tw,kw. (8872)

87 (((BNT162 or BNT162-01 or BNT162a1 or BNT162b1 or BNT162b2 or BNT162c2) and vaccin*) or N38TVC63NU).tw,kw. (320)

88 (((AZD1222 or ChAdOx1) and vaccin*) or Covishield\$2 or B5S3K2V0G8).tw,kw. (293) 
medRxiv preprint doi: https://doi.org/10.1101/2021.06.29.21255526; this version posted July 2,2021 . The copyright holder for this preprint (which was not certified by peer review) is the author/funder, who has granted medRxiv a license to display the preprint in perpetuity. It is made available under a CC-BY-ND 4.0 International license .

89 ((mRNA-1273 and vaccin*) or EPK39PL4R4).tw,kw. (191)

90 ((mRNA adj3 vaccin*) and (COVID-19 or COVID19 or coronavirus* or corona virus* or 2019-nCoV or nCoV or n-CoV or SARS-CoV-2 or SARS-CoV2 or SARSCoV-2 or SARSCoV2 or SARS2)).tw,kw. (624)

91 ((messenger RNA adj3 vaccin*) and (COVID-19 or COVID19 or coronavirus* or corona virus* or 2019-nCoV or $\mathrm{nCoV}$ or $\mathrm{n}-\mathrm{CoV}$ or SARS-CoV-2 or SARS-CoV2 or SARSCoV-2 or SARSCoV2 or SARS2)).tw,kw. (51)

92 (LV-SMENP-DC and vaccin*).tw,kw. (4)

93 ((Ad5-nCoV and vaccin*) or hAdOx1 nCoV-19).tw,kw. (27)

94 (("Ad26.COV2.S" or Ad26COVS1 or JNJ 78436735 or JNJ-78436735 or JT2NS6183B) and vaccin*).tw,kw. (48)

95 (severe acute respiratory syndrome vaccine/ or virus vaccine/) and (coronavirinae/ or betacoronavirus/ or exp SARS-related coronavirus/ or coronavirus infection/) (1072)

96 or/83-95 [COVID-19 VACCINES] (24142)

97 coronavirus disease 2019/pc [prevention] (11338)

98 coronavirus infection/pc [prevention] (10773)

99 pandemic/pc [prevention] (13313)

100 ((control* or decreas* or halt* or prevent* or reduc* or stop*) adj5 (COVID-19 or COVID19)).tw,kw. (20612)

101 ((control* or decreas* or halt* or prevent* or reduc* or stop*) adj5 (coronavirus* or corona virus*)).tw,kw. (4045)

102 ((control* or decreas* or halt* or prevent* or reduc* or stop*) adj5 (2019-nCoV or nCoV or n-CoV or SARS-CoV-2 or SARS-CoV2 or SARSCoV-2 or SARSCoV2 or SARS2)).tw,kw. (5266)

103 ((control* or decreas* or halt* or prevent* or reduc* or stop*) adj5 spread*).tw,kw. (50343)

104 coronavirus disease 2019/ep [epidemiology] (21716)

105 coronavirus infection/ep [epidemiology] (23538)

106 virus transmission/ (71786)

107 (transmit* or transmissi* or infectiousness* or infectivit*).tw,kw. (1223806)

108 ((COVID-19 or COVID19) adj5 (caus* or pass or passed or passes or passing or spread*)).tw,kw. (25607) 
medRxiv preprint doi: https://doi.org/10.1101/2021.06.29.21255526; this version posted July 2,2021 . The copyright holder for this preprint (which was not certified by peer review) is the author/funder, who has granted medRxiv a license to display the preprint in perpetuity.

It is made available under a CC-BY-ND 4.0 International license .

109 ((coronavirus* or corona virus*) adj5 (caus* or pass or passed or passes or passing or spread*)).tw,kw. (14961)

110 ((virus* or infection*) adj5 (caus* or pass or passed or passes or passing or spread*)).tw,kw. (378037)

111 ((2019-nCoV or nCoV or n-CoV or SARS-CoV-2 or SARS-CoV2 or SARSCoV-2 or SARSCoV2 or SARS2) adj5 spread*).tw,kw. (4130)

112 (unvaccinat* or nonvaccinat* or non-vaccinat* or "not vaccinat*").tw,kw. (41536)

113 or/97-112 [TRANSMISSION] (1725018)

11496 and 113 [COVID-19 VACCINES - DISEASE TRANSMISSION] (12480)

115 exp randomized controlled trial/ or controlled clinical trial/ (1474925)

116 clinical trial/ (1547919)

117 exp "controlled clinical trial (topic)"/ (212240)

118 (randomi\#ted or randomi\#ation? or randomly or RCT or placebo*).tw,kw. (3717620)

119 ((singl* or doubl* or trebl* or tripl*) adj (mask* or blind* or dumm*)).tw,kw. (751624)

120 trial.ti. (918992)

121 or/115-120 [RCT FILTER] (5181846)

122114 and $121[$ RCTs] (1039)

123 controlled clinical trial/ (565714)

124 "controlled clinical trial (topic)"/ (11706)

125 (control* adj2 trial).tw,kw. (1026519)

126 (nonrandom* or non-random* or quasi-random* or quasi-experiment*).tw,kw. (155262)

127 (nRCT or non-RCT).tw,kw. (987)

128 (control* adj3 ("before and after" or "before after")).tw,kw. (802576)

129 time series analysis/ (29189)

130 time series.tw,kw. (76299)

131 pretest posttest control group design/ (572)

132 (pre- adj3 post-).tw,kw. (286885) 
133 (pretest adj3 posttest).tw,kw. (19993)

134 controlled study/ (8225028)

135 (control* adj2 study).tw,kw. (956741)

136 control group/ (111838)

137 (control* adj2 group?).tw,kw. (1550032)

138 trial.ti. (918992)

139 or/123-138 [nRCT FILTER] (11225794)

140114 and 139 [nRCTs] (1883)

141 cohort analysis/ (988205)

142 cohort?.tw,kw. (1853635)

143 retrospective study/ (1966858)

144 longitudinal study/ (300363)

145 prospective study/ (1258395)

146 (longitudinal or prospective or retrospective).tw,kw. (3762504)

147 follow up/ (1692669)

148 ((followup or follow-up) adj (study or studies)).tw,kw. (131413)

149 observational study/ (330674)

150 (observation\$2 adj (study or studies)).tw,kw. (331340)

151 population research/ (115730)

152 ((population or population-based) adj (study or studies or analys\#s)).tw,kw. (54489)

153 ((multidimensional or multi-dimensional) adj (study or studies)).tw,kw. (274)

154 exp comparative study/ (3372186)

155 ((comparative or comparison) adj (study or studies)).tw,kw. (299493)

156 exp case control study/ (1370600)

157 ((case-control* or case-based or case-comparison) adj (study or studies)).tw,kw. (271380)

158 cross-sectional study/ (779053) 
medRxiv preprint doi: https://doi.org/10.1101/2021.06.29.21255526; this version posted July 2,2021 . The copyright holder for this preprint (which was not certified by peer review) is the author/funder, who has granted medRxiv a license to display the preprint in perpetuity. It is made available under a CC-BY-ND 4.0 International license .

159 (crosssection* or cross-section*).tw,kw. (1025287)

160 major clinical study/ (4154006)

161 or/141-160 [OBSERVATIONAL STUDY FILTER] (13631256)

162114 and 161 [OBSERVATIONAL STUDIES] (2070)

163122 or 140 or 162 [ALL STUDY DESIGNS] (3609)

164163 use oemezd [EMBASE RECORDS] (2063)

165 exp COVID-19 Vaccines/ (2374)

166 ((COVID-19 or COVID19) adj5 (immun* or inoculat* or vaccin*)).ti,ab,kw. (14212)

167 ((coronavirus* or corona virus*) adj5 (immun* or inoculat* or vaccin*)).ti,ab,kw. (4343)

168 ((2019-nCoV or nCoV or n-CoV or SARS-CoV-2 or SARS-CoV2 or SARSCoV-2 or SARSCoV2 or SARS2) adj5 (immun* or inoculat* or vaccin*)).ti,ab,kw. (8872)

169 (((BNT162 or BNT162-01 or BNT162a1 or BNT162b1 or BNT162b2 or BNT162c2) and vaccin*) or N38TVC63NU).ti,ab,kw. (308)

170 (((AZD1222 or ChAdOx1) and vaccin*) or Covishield\$2 or B5S3K2V0G8).ti,ab,kw. (274)

171 ((mRNA-1273 and vaccin*) or EPK39PL4R4).ti,ab,kw. (159)

172 ((mRNA adj3 vaccin*) and (COVID-19 or COVID19 or coronavirus* or corona virus* or 2019-nCoV or nCoV or n-CoV or SARS-CoV-2 or SARS-CoV2 or SARSCoV-2 or SARSCoV2 or SARS2)).ti,ab,kw. (624)

173 ((messenger RNA adj3 vaccin*) and (COVID-19 or COVID19 or coronavirus* or corona virus* or 2019-nCoV or $\mathrm{nCoV}$ or $\mathrm{n}-\mathrm{CoV}$ or SARS-CoV-2 or SARS-CoV2 or SARSCoV-2 or SARSCoV2 or SARS2)).ti,ab,kw. (51)

174 (LV-SMENP-DC and vaccin*).ti,ab,kw. (1)

175 ((Ad5-nCoV and vaccin*) or hAdOx1 nCoV-19).ti,ab,kw. (19)

176 (("Ad26.COV2.S" or Ad26COVS1 or JNJ 78436735 or JNJ-78436735 or JT2NS6183B) and vaccin*).ti,ab,kw. (40)

177 Viral Vaccines/ and (Coronavirus/ or Betacoronavirus/ or Coronavirus Infections/) (1912)

178 or/165-177 [COVID-19 VACCINES] (23646)

179 COVID-19/pc [prevention \& control] (5797) 
medRxiv preprint doi: https://doi.org/10.1101/2021.06.29.21255526; this version posted July 2,2021 . The copyright holder for this preprint

180 Coronavirus Infections/pc [prevention \& control] (10731)

181 Pandemics/pc [prevention \& control] (13225)

182 ((control* or decreas* or halt* or prevent* or reduc* or stop*) adj5 (COVID-19 or COVID19)).ti,ab,kw. (20612)

183 ((control* or decreas* or halt* or prevent* or reduc* or stop*) adj5 (coronavirus* or corona virus*)).ti,ab,kw. (4045)

184 ((control* or decreas* or halt* or prevent* or reduc* or stop*) adj5 (2019-nCoV or $\mathrm{nCoV}$ or $\mathrm{n}-\mathrm{CoV}$ or SARS-CoV-2 or SARS-CoV2 or SARSCoV-2 or SARSCoV2 or SARS2)).ti,ab,kw. (5266)

185 ((control* ${ }^{*}$ or decreas* or halt* or prevent* or reduc* or stop*) adj5 spread*).ti,ab,kw. (50343)

186 COVID-19/ep [Epidemiology] (11936)

187 COVID-19/tm [Transmission] (2511)

188 COVID-19/vi [Virology] (4305)

189 Coronavirus Infections/ep [Epidemiology] (23489)

190 Coronavirus Infections/tm [Transmission] (4693)

191 Coronavirus Infections/vi [Virology] (7620)

192 exp Disease Transmission, Infectious/ (350027)

193 (transmit* or transmissi* or infectiousness* ${ }^{*}$ or infectivit*).ti,ab,kw. (1223805)

194 ((COVID-19 or COVID19) adj5 (caus* or pass or passed or passes or passing or spread*)).ti,ab,kw. (25607)

195 ((coronavirus* or corona virus*) adj5 (caus* or pass or passed or passes or passing or spread*)).ti,ab,kw. (14961)

196 ((virus* or infection*) adj5 (caus* or pass or passed or passes or passing or spread*)).ti,ab,kw. (378037)

197 ((2019-nCoV or nCoV or n-CoV or SARS-CoV-2 or SARS-CoV2 or SARSCoV-2 or SARSCoV2 or SARS2) adj5 spread*).ti,ab,kw. (4130)

198 (unvaccinat* or nonvaccinat* or non-vaccinat* or "not vaccinat*").ti,ab,kw. (41536)

199 or/179-198 [TRANSMISSION] (1884551)

200178 and 199 [COVID-19 VACCINES - DISEASE TRANSMISSION] (12355) 
medRxiv preprint doi: https://doi.org/10.1101/2021.06.29.21255526; this version posted July 2,2021 . The copyright holder for this preprint (which was not certified by peer review) is the author/funder, who has granted medRxiv a license to display the preprint in perpetuity.

It is made available under a CC-BY-ND 4.0 International license .

201200 use cctr [CENTRAL RECORDS] (451)

20282 or 164 or 201 [ALL DATABASES] (3990)

203 remove duplicates from 202 (3282) [TOTAL UNIQUE RECORDS]

204203 use ppez [MEDLINE UNIQUE RECORDS] (1438)

205203 use oemezd [EMBASE UNIQUE RECORDS] (1419)

206203 use cctr [CENTRAL UNIQUE RECORDS] (425)

$* * * * * * * * * * * * * * * * * * * * * * * * * * *$

L-OVE

PICO - Prevention>SARS-CoV-2 Vaccines-Primary Studies

1711 records 
Appendix 2: Vaccine Efficacy or Effectiveness Against Symptomatic Infection

\begin{tabular}{|c|c|c|c|c|c|c|}
\hline Vaccine & Author & Country & Strain & $\begin{array}{c}\text { Dos } \\
\text { e }\end{array}$ & Days after Dose & Vaccine Efficacy $(95 \%$ CI) \\
\hline \multirow{18}{*}{$\begin{array}{l}\text { AstraZeneca } \\
(\mathrm{ChAdOx} 1 \\
\mathrm{nCoV}-19)\end{array}$} & Voysey et al. $^{5}$ & UK/Brazil & Wild type & $2^{\text {nd }}$ & $>14$ & $70.4 \%(54.8-80.6) \div$ \\
\hline & Voysey et al. ${ }^{4}$ & $\begin{array}{l}\text { UK/Brazil/S.Afr } \\
\text { ica }\end{array}$ & & 1 st & $22-30$ & $77 \%(47-90)$ \\
\hline & Voysey et al. ${ }^{4}$ & $\begin{array}{l}\text { UK/Brazil/S.Afr } \\
\text { ica }\end{array}$ & & $1 \mathrm{st}$ & $31-60$ & $73 \%(33-89)$ \\
\hline & Voysey et al. ${ }^{4}$ & $\begin{array}{l}\text { UK/Brazil/S.Afr } \\
\text { ica }\end{array}$ & & $1 \mathrm{st}$ & $61-90$ & $78 \%(36-93)$ \\
\hline & Voysey et al. ${ }^{4}$ & $\begin{array}{l}\text { UK/Brazil/S.Afr } \\
\text { ica }\end{array}$ & & $1 \mathrm{st}$ & $90-120$ & $32 \%(-142-81)$ \\
\hline & Voysey et al. $^{4}$ & $\begin{array}{l}\text { UK/Brazil/S.Afr } \\
\text { ica }\end{array}$ & Wild type & $2^{\text {nd }}$ & $>14$ & $66.7 \%(57.4-74.0)+$ \\
\hline & Voysey et al. ${ }^{4}$ & $\begin{array}{l}\text { UK/Brazil/S.Afr } \\
\text { ica }\end{array}$ & Wild type & $2^{\text {nd }}$ & $>14$ & $63.1 \%(51.8-71.7)$ \\
\hline & Voysey et $\mathrm{al}^{4}$ & $\begin{array}{l}\text { UK/Brazil/S.Afr } \\
\text { ica }\end{array}$ & Wild type & $2^{\text {nd }}$ & $>14$ & $80.7 \%(62.1-90.2) \dagger$ \\
\hline & Madhi et al. ${ }^{52}$ & South Africa & Wild type & $2^{\text {nd }}$ & $>14$ & $21.9 \%(-49.9-59.8)$ \\
\hline & Madhi et al. ${ }^{52}$ & South Africa & B.1.351 & $2^{\text {nd }}$ & $>14$ & $10.4 \%(-76.8-54.8)$ \\
\hline & Emary et al. ${ }^{6}$ & UK & $\begin{array}{l}\text { Wild type, B.1.1.7, } \\
\text { others }\end{array}$ & $2^{\text {nd }}$ & $>14$ & $74.2 \%(65-81.0)$ \\
\hline & Emary et al. $^{6}$ & UK & B.1.1.7 & $2^{\text {nd }}$ & $>14$ & $74.6 \%(41.6-88.9)$ \\
\hline & Pritchard et al. & UK & Wild type & 1 & $0-7$ & OR: $0.25(0.18$ to 0.35$)$ \\
\hline & Pritchard et al. & $\mathrm{UK}$ & Wild type & 1 & $8-20$ & OR: $0.42(0.32$ to 0.55$)$ \\
\hline & Pritchard et al. & UK & Wild type & 1 & 21 or more & OR: $0.37(0.27$ to 0.51$)$ \\
\hline & Bernal et al. ${ }^{53}$ & UK & Wild type and VOC & $1 \mathrm{st}$ & $7-9$ & aOR: 1.03 (95\% CI: 0.90 to 1.16$)$ \\
\hline & Bernal et al. & UK & Wild type and VOC & $1 \mathrm{st}$ & $21-27$ & aOR: 0.55 (95\% CI: 0.45 to 0.68$)$ \\
\hline & Bernal et al. & UK & Wild type and VOC & $1 \mathrm{st}$ & $>34$ & aOR: 0.27 (95\% CI: 0.10 to 0.73$)$ \\
\hline $\begin{array}{l}\text { Gamaleya } \\
\text { (Gam- } \\
\text { COVID-Vac) }\end{array}$ & Logunov et al. ${ }^{54}$ & Russia & Wild type & $2^{\text {nd }}$ & $\mathrm{NR}$ & $91 \cdot 1 \%(83 \cdot 8-95 \cdot 1)$ \\
\hline Janssen & Janssen $^{19}$ & Multiple & Wild type & $1^{\mathrm{st}}$ & $>14$ & $66.9(59-73.4)$ \\
\hline $\begin{array}{l}\text { Biotech } \\
\text { (Ad26.COV2 } \\
\text {.S) }\end{array}$ & Janssen $^{19}$ & Multiple & Wild type & $1^{\text {st }}$ & $>28$ & $66.1(55-74.8)$ \\
\hline Moderna & Baden et al. $^{18}$ & USA & Wild type & $2^{\text {nd }}$ & $>14$ & $94 \%(89.3-96.8)$ \\
\hline
\end{tabular}




\begin{tabular}{|c|c|c|c|c|c|c|}
\hline $\begin{array}{l}\text { (mRNA- } \\
1273 \text { ) }\end{array}$ & & & & & & \\
\hline \multirow{3}{*}{$\begin{array}{l}\text { Novavax } \\
\text { (NVX- } \\
\text { CoV2373) } \\
\end{array}$} & Novavax $^{55}$ & UK & Wild type & $2^{\text {nd }}$ & $>7$ & $89.3 \%(75.2-95.4)$ \\
\hline & Novavax ${ }^{55}$ & South Africa & Wild type & NR & NR & $49.4 \%(6.1-72.8)$ \\
\hline & Shinde et al. ${ }^{56}$ & South Africa & Wild type & 2nd & $>7$ & $60.1 \%(95 \%$ CI: 19.9 to 80.1$)$ \\
\hline \multirow{5}{*}{ Coronavac } & Palacios et al. & Brazil & Wild type & $1^{\mathrm{st}}$ & $\leq 14$ & $-3.3(-4.8$ to -1.9$)$ \\
\hline & Palacios et al. & Brazil & Wild type & $1^{\text {st }}$ & $14-28$ & $94.0(55.1$ to 99.2$)$ \\
\hline & Palacios et al. & Brazil & Wild type & $2 \mathrm{nd}$ & 14 & 50.7 (35.9 to 62.0) \\
\hline & Hitchings et al. ${ }^{57}$ & Brazil & Wild type and P1 & $\begin{array}{c}1 \text { or } \\
2 \\
\end{array}$ & $0-13$ & OR, $1.69(1.09-2.64)$ \\
\hline & Hitchings et al. & Brazil & Wild type and P1 & $\begin{array}{c}1 \text { or } \\
2\end{array}$ & $>14$ & $49.6 \%(11.3-71.4)$ \\
\hline \multirow{3}{*}{$\begin{array}{l}\text { Pfizer } \\
\text { BioNTech } \\
\text { (BNT162b2) } \\
\text { and } \\
\text { AstraZeneca } \\
\text { (ChAdOx1 } \\
\text { nCoV-19) }\end{array}$} & Lumley et al. ${ }^{17}$ & England & Wild type and B.1.1.7 & 1 & $>14$ & aIRR: $0.33(0.21$ to 0.52$)$ \\
\hline & Lumley et al. & England & Wild type and B.1.1.7 & 2 & $>14$ & \\
\hline & Lumley et al. & England & Wild type and B.1.1.7 & 1 & $>14$ & aIRR: $0.07(0.01$ to 0.51$)$ \\
\hline \multirow{15}{*}{$\begin{array}{l}\text { Pfizer } \\
\text { BioNTech } \\
\text { (BNT162b2) }\end{array}$} & Hall et al. ${ }^{11}$ & UK & Wild type & $2^{\text {nd }}$ & 7 & $85 \%(74-96)$ \\
\hline & Hall et al. ${ }^{11}$ & UK & Wild type & $1^{\text {st }}$ & 21 & $70 \%(53-87)$ \\
\hline & Polack et al. ${ }^{58}$ & Multiple & Wild type & $2^{\text {nd }}$ & $>7$ & $94.8 \%(89.8-97.6)$ \\
\hline & $\begin{array}{l}\text { Pfizer } \\
\text { (adolescents) }\end{array}$ & Multiple & Wild type & 2 & $\geq 7$ & $100.0(75.3,100.0)$ \\
\hline & Pfizer & Multiple & Wild type & 2 & $\geq 7$ & $100(78.1,100)$ \\
\hline & Pfizer & Multiple & Wild type & 1 & Before dose 2 & $75.0(7.4,95.5)$ \\
\hline & Pfizer & Multiple & Wild type & 2 & $<7$ & $100.0(-9.1,100.0)$ \\
\hline & Cabezas et al. ${ }^{59}$ & Spain & Wild & $\begin{array}{c}1 \text { or } \\
2\end{array}$ & NR & $\begin{array}{c}\mathrm{aHR}, 0.38(0.35-0.42) 0.43(0.39-0.49), 0.41 \\
(0.38-0.45)\end{array}$ \\
\hline & Cabezas et al. & Spain & Wild & 1 & 12 & $\begin{array}{c}\text { aHR:0.77 (0.69-0.86), } 0.8(0.68-0.93), 0.85 \\
(0.77-0.95)\end{array}$ \\
\hline & Cabezas et al. & Spain & Wild & 1 & NR & $\begin{array}{c}\text { aHR: } 0.53(0.49-0.58), 0.60(0.53-0.67), 0.57 \\
(0.53-0.63)\end{array}$ \\
\hline & & & & 2 & NR & $\begin{array}{c}\text { aHR: } 0.08(0.07-0.09), 0.12(0.10-0.15), 0.05 \\
(0.04-0.07)\end{array}$ \\
\hline & Pritchard et al. $^{7}$ & UK & Wild type & 1 & $0-7$ & OR: $0.34(0.27$ to 0.43$)$ \\
\hline & Pritchard et al. & UK & Wild type & 1 & $8-20$ & OR: $0.4(0.33$ to 0.5$)$ \\
\hline & Pritchard et al. & UK & Wild type & 1 & 21 or more & OR: $0.25(0.19$ to 0.32$)$ \\
\hline & Pritchard et al. & UK & Wild type & 2 & NR & OR: $0.09(0.05$ to 0.17$)$ \\
\hline
\end{tabular}




\begin{tabular}{|c|c|c|c|c|c|}
\hline Yelin et al ${ }^{60}$ & Israel & Wild type & NR & 11 & OR: $0.79(0.96$ to 0.65$)$ \\
\hline Yelin et al & Israel & Wild type & NR & 11 & OR: $0.20(0.26$ to 0.15$)$ \\
\hline Yelin et al & Israel & Wild type & NR & 11 & OR: 0.005 (0.014 to 0.002$)$ \\
\hline $\begin{array}{l}\text { Regev-Yochay et } \\
\text { al. }{ }^{14}\end{array}$ & Israel & Wild type & $1 \mathrm{st}$ & 4-10 & aVE: $21 \%(-32$ to 41$)$ \\
\hline $\begin{array}{l}\text { Regev-Yochay et } \\
\text { al. }\end{array}$ & Israel & Wild type & $\begin{array}{c}1 \text { or } \\
2\end{array}$ & $\begin{array}{c}11 \text { days post } 1 \\
\text { dose }\end{array}$ & aVE: 80 (69 to 87$)$ \\
\hline $\begin{array}{l}\text { Regev-Yochay et } \\
\text { al. }\end{array}$ & Israel & Wild type & 1 & $\geq 11$ & aVE: 90 (84 to 94$)$ \\
\hline Bernal et al..$^{53}$ & UK & Wild type and VOC & $1 \mathrm{st}$ & $7-9$ & aOR: 1.10 (95\% CI: 0.98 to 1.24$)$ \\
\hline Bernal et al. & UK & Wild type and VOC & $1 \mathrm{st}$ & $21-27$ & aOR: 0.45 (95\% CI: 0.39 to 0.53$)$ \\
\hline Bernal et al. & UK & Wild type and VOC & $1 \mathrm{st}$ & $>34$ & aOR: 0.43 (95\% CI: 0.29 to 0.64$)$ \\
\hline Amit et al. ${ }^{12}$ & Israel & Wild type & $1^{\mathrm{st}}$ & $15-28$ & $75 \%(52-87)$ \\
\hline Haas et al. ${ }^{9}$ & Israel & Wild type & 2 & $\geq 7$ & $97 \cdot 0 \%(96 \cdot 7-97 \cdot 2)$ \\
\hline Haas et al. & Israel & Wild type & 2 & $\geq 14$ & $97 \cdot 7 \%(97 \cdot 5-97 \cdot 9)$ \\
\hline Haas et al. & Israel & Wild type & 1 & $14-21$ & $62 \cdot 5(59 \cdot 3-65 \cdot 4)$ \\
\hline Mason et al. ${ }^{61}$ & England & Wild type & $\begin{array}{c}1 \text { or } \\
2\end{array}$ & $14-20$ & $-16.9 \%(9.4$ to -36.7$)$ \\
\hline Mason et al. & England & Wild type & $\begin{array}{c}1 \text { or } \\
2\end{array}$ & $21-27$ & $-55.2 \%(-40.8$ to -66.8$)$ \\
\hline Mason et al. & England & Wild type & $\begin{array}{c}1 \text { or } \\
2\end{array}$ & $28-34$ & $-53.7 \%(-35.4$ to -66.6$)$ \\
\hline Mason et al. & England & Wild type & $\begin{array}{c}1 \text { or } \\
2\end{array}$ & $35-41$ & $-70.1 \%(-55.1$ to -80.1$)$ \\
\hline Dagan et al. ${ }^{8}$ & Israel & Wild type, B.1.1.7 & $1^{\mathrm{st}}$ & $14-20$ & $57 \%(50-63)$ \\
\hline Dagan et al. ${ }^{8}$ & Israel & Wild type, B.1.1.7 & $1^{\mathrm{st}}$ & $21-27$ & $66 \%(57-73)$ \\
\hline Dagan et al. ${ }^{8}$ & Israel & Wild type, B.1.1.7 & $2^{\text {nd }}$ & $>7$ & $94 \%(87-98)$ \\
\hline
\end{tabular}

$\$$ Low Dose (LD) or Standard Dose (SD) vs SD; $\uparrow$ LD vs SD. NB: Efficacy reported for RCTs and effectiveness for observational studies 


\section{Appendix 3: Vaccine Efficacy or Effectiveness Against Any Positive PCR (Symptomatic and Asymptomatic)}

\begin{tabular}{|c|c|c|c|c|c|c|}
\hline Vaccine & $\begin{array}{l}\text { Author (Trial } \\
\text { Name) }\end{array}$ & Country & Virus Type & $\begin{array}{c}1^{\text {st }} \text { or } \\
2^{\text {nd }} \\
\text { Dose }\end{array}$ & $\begin{array}{c}\text { Post-vaccination } \\
\text { Day }\end{array}$ & Effect Size, p-value \\
\hline \multirow{21}{*}{$\begin{array}{l}\text { Pfizer } \\
\text { BioNTech } \\
(\text { BNT162b2) }\end{array}$} & \multirow{8}{*}{ Bernal et al. ${ }^{53}$} & \multirow{8}{*}{ UK } & \multirow{8}{*}{ Wild type and 202012/01 } & $1^{\text {st }}$ & $7-9$ & aOR: 1.23 (95\% CI: 1.12 to 1.36$)$ \\
\hline & & & & $1^{\text {st }}$ & $14-20$ & aOR: 0.84 (95\% CI: 0.77 to 0.91$)$ \\
\hline & & & & $1^{\text {st }}$ & $21-27$ & aOR: 0.61 (95\% CI: 0.54 to 0.69$)$ \\
\hline & & & & $1^{\text {st }}$ & $28-34$ & aOR: 0.50 (95\% CI: 0.42 to 0.59$)$ \\
\hline & & & & $1^{\text {st }}$ & $35-41$ & aOR: 0.57 (95\% CI: 0.46 to 0.71$)$ \\
\hline & & & & $1^{\text {st }}$ & $42+$ & aOR: 0.44 (95\% CI: 0.33 to 0.57$)$ \\
\hline & & & & $2^{\text {nd }}$ & $7-13$ & aOR: 0.26 (95\% CI: 0.18 to 0.39$)$ \\
\hline & & & & $2^{\text {nd }}$ & $14+$ & aOR: 0.17 (95\% CI: 0.12 to 0.23$)$ \\
\hline & Britton et al. ${ }^{62}$ & USA & Wild type & $1^{\text {st }}$ & $0-14$ & VE:63\% (95\% CI = 33\%-79\%) \\
\hline & \multirow{4}{*}{$\begin{array}{l}\text { Glampson et } \\
\text { al. } .^{63}\end{array}$} & \multirow{4}{*}{ UK } & \multirow{4}{*}{$\begin{array}{l}\text { Wild type and B.1.1.7 } \\
\text { (dominant) }\end{array}$} & $1^{\text {st }}$ & $0-7$ weeks & HR: 1.03 (95\% CI: 0.91 to 1.17$), p=0.65$ \\
\hline & & & & $1^{\text {st }}$ & $8-14$ weeks & HR: 0.9 (95\% CI: 0.8 to 1.0$), p=0.06$ \\
\hline & & & & $1^{\text {st }}$ & 15-21 weeks & HR: 0.42 (95\% CI: 0.36-0.5), p<0.0001 \\
\hline & & & & $1^{\text {st }}$ & 22-28 weeks & HR: 0.22 (95\% CI: 0.18 to 0.27$), p<0.0001$ \\
\hline & $\begin{array}{l}\text { Gras-Valenti } \\
\text { et al. }{ }^{64}\end{array}$ & Spain & Wild type & $1^{\text {st }}$ & 12 & $\begin{array}{l}\text { VEa: } 52.6 \% \text { (95\%CI: } 1.1-77.3) \\
\text { VEa in the subgroup of HCP studied for } \\
\text { suspected disease:74.6\% (CI95\%: } 38.4- \\
89.5)\end{array}$ \\
\hline & \multirow{3}{*}{ Haas et al. ${ }^{9}$} & \multirow{3}{*}{ Israel } & \multirow{3}{*}{$\begin{array}{l}\text { Wild type and B.1.1.7 } \\
(94.5 \%)\end{array}$} & $2^{\text {nd }}$ & $\geq 7$ & aVE:95·3\% (94.9-95.7) \\
\hline & & & & $2^{\text {nd }}$ & $\geq 14$ & aVE:96.5\% (96.3-96.8) \\
\hline & & & & $1^{\text {st }}$ & $14-21$ & aVE:57·7 (54.9-60·3) \\
\hline & \multirow[b]{3}{*}{ Kustin et al. ${ }^{65}$} & \multirow[b]{3}{*}{ Israel } & B.1.1.7 & $2^{\text {nd }}$ & 7 & OR of $6: 4, p=0.38$ \\
\hline & & & B.1.351 & $2^{\text {nd }}$ & 7 & OR of $8: 1, p=0.02$ \\
\hline & & & B.1.1.7 & $\begin{array}{l}1^{\text {st }} \text { and } \\
2^{\text {nd }}\end{array}$ & $\begin{array}{c}14 \text { post dose } 1 \text { to } \\
7 \text { days post dose } \\
2 \\
\end{array}$ & OR $26: 10, p=0.006$ \\
\hline & Lumley et al. ${ }^{17}$ & England & Wild type and VOC & $1^{\text {st }}$ & $1-7$ & IRR $(95 \% \mathrm{CI}): 1.07(0.79$ to 1.45$)$ \\
\hline
\end{tabular}




\begin{tabular}{|c|c|c|c|c|c|c|}
\hline Vaccine & $\begin{array}{l}\text { Author (Trial } \\
\text { Name) }\end{array}$ & Country & Virus Type & $\begin{array}{c}1^{\text {st }} \text { or } \\
2^{\text {nd }} \\
\text { Dose } \\
\end{array}$ & $\begin{array}{l}\text { Post-vaccination } \\
\text { Day }\end{array}$ & Effect Size, p-value \\
\hline & & & & $1^{\text {st }}$ & $8-14$ & IRR (95\% CI): $1.21(0.89$ to 1.64$)$ \\
\hline & & & & $1^{\text {st }}$ & $15-21$ & IRR $(95 \% \mathrm{CI}): 0.37(0.22$ to 0.63$)$ \\
\hline & & & & $1^{\text {st }}$ & $22-28$ & IRR $(95 \%$ CI): 0.32 (0.18 to 0.6$)$ \\
\hline & & & & $1^{\text {st }}$ & $29-35$ & IRR $(95 \%$ CI $): 0.4(0.21$ to 0.75$)$ \\
\hline & & & & $1^{\text {st }}$ & $36-42$ & IRR $(95 \% \mathrm{CI}): 0.34(0.16$ to 0.73$)$ \\
\hline & Mason et al. ${ }^{61}$ & England & Wild type & $1^{\text {st }}$ or $2^{\text {nd }}$ & $17-38$ & NR \\
\hline & \multirow{3}{*}{$\begin{array}{l}\text { Menni et al. }{ }^{66} \\
\text { (COVID } \\
\text { Symptom } \\
\text { Study) } \\
\end{array}$} & \multirow{3}{*}{$\mathrm{UK}$} & Wild type and B1.1.9 & $1^{\text {st }}$ & $12-20$ & RR: $-58 \%$ [95\% CI -62 to -54$]$ \\
\hline & & & Wild type and B1.1.11 & $1^{\text {st }}$ & $21-44$ & RR: $-69 \%[95 \%$ CI -72 to -66$]$ \\
\hline & & & Wild type and B1.1.7 & $1^{\text {st }}$ & $5-11$ & RR: $-39.28 \%$ [95\% CI -34.37 to -43.90$]$ \\
\hline & \multirow{8}{*}{$\begin{array}{l}\text { Moustsen- } \\
\text { Helms et al. }{ }^{67}\end{array}$} & \multirow{8}{*}{ Denmark } & \multirow{8}{*}{ Wild type } & $1^{\text {st }}$ & $0-14$ & $\begin{array}{l}\text { LTCF: Adjusted VE: }-0.40 \text { (95\% CI: }-0.62 \\
\text { to }-0.02)\end{array}$ \\
\hline & & & & $1^{\text {st }}$ & $>14$ & $\begin{array}{l}\text { LTCF: Adjusted VE: } 0.21 \text { (95\% CI: }-0.11 \\
\text { to } 0.44)\end{array}$ \\
\hline & & & & $2^{\text {nd }}$ & $0-7$ & $\begin{array}{l}\text { LTCF: Adjusted VE: } 0.52 \text { (95\% CI: } 0.27 \text { to } \\
0.69)\end{array}$ \\
\hline & & & & $2^{\text {nd }}$ & $>7$ & $\begin{array}{l}\text { LTCF: Adjusted VE: } 0.64 \text { (95\% CI: } 0.14 \text { to } \\
0.84)\end{array}$ \\
\hline & & & & $1^{\text {st }}$ & $0-14$ & $\begin{array}{l}\text { HCW: Adjusted VE: }-1.04 \text { (95\% CI: }-1.18 \\
\text { to }-0.91)\end{array}$ \\
\hline & & & & $1^{\text {st }}$ & $>14$ & $\begin{array}{l}\text { HCW: Adjusted VE: } 0.17 \text { (95\% CI: } 0.04 \text { to } \\
0.28)\end{array}$ \\
\hline & & & & $2^{\text {nd }}$ & $0-7$ & $\begin{array}{l}\text { HCW: Adjusted VE: } 0.46 \text { (95\% CI: } 0.28 \text { to } \\
0.59)\end{array}$ \\
\hline & & & & $2^{\text {nd }}$ & $>7$ & $\begin{array}{l}\text { HCW: Adjusted VE: } 0.90 \text { (95\% CI: } 0.82 \text { to } \\
0.95)\end{array}$ \\
\hline & \multirow{4}{*}{$\begin{array}{l}\text { Pritchard et } \\
\text { al. }^{7}\end{array}$} & \multirow{4}{*}{$\mathrm{UK}$} & \multirow{4}{*}{ Wild type } & $1^{\text {st }}$ & $0-7$ & OR $(95 \% \mathrm{CI}): 0.4(0.34$ to 0.47$)$ \\
\hline & & & & $1^{\text {st }}$ & $8-20$ & OR $(95 \% \mathrm{CI}): 0.46(0.4$ to 0.53$)$ \\
\hline & & & & $1^{\text {st }}$ & $\geq 21$ & OR $(95 \% \mathrm{CI}): 0.33(0.28$ to 0.39$)$ \\
\hline & & & & $2^{\text {nd }}$ & NR & OR $(95 \% \mathrm{CI}): 0.28(0.21$ to 0.36$)$ \\
\hline & \multirow{2}{*}{ Shrotri et al. ${ }^{16}$} & \multirow{2}{*}{ UK } & \multirow{2}{*}{ Wild type } & $1 \mathrm{st}$ & $0-6$ & aHR (95\% CI): $0.84(0.39--1.81)$ \\
\hline & & & & $1 \mathrm{st}$ & 7 to 13 & aHR $(95 \%$ CI): $1.11(0.65-1.88)$ \\
\hline
\end{tabular}




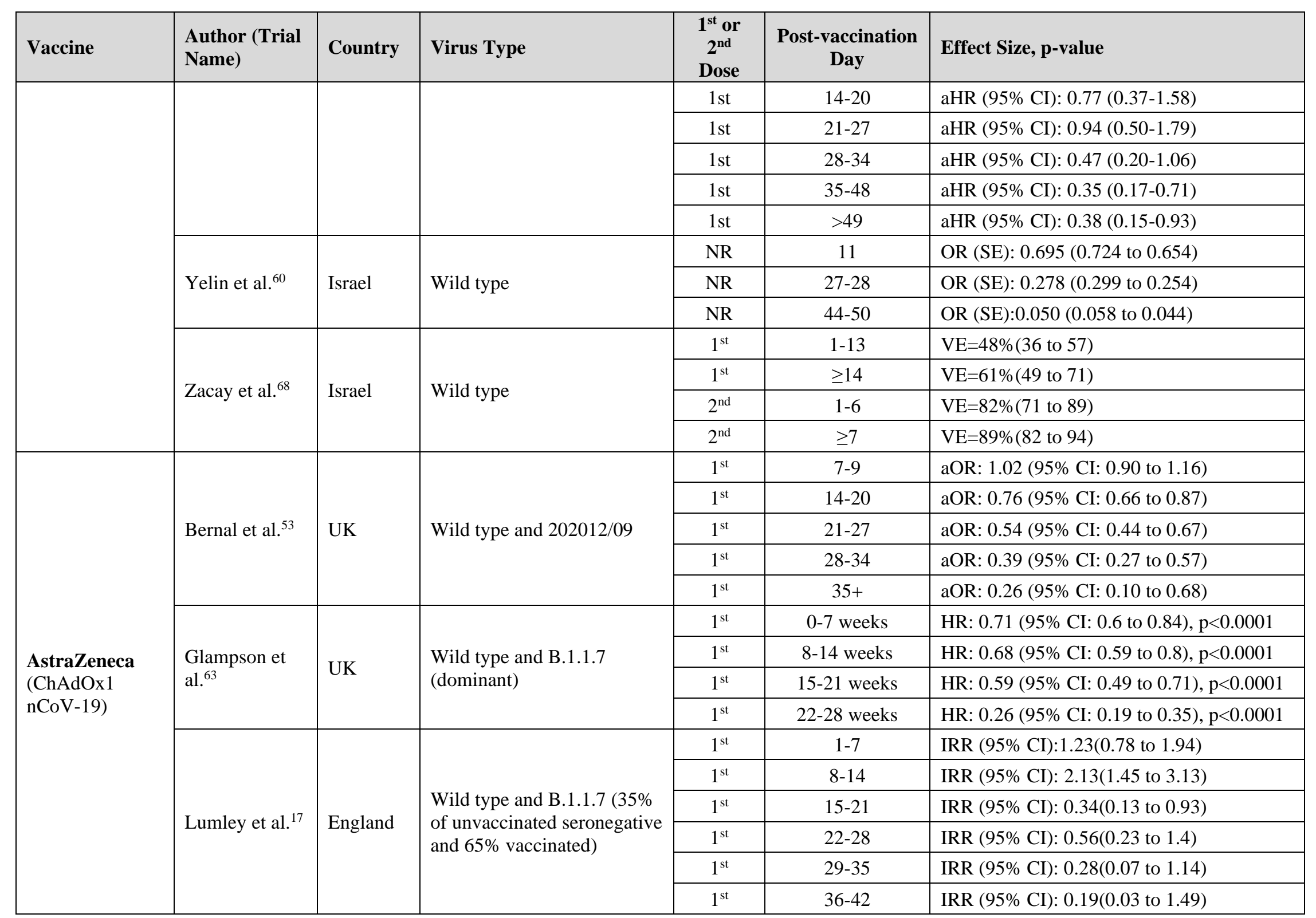




\begin{tabular}{|c|c|c|c|c|c|c|}
\hline Vaccine & $\begin{array}{l}\text { Author (Trial } \\
\text { Name) }\end{array}$ & Country & Virus Type & $\begin{array}{c}1^{\text {st }} \text { or } \\
2^{\text {nd }} \\
\text { Dose } \\
\end{array}$ & $\begin{array}{l}\text { Post-vaccination } \\
\text { Day }\end{array}$ & Effect Size, p-value \\
\hline & \multirow{3}{*}{ Menni et al. ${ }^{66}$} & \multirow{3}{*}{ UK } & \multirow{3}{*}{ Wild type and B1.1.7 } & $1^{\text {st }}$ & $5-11$ & RR: -45.97 [95\% CI -35.22 to -55.22$]$ \\
\hline & & & & $1^{\text {st }}$ & $12-20$ & RR: $-39 \%[95 \%$ CI -53 to -21$]$ \\
\hline & & & & $1^{\text {st }}$ & $21-44$ & RR: $-60 \%(95 \%$ CI -68 to -49$)$ \\
\hline & \multirow{3}{*}{$\begin{array}{l}\text { Pritchard et } \\
\text { al. }^{7}\end{array}$} & \multirow{3}{*}{ UK } & \multirow{3}{*}{ Wild type } & $1^{\text {st }}$ & $0-7$ & OR $(95 \% \mathrm{CI}): 0.35(0.28$ to 0.42$)$ \\
\hline & & & & $1^{\text {st }}$ & $8-20$ & OR $(95 \% \mathrm{CI}): 0.44(0.36$ to 0.52$)$ \\
\hline & & & & $1^{\text {st }}$ & $\geq 21$ & OR $(95 \% \mathrm{CI}): 0.36(0.3$ to 0.45$)$ \\
\hline & \multirow{7}{*}{$\begin{array}{l}\text { Shrotri et al. }{ }^{16} \\
\text { (VIVALDI) }\end{array}$} & \multirow{7}{*}{$\mathrm{UK}$} & \multirow{7}{*}{ Wild type } & $1^{\text {st }}$ & 7 to 13 & aHR (95\% CI): 0.58(0.35-0.96) \\
\hline & & & & $1^{\text {st }}$ & $14-20$ & aHR (95\% CI): $0.95(0.50-1.84)$ \\
\hline & & & & $1^{\text {st }}$ & $21-27$ & aHR (95\% CI): 0.73(0.37-1.44) \\
\hline & & & & $1^{\text {st }}$ & $28-34$ & aHR (95\% CI): 0.33(0.16-0.68) \\
\hline & & & & $1^{\text {st }}$ & $35-48$ & aHR (95\% CI): 0.32(0.15-0.66) \\
\hline & & & & $1^{\text {st }}$ & $>49$ & aHR (95\% CI): 0.64(0.26-1.56) \\
\hline & & & & $1^{\text {st }}$ & $0-6$ & aHR (95\% CI): $0.51(0.26-0.99)$ \\
\hline \multirow{3}{*}{$\begin{array}{l}\text { Janssen Biotech } \\
(\operatorname{Ad} 26 . \mathrm{COV} 2 . \mathrm{S})\end{array}$} & \multirow{3}{*}{$\begin{array}{l}\text { Corchado- } \\
\text { Garcia et al. }{ }^{69}\end{array}$} & \multirow{3}{*}{ USA } & \multirow{3}{*}{ Wild type } & $1^{\text {st }}$ & $1+$ & VE: $50.6 \%$ (95\% CI: 14 to 74$)$ \\
\hline & & & & $1^{\text {st }}$ & $8+$ & VE:65.5\% (95\% CI: 23.3 to 87.5 \\
\hline & & & & $1^{\text {st }}$ & $15+$ & VE:76.7\% (95\% CI: 30.3 to 95.3$)$ \\
\hline \multirow{2}{*}{$\begin{array}{l}\text { Sinovac Life } \\
\text { Sciences } \\
(\text { CoronaVac) }\end{array}$} & \multirow{2}{*}{$\begin{array}{l}\text { Hitchings et } \\
\text { al. }{ }^{57}\end{array}$} & \multirow{2}{*}{ Brazil } & \multirow{2}{*}{ Wild type and P.1 (75\%) } & $\begin{array}{l}\text { at least } \\
1 \text { dose }\end{array}$ & $\geq 14$ & VE:35.1\%; 95\% CI, -6.6 - 60.5 \\
\hline & & & & $\begin{array}{l}\text { at least } \\
1 \text { dose }\end{array}$ & $0-13$ & OR, $1.85 ; 95 \%$ CI, $1.26-2.71$ \\
\hline \multirow{8}{*}{$\begin{array}{l}\text { Pfizer } \\
\text { BioNTech } \\
\text { (BNT162b2) or } \\
\text { Moderna } \\
\text { (mRNA-1273) }\end{array}$} & \multirow{6}{*}{$\begin{array}{l}\text { Andrejko et } \\
\text { al. }^{70}\end{array}$} & \multirow{6}{*}{ USA } & \multirow{6}{*}{$\begin{array}{l}\text { Wild type and } 69 \% \text { of } \\
\text { B.1.1.7, B.1.427, or B.1.429 }\end{array}$} & $1^{\text {st }}$ & $1-7$ & VE: $19.7,95 \%$ CI: -125.9 to 72 \\
\hline & & & & $1^{\text {st }}$ & $8-14$ & VE: $66.3,95 \%$ CI: -68.7 to 93.3 \\
\hline & & & & $1^{\text {st }}$ & $15+$ & VE:58.9, 95\% CI: -9.7 to 91.9 \\
\hline & & & & $2^{\text {nd }}$ & $1-7$ & VE:73.8, $95 \%$ CI: 14.78 to 91.9 \\
\hline & & & & $2^{\text {nd }}$ & $8-14$ & VE:78.4, $95 \%$ CI: 23.2 to 94.3 \\
\hline & & & & $2^{\text {nd }}$ & $15+$ & VE: $85.7,95 \%$ CI: 67.2 to 93.9 \\
\hline & Monge et al. ${ }^{71}$ & Spain & Wild type & $1^{\text {st }}$ or $2^{\text {nd }}$ & $0-29+$ & $\mathrm{NR}$ \\
\hline & & USA & Wild type & $1^{\mathrm{st}}$ & $1-7$ & VE: $53.6 \%$ (95\% CI: $40.9 \%$ to $63.8 \%)$ \\
\hline
\end{tabular}




\begin{tabular}{|c|c|c|c|c|c|c|}
\hline Vaccine & $\begin{array}{l}\text { Author (Trial } \\
\text { Name) }\end{array}$ & Country & Virus Type & $\begin{array}{c}1^{\text {st }} \text { or } \\
2^{\text {nd }} \\
\text { Dose }\end{array}$ & $\begin{array}{l}\text { Post-vaccination } \\
\text { Day }\end{array}$ & Effect Size, p-value \\
\hline & \multirow{12}{*}{$\begin{array}{l}\text { Pawlowski et } \\
\text { al. }^{72}\end{array}$} & & & $1^{\text {st }}$ & $8-14$ & VE: $46.7 \%$ (95\% CI: $31.1 \%$ to $58.9 \%$ ) \\
\hline & & & & $1^{\mathrm{st}}$ & $15-21$ & VE: $69.2 \%$ (95\% CI: $54.1 \%$ to $79.8 \%$ ) \\
\hline & & & & $1^{\mathrm{st}}$ & $22-28$ & VE: $74.2 \%$ (95\% CI: $58.4 \%$ to $84.7 \%$ ) \\
\hline & & & & $1^{\text {st }}$ & $29-35$ & VE: $83.0 \%$ (95\% CI: $63.6 \%$ to $93.1 \%)$ \\
\hline & & & & $2^{\text {nd }}$ & $36-42$ & VE:92.5\% (95\% CI: $70.2 \%$ to $99.1 \%$ ) \\
\hline & & & & $1^{\mathrm{st}}$ & $1-7$ & VE (95\% CI): 53.7 (41 to 63.8$)$ \\
\hline & & & & $1^{\mathrm{st}}$ & $8-14$ & VE (95\%CI): 46.7 (31.1 to 59) \\
\hline & & & & $1^{\mathrm{st}}$ & $15-21$ & VE (95\%CI): 69.2 (54.2 to 79.9$)$ \\
\hline & & & & $1^{\mathrm{st}}$ & $22-28$ & VE (95\%CI): 74.2 (58.4 to 84.7$)$ \\
\hline & & & & $1^{\text {st }}$ & $29-35$ & VE (95\%CI): 83 (63.6 to 93.1) \\
\hline & & & & $1^{\mathrm{st}}$ & $36-42$ & VE (95\%CI): $92.5(70.2$ to 99.1$)$ \\
\hline & & & & $2^{\text {nd }}$ & $36+$ & VE (95\% CI): 89 (69.1 to 97.2$)$ \\
\hline \multirow{4}{*}{$\begin{array}{l}\text { Pfizer } \\
\text { BioNTech } \\
\text { (BNT162b2) or } \\
\text { AstraZeneca } \\
\text { (ChAdOx1 } \\
\text { nCoV-19) }\end{array}$} & \multirow{4}{*}{$\begin{array}{l}\text { Pritchard et } \\
\text { al. }^{7}\end{array}$} & \multirow{4}{*}{ UK } & \multirow{4}{*}{ Wild type } & $1^{\mathrm{st}}$ & $0-7$ & OR (95\% CI): 0.38 (0.33 to 0.43$) ; \mathrm{p}<0.001$ \\
\hline & & & & $1^{\mathrm{st}}$ & $8-20$ & OR (95\% CI): $0.45(0.4$ to 0.51$) ; \mathrm{p}<0.001$ \\
\hline & & & & $1^{\mathrm{st}}$ & $\geq 21$ & OR (95\% CI): $0.35(0.3$ to 0.4$) ; \mathrm{p}<0.001$ \\
\hline & & & & $2^{\text {nd }}$ & $\mathrm{NR}$ & OR (95\% CI): $0.3(0.23$ to 0.38$) ; p<0.001$ \\
\hline \multirow{4}{*}{$\begin{array}{l}\text { Pfizer } \\
\text { BioNTech } \\
\text { (BNT162b2) or } \\
\text { Moderna } \\
\text { (mRNA-1273) } \\
\text { or Janssen } \\
\text { Biotech } \\
\text { (Ad26.COV2.S) }\end{array}$} & \multirow{4}{*}{$\begin{array}{l}\text { Thompson et } \\
\text { al. }^{73}\end{array}$} & \multirow{4}{*}{ USA } & \multirow{4}{*}{ Wild type } & $1^{\mathrm{st}}$ & NR & IRR per 1000 person days: 0.19 \\
\hline & & & & $1^{\mathrm{st}}$ & $\geq 14$ & IRR per 1000 person days: 0.32 \\
\hline & & & & $\begin{array}{l}1^{\text {st }} \text { and } \\
2^{\text {nd }}\end{array}$ & $\begin{array}{c}\geq 14 \text { after first } \\
\text { dose through } \\
\text { receipt of second } \\
\text { dose } \\
\end{array}$ & IRR per 1000 person days: 0.12 \\
\hline & & & & $2^{\text {nd }}$ & $\geq 14$ & IRR per 1000 person days: 0.04 \\
\hline \multirow{3}{*}{ NR } & \multirow{3}{*}{$\begin{array}{l}\text { Rudolph et } \\
\text { al. }{ }^{74}\end{array}$} & \multirow{3}{*}{ USA } & \multirow{3}{*}{ Wild type } & $\begin{array}{l}1^{\text {st }} \text { and } \\
2^{\text {nd }}\end{array}$ & 7 & RR:0.70 (95\%CI 0.45, 1.10) \\
\hline & & & & $\begin{array}{l}1^{\text {st }} \text { and } \\
2^{\text {nd }}\end{array}$ & 14 & RR:0.86 (95\%CI 0.51, 1.46) \\
\hline & & & & $\begin{array}{l}1^{\text {st }} \text { and } \\
2^{\text {nd }}\end{array}$ & 21 & RR:0.67 (95\%CI 0.40, 1.11) \\
\hline
\end{tabular}




\begin{tabular}{|l|l|l|l|c|c|l|}
\hline Vaccine & $\begin{array}{l}\text { Author (Trial } \\
\text { Name) }\end{array}$ & Country & Virus Type & $\begin{array}{c}\mathbf{1}^{\text {st }} \text { or } \\
\mathbf{2}^{\text {nd }} \\
\text { Dose }\end{array}$ & $\begin{array}{c}\text { Post-vaccination } \\
\text { Day }\end{array}$ & Effect Size, p-value \\
\hline & & & $\begin{array}{c}1^{\text {st }} \text { and } \\
2^{\text {nd }}\end{array}$ & 28 & RR:0.37 (95\%CI $0.20,0.68)$ \\
\hline
\end{tabular}

